\title{
The Archaeology of Cosmic Impact: Lessons from Two Mid-Holocene Argentine Case Studies
}

\author{
Gustavo Barrientos $\cdot$ W. Bruce Masse
}

Published online: 15 September 2012

(C) Springer Science+Business Media, LLC 2012

\begin{abstract}
Cosmic impact is a category of natural catastrophe neglected or misunderstood by most archaeologists in reconstructions of past human population dynamics. We discuss the nature of impact by asteroids and comets and what is known and theorized about the Quaternary Period impact record. As case studies for our exploration of how archaeological method and theory can be productively applied to the study of cosmic impact, we focus on two confirmed Holocene asteroid impacts in central and northeastern Argentina, Rio Cuarto and Campo del Cielo, both likely dating between 6 and 3 cal ky BP. We model and assess the potential destructive effects of these impacts on contemporary hunting and gathering populations using several lines of evidence. The search for Quaternary Period cosmic impacts, along with the documentation of the effects of confirmed cosmic impacts on human populations, particularly of those organized in small-scale social groups, represents a challenge and key opportunity for future archaeological research.
\end{abstract}

Keywords Extraterrestrial object collisions · Quaternary Period · Archaeological evidence and judgment criteria · Campo del Cielo and Río Cuarto impact events

\section{Introduction}

"Impact cratering is the most fundamental geologic process in the Solar System" (Melosh 2011:222).

\section{G. Barrientos}

Facultad de Ciencias Naturales y Museo, Universidad Nacional del La Plata, Paseo del Bosque s/n, B1900FWA, La Plata, Argentina

e-mail: barrient@museo.fcnym.unlp.edu.ar

\section{G. Barrientos}

Consejo Nacional de Investigaciones Científicas y Técnicas (CONICET), Buenos Aires, Argentina

\section{W. B. Masse ( $\square)$}

Guest Scientist, Environmental Stewardship Group, Los Alamos National Laboratory, Mailstop J978, Los Alamos, NM, USA 87545

e-mail:wbmasse@gmail.com 
Cosmic impact has been a key component of all stages of the evolving Solar System. Impacts on Earth by asteroids, comets, and meteoroids occurred not only in the distant past, but also throughout the Pleistocene and Holocene, the entire time span that constitutes the temporal domain of archaeology. Few archaeologists, however, have participated in research and issues concerning impacts despite the present debate over the hypothesis that the start of the Younger Dryas climate reversal at around 12.9 cal ky BP may have been caused by a comet impact on or over the Laurentide ice sheet (Firestone et al. 2007; Kennett et al. 2009).

Some archaeologists question the Younger Dryas impact hypothesis because the purported effects of the modeled impact appear to poorly match the archaeological and paleoenvironmental record (Surovell et al. 2009b; Haynes et al. 2010; Holliday and Meltzer 2010; Collard et al. 2010). Other researchers question the potential role of cosmic impact as a trigger for the rapid climate change observed at the start of the Younger Dryas climatic event (Broecker et al. 2010), as well as questioning the proposed nature of the impactor (Boslough 2010). Prickly questions have also been raised regarding various hypothesized impact products (e.g., Marlon et al. 2009; French and Koeberl 2010; Scott et al. 2010; Pinter et al. 2011; Tian et al. 2011; van Hoesel et al. 2012).

The science media have latched onto these objections as representing compelling evidence of fatal flaws in the Younger Dryas impact hypothesis (e.g., Kerr 2008, 2010), with this view being further fueled by the recent pronouncement of a requiem for the Younger Dryas cosmic impact hypothesis by one group of researchers (Pinter et al. 2011). Based on these criticisms, it is not surprising that many archaeologists have become skeptical or antagonistic toward the Younger Dryas impact hypothesis, and by implication, toward the archaeological study of cosmic impact itself (e.g., Holliday and Meltzer 2010).

This alleged requiem is at best premature. The Younger Dryas impact debate is still early in its trajectory, with numerous ongoing investigations that may support aspects of the impact hypothesis (e.g., Kurbatov et al. 2010; Melott et al. 2010; Kennett and Teller 2011; Mahaney et al. 2011; Anderson et al. 2011; Andronikov et al. 2011; Higgins et al. 2011; Fayek et al. 2012; Bunch et al. 2012; Israde-Alcántara et al. 2012). It seems unwise to dismiss the hypothesis before the completion of the studies currently under development and a thorough review of their results. It is worth noting that Haynes et al. (2010:4014) adopt a tempered approach to the debate, observing that although their analyses and interpretations do not support the Younger Dryas impact hypothesis, neither do they preclude the occurrence of such an impact event; they also recognize that the debate has led to productive new research and knowledge (see also French and Koeberl 2010:153-154).

Archaeologists need to step back from the singular focus of the Younger Dryas impact debate and look at the broader issue. Cosmic impacts occurred throughout the Quaternary Period. Without sufficient exposure to cosmic impact theory, and lacking a body of pertinent data and archaeological and anthropological method and theory specific to the study of cosmic impact, most archaeologists presently lack the training and experience to evaluate hypotheses of cosmic impact and to search for and to identify the likely signatures of cosmic impact in the archaeological record. We understand the frustrations surrounding the Younger Dryas impact debate; such frustrations should not be allowed to trivialize the general relevance of cosmic impact 
for humankind's past and for archaeology. The Younger Dryas impact hypothesis debate will continue to generate critically important insights and tools for the study of the relationship between cosmic impacts and past human populations; however, the archaeology community can ill afford to wait for the debate to fully mature and take its due course over the next decade or two before addressing the ramifications of the overall suite of cosmic impacts that may have occurred during the Quaternary Period.

Threshold globally catastrophic impacts, capable of killing a quarter of Earth's human population and triggering climate change, are modeled by planetary scientists to occur on average once per million years (Chapman and Morrison 1994; Toon et al. 1997; Morrison et al. 2002; Paine and Peiser 2004; Bobrowsky and Rickman 2007), well within the scope of human biological and cultural evolution. The minimum energy release from such an impact approaches one million megatons $\left(10^{6} \mathrm{Mt}\right), 50$ million times that of the 13 kiloton (kt) Hiroshima and $23 \mathrm{kt}$ Nagasaki atomic weapons (U.S. Congress 1989), heuristically averaged here as $20 \mathrm{kt}$. Toward the other end of the scale are impacts such as the 1908 Tunguska airburst that leveled $2,150 \mathrm{~km}^{2}$ of Siberian forest. These occur on average between 100 and 1,500 years and yield an energy release of between 4 and $15 \mathrm{Mt}$, i.e., 200-750 times that of Hiroshima/Nagasaki (Longo 2007; Boslough and Crawford 2008; Rubtsov 2009). In between are impacts with local $\left(10-10^{3} \mathrm{Mt}\right)$ and regional/continental $\left(10^{3}-10^{5} \mathrm{Mt}\right)$ effects, occurring on average between hundreds to hundreds of thousands of years.

Based on the modeled frequency of impact, we estimate that between 65 and 300 cosmic impacts equal to or greater than $10^{3} \mathrm{Mt}$, including two or more globally catastrophic impacts, may have occurred somewhere on Earth during the past three million years. Between 2,150 and 10,000 impacts may have occurred in the range of $10-10^{3} \mathrm{Mt}$. Despite the fact that most impacts would have occurred in ocean settings (with their own unique consequences) or in terrestrial settings devoid of human occupancy (e.g., the Americas prior to settlement), these numbers are not trivial from a human biological and sociocultural evolution perspective and all such impact events should be of interest to archaeologists. We also should not dismiss the human effects of the more frequent cosmic impacts with an energy yield of less than 10 Mt. They would have had profound psychological, behavioral, cultural, and occasional lethal ramifications for the individuals and societies that experienced the event.

Planetary scientists, in their conservative approach to estimate and explain the hazard of asteroid and comet impact to the general public and government agencies, have downplayed the possibility that cosmic impacts were significant in human history. The following comment is typical of the near-Earth-object (NEO) hazard research community: "There have been reports of doubtful credibility from antiquity, as well as more recent anecdotes, of death by meteorite falls. While such an accident is certainly possible, there has been no confirmed, credible report of a human dying from a meteorite strike" (Chapman 2008:418).

This assumption reflects a lack of understanding regarding a natural sciences approach to study myths and oral traditions relating to past natural catastrophes (Blong 1982; Piccardi and Masse 2007; Cashman and Giordano 2008; Hamacher and Norris 2009). Myths collected from Brazilian Gê tribes explicitly state that a meteorite impact once killed several persons bathing or swimming in a small stream (Nimuenjajú in Wilbert and Simoneau 1978:125; Nimuenjajú in Wilbert and 
Simoneau 1984a:45-46; Masse and Masse 2007). There is no reason to question the legitimacy of the account given the details in the storyline description and the manner in which the story was collected (Wilbert 1978:2-3; Wilbert and Simoneau 1984a:12). Similarly, several of the 15 meteorite impact human fatality stories listed by Lewis (1996:176-182) are likely based on actual events. There also were fatalities associated with the 1908 Tunguska airburst impact (Suslov 2006) that are overlooked in most discussions of the impact event.

Equally problematic are apparent biases in the application of stochastic probabilities derived from the Solar System cratering record and the observed near-Earth asteroid and comet population that ignore or uncritically dismiss potential geological, paleoenvironmental, archaeological, and anthropological evidence for recent catastrophic impact (Baillie 2007a; Masse 2007; Masse et al. 2010). It is incorrect to assume that, because the last $15 \mathrm{ky}$ represents a relatively short interval within geologic history, major cosmic impact events $(\geq 1,000 \mathrm{Mt})$ could not have taken place and somehow all recent impacts avoided killing humans. Impacts are no different from other phenomena subject to power law scaling and stochastic occurrence. Impacts do become more uncommon with increasing size and magnitude; however, a major event can occur at any location on Earth and at any point in time. There is the potential for rare clusters of multiple impact events to occur at any point along the timeline (Jourdan et al. 2012), including one or more major events (Perlmutter and Muller 1988; Chatterjee and Rudra 2008; Farley 2009) as is observed with other natural hazards such as tropical cyclones and earthquakes (Mumby et al. 2011; Thenhaus et al. 2011).

NEO specialists have devoted much of their careers attempting to convince skeptical colleagues and political pundits that impact hazards are real and serious (e.g., Gehrels 1994; Morrison et al. 2002; Chapman 2008), and to bring the impact hazard message to science and the public at large (e.g., National Research Council 2010; Chapman 2011; Friend 2011; Jourdan and Reimold 2012). They are justifiably concerned about future impacts. Regrettably, most members of the NEO community of planetary scientists do not perceive the implications of their own data for the humanities and for historical social and behavioral science. There is little recognition by physical scientists and the archaeological community itself that cosmic impacts would have influenced aspects of Quaternary Period history and that archaeologists can play a significant ground-truthing role in recognizing and dating these impacts (see however, Paine and Peiser 2004; Baillie 2007a; Bobrowsky and Rickman 2007). Such data not only are important for resolving questions about the role of cosmic impact in culture history, behavior, and process, but also directly support the evaluation of cosmic impact risks and effects, thus providing information of potential vital importance to policy makers. Dismissive attitudes, such as those noted above and elsewhere (e.g., Pinter and Ishman 2008; Bourgeois and Weiss 2009; French and Koeberl 2010:148; Morrison 2010) discourage participation by archaeologists and kindred historical disciplines. The Quaternary Period record and dating of cosmic impact is poorly known and deserves greater attention.

Archaeologists, geoarchaeologists, paleoanthropologists, and archaeologically oriented paleoenvironmental specialists conduct fieldwork throughout the world. They employ a variety of skills and tools that can be brought to bear for the identification of Quaternary Period cosmic impacts and the study of their effects. These include a 
focus on microstratigraphy and the application of a wide range of methods and techniques to explore the nature of archaeological remains - and potentially impact related materials - in terms of chronology and context. Archaeologists are comfortable with interdisciplinary and multidisciplinary collaborations and with explanatory approaches that attempt to bridge the gulf between the physical, social, and behavioral sciences and the humanities. The search for evidence of cosmic impact events and their cultural and environmental effects should be added to the inventory of topics worthy of study by archaeology. Archaeologists can contribute to current models of the risks and effects of impact by exploring the myriad human consequences of impact at local and regional scales of social integration.

To accomplish this task, however, archaeologists have to become aware of the risks and effects of impact events and acquire the necessary knowledge about different aspects of the problem. This paper is intended to provide an introduction to the subject and to illustrate how archaeological research on the human populationlevel effects of a cosmic impact event might proceed. Consequently, the first aim of this paper is to share the known and theorized Quaternary Period record of cosmic impact in order to highlight the potential significance of cosmic impact for the study of human biological and sociocultural evolution, and the second aim is to apply archaeological and anthropological data and methods to complement geoscience studies of two confirmed mid-Holocene asteroid impacts in Argentina.

We begin by presenting an overview of cosmic impact science to establish an initial framework for exploring the potential role of Quaternary Period impacts in human biological and sociocultural evolution. This includes discussion of (1) the Solar System and the potential for cosmic impact; (2) impact structures and the mineralogical and geochemical characteristics of cosmic impact; (3) the physical effects of cosmic impact of differing magnitudes (in terms of energy release), particularly with respect to a sample of well-studied recent smaller impacts; and (4) the rates and probabilities of occurrence of cosmic impact by magnitude during the past three million years. We then apply archaeological and anthropological data and methods to the study of two confirmed asteroid impacts. We explore what constitutes proof that a particular cosmic impact event occurred in the past and what this might mean in terms of its population-level effects on humans. The standards of proof for identifying the physical signatures of a cosmic impact event are much better developed within the planetary sciences than those pertaining to what different types and magnitudes of impacts might mean in terms of effects on past human populations. These issues have a bearing on the selection of case studies to illustrate and justify why archaeologists should have a significant role in cosmic impact research.

Promising initial studies have been performed on two confirmed impacts. One is the small late Holocene Kaalijärv asteroid impact in Estonia (Veski et al. 2007). The other is the $800 \mathrm{ky} \mathrm{BP}$ impact event responsible for the formation of the extensive Australasian tektite strewn field, which may have implications for aspects of human evolution (Langbroek and Roebroeks 2000). There has also been significant recent work with the hypothesized late Holocene Chiemgau crater field in southern Germany (Ernstson et al. 2010; Rappenglück et al. 2010, 2011), and a hypothesized Mesopotamian/Near Eastern impact event around 4.2 cal ky BP (Courty 1998, 2001; Courty et al. 2008). Masse and colleagues (Masse 1998, 2007; Abbott et al. 2007; Gusiakov et al. 2010) have hypothesized and modeled that the universal 
myth of the "great flood" was the result of a deepwater Indian Ocean comet impact around 4.8 cal ky BP.

Each of these known or suspected impact events, along with the Younger Dryas impact hypothesis, is marked by contentious debate regarding dating or the nature and reality of the impactors and their alleged products and signatures. This limits their suitability as test cases for the initial development of archaeological approaches to cosmic impact theory.

Campo del Cielo in northeastern Argentina (modeled here at 1-2 Mt) and Rio Cuarto in central Argentina (modeled here at $10^{3}-10^{4} \mathrm{Mt}$ ) are the confirmed impact cases most immediately amenable to broad-spectrum archaeological and anthropological analysis. Both asteroid impacts date to the middle Holocene and have been robustly studied and discussed by planetary scientists. Data suggest that both events may have affected contemporary hunter-gatherer populations, though in different ways. We summarize the physical characteristics of the Argentine impacts, including a discussion of probable observations of the impacts contained in regional mythologies. We then apply a rough estimation of the likely effects of both events from a human population and environmental standpoint. This is followed by the analysis of the frequency distribution of the uncalibrated and calibrated ages within Holocene radiocarbon datasets from different sampling areas in central Argentina. These data are evaluated in relation with presumed climatic/paleoecological variations that occurred during the Holocene as measured by different proxies to major changes in the bioarchaeological record, and by reference to the nature and inferred ages of the Campo del Cielo and Río Cuarto impact events.

Our methods and conclusions are not intended to be determinative, nor are they exhaustive; rather they are meant to provoke and suggest directions for future research. We cannot overemphasize the difficulty of interpreting the effects that recent cosmic impacts had on human population dynamics. The potential of archaeological and anthropological data to define impact candidates is made difficult due to the lack of present unequivocal physical signatures for most Quaternary Period impacts, the lack of high precision dating for confirmed impacts, and the lack of clear standards of proof of impact and their effects on human populations, particularly of those organized in small-scale social groups. Through future comprehensive systematic field and laboratory studies, along with continued efforts to theorize and develop new analytical methods, we can achieve the full promise offered by the application of archaeological and anthropological methods and theory to the study of recent cosmic impact.

\section{Understanding Cosmic Impact}

The Solar System and the Potential for Cosmic Impact

The Sun and the eight planets and their moons share the Solar System with a variety of other objects and debris left over from its formation and evolution (Bottke et al. 2002; Hartmann and Miller 2005; Bottke 2007; Karttunen et al. 2007; Daniels 2009; de Pater and Lissauer 2010; Chaisson and McMillan 2011; Melosh 2011). These include dwarf planets (including Pluto), asteroids, comets, meteoroids, and 
interplanetary dust. The conditions and processes that led to the present nature and orbital configurations of these objects are complex and varied, and are subject to ongoing debate and refinement (e.g., Asphaug 2009). The following brief sketch highlights aspects pertinent to our discussion of cosmic impact.

\section{Solar System Structure}

The planets and their moons lie on the ecliptic plane, the two-dimensional space characterized by the orbit of the Earth and other planets around the Sun. This plane resulted from the evolution of the protoplanetary disc around the early Sun. The planets revolve around the Sun in near-circular elliptical orbits. The average distance of the Earth from the Sun is $\sim 150,000,000 \mathrm{~km}$, a unit of measurement referred to as an astronomical unit (AU), and which is useful for discussions of Solar System structure.

There are several regions within the Solar System important for understanding cosmic impact. Extending out from the Sun these include the asteroid belt (now referred to as the Main Belt), and the trans-Neptunian Kuiper Belt, Scattered Disc, and Oort Cloud. The first two of these are situated along the ecliptic plane. The Main Belt is between Mars and Jupiter approximately 2.1 to 3.3 AU from the Sun. Its population of more than 100 million objects not only contains the great majority of asteroids but also includes a small percentage (possibly around $0.25 \%$ ) of inert comets (Hsieh and Jewitt 2006; Bertini 2011).

The Kuiper (Edgeworth-Kuiper) Belt is a thick donut-shaped area just beyond the orbit of Neptune (30 AU). It extends along the ecliptic plane at a distance of between 30 and 55 AU from the Sun, and contains comets and other icy debris along with the majority of identified dwarf planets. The great majority of documented Kuiper Belt objects appear to have stable orbits, however, some dwarf planets along with more than 200 other objects have much more extreme orbits (Duncan and Levision 1997; de Pater and Lissauer 2010). This likely represents just a tiny percentage of all such "Scattered Disc" objects. Some Solar System researchers view these Scattered Disc objects as being a subset of the Kuiper Belt. Scattered Disc objects do not have stable orbits and it is likely that their present configurations are the result of earlier interactions with the four larger gaseous planets. It is assumed that the unstable orbits of Scattered Disc objects will lead to their eventual migration outward to the Oort Cloud, or inward past Neptune. It is thought by some astronomers that the Scattered Disc is the source of most "short-period comets" with orbital passages around the Sun of less than 200 years. The Kuiper Belt and Scattered Disc together may contain hundreds of thousands of icy objects greater than $100 \mathrm{~km}$ in diameter and perhaps as many as a trillion comets.

The Oort Cloud is a large diffuse globular cloud of icy objects that surround the Sun in all directions between about 1,000 to 100,000 AU. More than a billion comets, perhaps as many as two trillion are thought to reside in the inner Oort Cloud.

\section{Asteroids}

Asteroids and comets are of particular significance for the study of cosmic impact. Asteroids ("minor planets" less than $c a .500 \mathrm{~km}$ in diameter) are predominately rocky 
objects that revolve around the Sun. More than 250,000 asteroids have been catalogued including orbital calculations, with another 250,000 asteroids having been detected but not yet adequately documented. Perhaps $99 \%$ of all asteroids greater in diameter than $100 \mathrm{~km}$ and more than half of all objects greater than $10 \mathrm{~km}$ in diameter have been identified and catalogued (National Research Council 2010; Chaisson and McMillan 2011). Recently, the claim has been made that $90 \%$ of the near-Earth asteroid (NEA) population greater than $1 \mathrm{~km}$ in diameter has been identified (Mainzer et al. 2011). These studies indicate that only a couple dozen asteroids are more than $200 \mathrm{~km}$ in diameter, with most being smaller than a few kilometers.

Direct imaging by the largest ground-based telescopes and radar measurements are the favored methods of asteroid measurement. However, direct imaging, even with adaptive optics, is limited to the larger asteroids of the Main Belt, while radar measurements are largely constrained to observations of NEAs. The diameters of most asteroids are spatially irresolvable by direct imaging and are instead calculated based on an estimate of the absolute magnitude of the asteroid (computed from the observed apparent magnitudes of the object at various times and positions) in relation to a generalized value for the albedo or reflecting power of the surface of the asteroid. Measurement by optical interferometry involving multiple telescopes or multiple mirror segments working together is increasingly being used to help better resolve the sizes and shapes of small Solar System objects (e.g., Li et al. 2011).

Approximately $75 \%$ of all asteroids appear to be carbonaceous (C-type), that is they contain a large amount of carbon within their matrix, $15 \%$ are silicate or rocky/ stony composition (S-type), whereas the remaining $10 \%$ represent other types, primarily metal-rich (M-type) objects that contain large fractions of iron-nickel or other metals. Composition is generally derived by calculations of density, albedo, and surface spectrum. Actual samples collected during the Hayabusa mission to the Stype asteroid Itokawa (Fujiwara et al. 2006; Krot 2011) have revealed a complex and fascinating formation history, including the catastrophic disaggregation of the asteroid by one or more impacts and subsequent coalescence leading to its current configuration as a rubble-pile object. The samples also indicate that S-Type asteroids are the parent bodies for stony chondritic (containing chondrules) meteorites found on the Earth.

It is notable that the great majority ( $c a .85 \%$ ) of Earth's meteorites are ordinary chondrites (Norton and Chitwood 2008; Smith et al. 2009), a finding that may relate to the observation that S-Type asteroids dominate the inner portion (closest to Earth) of the Main Belt; C-Type asteroids dominate the middle and outer portions. Chondrites are largely composed of the silicate minerals olivine (common in rocks such as basalt) and pyroxenes, along with elemental ironnickel (rare in terrestrial rocks). Of the more than 4,000 named minerals known to form in Earth's terrestrial environments, about 280 are also found in meteorites (Norton and Chitwood 2008).

As of January 2009, there had been at least 1,074 observed meteorite falls linked with recovered meteorites, of which $94 \%$ were chondrites (including carbonaceous chondrites), with the remainder being achondrites, irons, and stony-irons, (Smith et al. 2009). Remarkably, of the nearly 37,000 individual studied meteorites (in which multiple meteorites from a single fall are counted as a single entity), including the more than 25,000 specimens recovered from Antarctica (e.g., Cassidy 2003), they likely 
originate from only around 100 parent asteroids. A few meteorites have also been determined to represent the ejecta from cosmic impacts on Mars and the Moon.

Matter in the Solar System, including asteroids, is constantly subjected to small perturbations by the gravitational properties of planets and by other forces. These include the important Yarkovsky effect, which due to uneven temperature distributions across the surfaces of meter to $10-\mathrm{km}$-sized objects alter the orbits of these objects. For example, high precision measurements of 500-m-diameter asteroid 1999 RQ36 suggest that the Yarkovsky effect has caused the asteroid to deviate approximately $160 \mathrm{~km}$ from its original orbit over the course of 12 years of observation (NASA Home 2012). Over lengthy periods of time (hundreds to millions of years), these forces can perturb Main Belt asteroids (and comets) from their more stable orbits leading to gravitational interaction with Jupiter or Mars, and possible collisions with other asteroids or comets, and planets and their moons.

Most asteroids maintain relatively stable near-circular elliptical orbits around the Sun. Several other groupings of asteroids (Amor, Apollo, Aten, Atira) are classified depending on location and orbital stability (NASA Jet Propulsion Laboratory 2012a). Some asteroids have highly elliptical orbits that bring them into the inner Solar System. NEOs, including both near-Earth comets (NEC) and asteroids (NEA), have orbital perihelia less than 1.3 AU from the Sun. As of July 28, 2012 at least 9,076 NEAs have been documented (NASA Jet Propulsion Laboratory 2012a), with new NEAs being added weekly. Potentially hazardous asteroids (PHAs) are NEAs whose minimum orbit intersection distance with the Earth is less than or equal to $0.05 \mathrm{AU}$, and whose diameters are greater than $150 \mathrm{~m}$; about $12 \%$ (154) of the 1,322 documented PHAs have diameters larger than $1 \mathrm{~km}$. Recent observational data indicate that the NEA population consists of 20,500 $\pm 3,000$ objects with a diameter greater than $100 \mathrm{~m}$, and $981 \pm 19$ objects with a diameter greater than $1 \mathrm{~km}$ (Mainzer et al. 2011). The three largest documented NEAs (NASA National Space Science Data Center 2012) include 5-km-diameter Phaethon, Eros at $33 \times 13 \mathrm{~km}$, and 32-kmdiameter Ganymed (not to be confused with Ganymede, a moon of Jupiter), which is three times the size of the modeled Chicxulub impactor that extirpated the dinosaurs 65 million years ago.

Modeling indicates that NEAs can get trapped in stable non-Earth-crossing orbits or ejected out of the Solar system. A significant percentage (10-20\% or more) of NEAs will eventually collide with planets and their moons, including the Earth (Gladman et al. 2000; de Pater and Lissauer 2010:369). Not included are comets, such as Shoemaker-Levy 9, whose calved fragments crashed into Jupiter in 1994. These NEO collisions would occur randomly during the next roughly 10 million years, the modeled dynamical lifetime for NEOs (Gladman et al. 2000; de Pater and Lissauer 2010:369). Because the NEO population is constantly being replenished, the possibility of Earth impact is always present and may at times fluctuate dramatically (Bottke et al. 2009).

\section{Comets}

Comets are objects primarily consisting of dust-sized particles mixed with variable amounts of methane, ammonia, carbon dioxide, and ordinary water ice. Data collected during the last decade of telescopic observation and from visits of spacecraft to 
comets such as the Deep Impact and Stardust Recovery missions (A'Hearn 2006) have revealed important information regarding the composition and likely origins and evolutionary history of sampled comets.

Comets, like asteroids, can be perturbed from their more stable near-circular orbits and assume potentially Earth-crossing elliptical orbits. Short-period comets are modeled to originate in the Kuiper belt (and theoretically the Main Belt) and make a complete orbit around the Sun in less than 200 years. The most famous short-period comet is Comet Halley with a current orbit of 75-76 years. Long-period comets originate in the Oort Cloud and have orbital passages greater than 200 years, often exceeding thousands or even several hundred thousand years.

NECs include only short-period comets with orbital periods of less than 200 years due to observational constraints. Comets make up less than $10 \%$ of the NEO threat (Collins et al. 2005; Bobrowsky and Rickman 2007), with most models suggesting a much smaller percentage. There are at least 92 documented NECs, about $1 \%$ of all NEOs (NASA Jet Propulsion Laboratory 2012a). This percentage may increase as technology advances and our observational skills increase.

Comets are inherently more dangerous than asteroids despite being composed primarily of ice and dust. This is partly due to the longer lengths of comet orbits that increase the possibility of perturbation by the larger gaseous planets and Sun and interactions with other objects, which often results in calving such as occurred with Comet Shoemaker-Levy 9. Calving typically results in larger fragments that do not burn up during entry into our atmosphere. The cumulative effects of multiple strikes on Earth from a comet recently calved from its perihelion passage around the Sun will have approximately the same total energy release as the single original object unless some of the calved fragments miss the Earth. Additionally, comets may not follow strictly stochastic principles with regard to size distribution and appearance in the inner Solar System. The range of diameters defined for 18 NECs (NASA Jet Propulsion Laboratory 2012b) is between 1.2 and $26 \mathrm{~km}$, roughly mirroring that for NEAs with the exception that all are larger than $1 \mathrm{~km}$ in diameter. Giant comets $(>100 \mathrm{~km}$ diameter) that are perturbed into the inner Solar System may calve and disintegrate over thousands or a few million years during which some planetary scientists argue there is an increased chance for Earth impact (Asher et al. 1994; Napier 2010). Comets also have much greater velocities than asteroids, traveling at speeds of around 30-70 km/s instead of asteroids at about $12-20 \mathrm{~km} / \mathrm{s}$. Napier and Asher (2009) make a compelling case that the risk of comet impact may be underestimated.

\section{Meteoroids, Meteors, and Meteorites}

Meteoroids are dust-to-boulder-sized solid objects traveling in interplanetary space. Meteoroids become meteors as they burn up upon entering our atmosphere. Annual meteor showers and periodic meteor storms on Earth are the product of the orbit of Earth intersecting the debris streams of comets and asteroids (Jenniskens 2006). For example, the Orinids and Eta Aquarids are associated with passages of Comet Halley, the Leonids with Comet Temple-Tuttle, and the Perseids with Comet Swift-Tuttle. Based on orbital characteristics, some meteors and meteor showers are identified as debris from the breakup of asteroids. 
Meteors brighter than naked-eye-visible planets are often referred to as fireballs; exceptionally bright fireballs are sometimes referred to as bolides, particularly when they explode in the atmosphere. This is not to be confused with the term bolide used by some geologists to refer to asteroids, comets, and meteoroids large enough to form a crater upon impact with the Earth's surface. Potentially confusing is the use of the term fireball to also describe the plume of hot gases that leaves a comet or asteroid impact site preceded by a bow shock wave in the lower atmosphere.

Meteorites are objects larger than $10 \mu \mathrm{m}$ in size $(1 \mu \mathrm{m}=1 / 1000 \mathrm{~mm}$ or one millionth of a meter), derived from meteoroids, asteroids, comets, and the products of impacts on asteroids, dwarf planets, planets, and their moons (Rubin and Grossman 2010). They coherently survive passage through the atmosphere. A meteorite between $10 \mu \mathrm{m}$ and $2.0 \mathrm{~mm}$ in size is termed a micrometeorite.

Impact Structures and the Mineralogical and Geochemical Products of Impact

\section{Impact Craters and Structures}

The most obvious impact features are craters, which together with associated features form what is termed an impact structure (Mark 1987; Hodge 1994; French 1998; Melosh 2011; Planetary and Space Science Centre 2011). Impact structures are formed when a meteoroid, asteroid, or comet collides with Earth and creates a cavity or depression in the ground. Most craters are circular, with the exception of very low angle or oblique impacts that can form elliptical craters. Craters weather and degrade through time resulting in increasingly ambiguous impact structures recognizable by fewer defined impact features and products.

Non-hypervelocity impact structures are created by objects a few meters or less in size. Their kinetic energy and original velocity is lost in the atmosphere through ablation and disintegration; they strike the ground at near-terminal speeds of just a few hundred meters per second rather than speeds greater than $\sim 4 \mathrm{~km} / \mathrm{s}$ required for hypervelocity impact. The meteorite penetrates just a short distance into the ground, excavating a pit a few times larger than the diameter of the impactor and can end in a short tunnel. These penetration craters or penetration funnels are at most just a few tens of meters in diameter/length. The funnel often contains a significant portion of the impacting meteorite. Campo del Cielo in northeastern Argentina has a number of these penetration funnels.

Hypervelocity impact structures on Earth are divided into two structural classes based on impactor size, speed, angle of atmospheric entry, and the composition of the impactor and impact target. Craters less than 2-4 km in diameter, such as Barringer Crater, tend to be "simple;" they exhibit a depth-to-diameter ratio of about 1:5 and have a smooth bowl shape. For larger "complex" craters there is a central peak or peak ring produced as the crater floor rebounds from the compressional shock of impact. Complex impact structures are also shallower because gravity collapses the initially steep crater walls resulting in depth-to-diameter ratios greater than 1:5. Two or more interior rings may also be associated with the largest complex craters, with the overall structure commonly being referred to as a multi-ring basin.

Hypervelocity terrestrial impact structures are modeled as being formed in three somewhat arbitrary stages (Gault et al. 1968; French 1998; French and Koeberl 2010; 
de Pater and Lissauer 2010; Melosh 2011; Collins et al. 2012). The first two are the contact/compression and the excavation stages produced by the extreme pressures and supersonic shock waves of impact, followed by the modification stage, which is largely governed by gravity and the nature of the target.

The contact and compression stage begins at the instant the impacting projectile strikes the target surface at speeds near its original cosmic velocity, typically greater than $10 \mathrm{~km} / \mathrm{s}$. As the projectile penetrates to a depth one to two times the diameter of the projectile, the kinetic energy converts into intense, transient, high-pressure stress waves not present in ordinary geological processes. These shock waves radiate out through the target rock at velocities greater than the speed of sound setting a large volume of the target rock into motion. The expanding target shock wave loses energy rapidly as the energy density decreases and as additional energy is lost to the target rock through the processes of heating, deformation, and acceleration. Simultaneously upon impact a reflection shock wave transits through the projectile, and upon reversing direction once it reaches the other side of the projectile creates a rarefaction wave (release wave) that releases the high pressures of the shock wave causing the projectile to melt and vaporize. The shock wave will transit through the lower atmosphere followed by the impact fireball, a rapidly rising and expanding vapor plume of gases and fine dust capable of achieving high velocity.

At this point of crater formation, which typically has lasted less than $1 \mathrm{~s}$ (for objects smaller than $20 \mathrm{~km}$ in diameter), a roughly hemispherical envelope of shock waves surrounds the volatilizing projectile. During the excavation stage, the release wave exiting the disintegrating projectile combines with the target shock waves to fracture and shatter the target rock within the hemisphere, forming a transient crater. Some of the material in the upper portion of the transient crater is converted into kinetic energy ejecting near surface rock fragments at high velocities (several kilometers per second), as well as forming an ejecta curtain of smaller particles. The duration of the excavation stage lasts a few seconds for smaller craters, such as Arizona's Barringer crater and roughly $90 \mathrm{~s}$ for a $200-\mathrm{km}$-diameter crater. At the end of the contact and compression stage and early during the excavation stage impact melts form along the surface of the transient crater.

The modification stage begins as soon as the transient crater has reached it final form and the shock waves have decayed to low-pressure elastic stress waves beyond the crater rim at the edge of the transient crater. More conventional processes such as rock mechanics and gravity take over, resulting in the collapse of steep crater walls and the uplift of central peaks in complex craters and the formation of rings in multiring basins. These processes largely take place within a few minutes of crater excavation, resulting in what is considered as the final crater.

In summary, hypervelocity impact structures are typically distinguished by the following characteristics:

- A bowl-shaped final crater or in the case of complex impact structural basins, central peaks and internal rings for the largest craters.

- Displaced fill in the transient crater containing breccia (rock composed of broken fragments of minerals or rock cemented together by a fine-grained matrix) and occasional lenses of highly shocked breccia with associated impact melts (melted target rocks). 
- Fractured and brecciated target rocks below the base of the transient crater.

- Dikes (sheet intrusions cross-cutting pre-existing rock formations) variously containing melts and fragmental impact breccias below the transient crater.

- A crater rim formed at the edges of the transient crater, exhibiting large blocks of uplifted target rock and breccia dikes.

- Broad coherent sheets of impact melt on top of the basin within complex craters, in addition to the central uplifted peak and occasional internal rings.

- A layer of proximal ejecta (the ejecta blanket) extending away from the crater rim, being thicker at the rim. Distal ejecta in larger impacts can be thrown out hundreds and even thousands of kilometers from the impact site, in some cases forming a worldwide layer such as the famous iridium clay layer that marks the Chicxulub impact event.

These in turn gradually merge into the more long-term processes of geological mass movement, isostatic uplift, erosion, and sedimentation within and around the impact structure.

\section{Mineralogical and Geochemical Products of Impact}

A handful of features of rocks and minerals currently are considered reliably diagnostic of cosmic impact (French and Koeberl 2010). These include but are not necessarily limited to the following.

- Preserved meteoritic fragments of the impactor are infrequently observed in and around impact structures. More typical is the incorporation of meteoritic material into impact-produced breccias and melt rocks and impact ejecta during crater formation, which can be detected by their chemical and isotopic signatures. The now famous K-Pg ("KT") boundary iridium layer is an example of meteoritic material as a component of a worldwide ejecta layer. The likely extraterrestrial nature of the $\mathrm{K}-\mathrm{Pg}$ boundary layer iridium was signaled due to the much higher concentration of iridium in the boundary layer clays than is normally present in the Earth's crust (Alvarez et al. 1980).

- Shatter cones represent the only shock effect visible as outcrops and as hand specimens in highly eroded sites. They are low shock pressure sets of conical fractures in target rock that exhibit the nesting of multiple cones, largely parallel orientation of cone axes, radial divergence of striations downward and outward from the cone apices, and subsidiary striations along the cone surface that have been likened to the hairs of a horse tail.

- High-pressure (diaplectic) mineral glasses are tectosilicate minerals, such as quartz and feldspar, converted into amorphous "glassy" phases without actual melting. These glasses typically retain the form of the original mineral ("pseudomorphs").

- High-pressure mineral phases represent the conversion of target rock minerals into new homogenous physical and chemical phases that are typically stable at the high pressures present in the lower crust or mantle of the Earth. Examples include coesite (shocked quartz) and stishovite (the densest polymorph of quartz). The presence of nanodiamonds formed from graphite with crystals in the range of 3-5 $\mathrm{nm}(1 \mathrm{~nm}=$ one billionth of a meter) is known for some impact sites, but remains controversial within the context of the Younger Dryas impact hypothesis. 
- High-temperature glasses and melts can be created when rock close to the impact is raised to temperatures greater than $1,500{ }^{\circ} \mathrm{C}$, sufficient to melt and decompose minerals. The high temperatures are also significant in that they can homogenize the chemical composition of the resulting melts and reset isotopic systems used in radiometric age measurement. The value of high temperature glasses as an indicator of impact and as a chronometric tool is illustrated in our discussion below of the Rio Cuarto impact.

- The presence of shock-induced planar microdeformation features in quartz is currently one of the most common methods of deducing that an impact has taken place. Quartz is abundant, durable, and exhibits striking deformation features over a range of shock-wave pressures. Most common are planar fractures (PFs) and planar deformation features (PDFs). PFs are identical in appearance to cleavage, but typically occur in multiple sets, two to three per quartz grain. The planes consist of open fractures, frequently filled with secondary material. Quartz PDFs consist of multiple sets of thin planes traversing a sizable fraction of the width of the quartz grain, notable for their parallel close spacing in two or more discrete orientations. Quartz is the second most common mineral (after feldspar) in Earth's continental crust, but some potential target locations lack suitable material.

- Potassium feldspar (K-feldspar) grains can exhibit impact shock-induced PDFs, such as documented in the fallback layer within Bosumtwi crater (Koeberl et al. 2007). Feldspar has received less attention to date for impact studies than has quartz.

Particularly interesting are impact-generated glassy spherules and microspherules commonly found in distal ejecta layers. These are millimeter- to centimeter-sized droplets of inclusion-free impact melt ejected to regional or even global distances from the crater, but are rare in the proximal deposits around the crater.

Tektites represent a distinct subgroup of spherules. They are chemically homogenous impact glasses, typically several centimeters in size and often spherically symmetric occurring in at least four well-defined strewn fields (Koeberl 1994; Glass et al. 2004). Three are associated with known impact structures or craters-the North American strewn field with the Chesapeake Bay impact structure, the Central European strewn field with Ries crater in southern Germany, and the Ivory Coast strewn field with Bosumtwi crater in Ghana. The 10.5-km-diameter Bosumtwi crater was formed during the mid-Pleistocene, and is one of largest currently confirmed Quaternary Period impact events $\left(10^{4} \mathrm{Mt}\right)$. Microtektites $(<1 \mathrm{~mm}$ in diameter), associated with the Chesapeake Bay and Bosumtwi impact events, are common in marine sediments adjacent to their respective tektite strewn fields; there are no known microtektites associated with the Ries impact event.

The Australasian tektite strewn field is especially significant for us. It is by far the largest of the four strewn fields, covering more than $10 \%$ of the surface of the Earth, and is the most recent, dating to around $800 \mathrm{ky} \mathrm{BP}$. It is also the only one of the four strewn fields to lack an identified associated impact structure (Koeberl 1994; Folco et al. 2010), which is quite puzzling. Australasian tektites and microtektites range from the southeastern coast of Africa eastward more than 14,000 km to the central Pacific, and southward from Burma and southern China to the Transantarctic Mountains of Antarctica. These distances indicate that the 
impact exceeded the energy release for a threshold globally catastrophic event. The crater diameter has been modeled at $43 \pm 9 \mathrm{~km}$ (Glass and Koeberl 2006). Physical evidence of the tektites and microtektites favors an impact location within Indochina or directly adjacent waters (Ma et al. 2004; Glass and Koeberl 2006; Prasad et al. 2007, 2010). A terrestrial impact would imply that some obscuring mechanism, such as burial in the alluvium of the Mekong Valley, has to be invoked to hide the crater from detection. The difficulties of identifying oceanic impacts, combined with the water content of Australasian tektites and the defined levels and distribution of beryllium-10 (Ma et al. 2004; Watt et al. 2011), point to the hypothesis that the impact location is somewhere off the coast of Vietnam. A better understanding of the Australasian impact event and its precise location are critical for any future understanding of this event and the overall picture of cosmic impact during the Quaternary Period.

\section{The Difficulties of Identifying Impact Structures and Products}

More than 42,000 impact craters with diameters greater than $5 \mathrm{~km}$ have been catalogued for Mars (Barlow 2010). The Moon, whose diameter is about $27 \%$ that of Earth and thus has a surface area only $7.4 \%$ that of Earth, exhibits more than 30,000 craters greater than $1 \mathrm{~km}$ in diameter (Daniels 2009). Despite hundreds of thousands of major impacts $\left(\geq 10^{3} \mathrm{Mt}\right)$ and millions of smaller impacts throughout the history of the Earth, fewer than 200 impact structures have been confirmed (Planetary and Space Science Centre 2011). These small numbers reflect the fact that the surface of the Earth is subject to many dynamic geophysical processes (flooding, earthquakes, landslides, eolian dune formation, volcanic eruptions, sea-level change, glacier formation and retreat, and erosion) that increasingly through time serve to mask the physical signatures of individual impact events, including craters. The smaller craters and impact structures are generally easier to obliterate than the larger ones.

Not all circular depressions are impact craters; the great majority are products of other processes such as volcanic calderas, karstic sinkholes, salt domes, and tectonic folding. This greatly complicates the task of impact crater identification just on the basis of crater outline.

Also significant, not all impact events result in crater formation. Airbursts (e.g., Tunguska) are objects that explode and release most of their energy in the atmosphere above the Earth's surface. The frequency and magnitude of airbursts impact are still critical topics of research (Bland and Artemieva 2003; Morrison et al. 2002; papers in Bobrowsky and Rickman 2007), as demonstrated by the recent downsizing of the magnitude of Tunguska and increasing the frequency of this class of impact event (Boslough and Crawford 2008). Wasson (2003) suggests that weakly structured objects can create airbursts much larger and more energetic than Tunguska. An example of such an object would be Comet Shoemaker-Levy 9 that broke up into 21 separate fragments before colliding with Jupiter in July 1994. Wasson argues that a super-Tunguska impact could produce such a large fireball on detonation that the ground surface over a brief period of time would reach temperatures greater than $2,000{ }^{\circ} \mathrm{C}$, melting anhydrous soils such as loess and dune sand. Wasson suggests that his largest modeled airbursts, exceeding 1,000 Mt, could impact surface areas greater 
than $100,000 \mathrm{~km}^{2}$, a possibility having implications for our discussion below of the Rio Cuarto impact. Boslough and Crawford (2008) have modeled chondritic asteroids capable of producing similar effects but with considerably less energy necessary to produce the airburst glass melts.

More critical in terms of the absence of confirmed impact structures is the fact that water covers more than $70 \%$ of the Earth's surface (with $14 \%$ of the Earth's surface being ice covered) and yet few oceanic or lake impact structures have been identified (Dypvik et al. 2004). Only $15 \%$ of the confirmed impacts were formed in marine environments, virtually all of which represented shallow continental crust settings. Less than $4 \%$ of the confirmed impact structures are currently underwater, none of which date to the past 35 million years. Only a single deepwater impact event has been identified, the 2.5 million-year-old Eltanin tektite strewn field in the Bellinghausen Sea, for which no crater has been identified. Ocean impact craters forming in deeper waters away from shallow continental margins are subject to violent water resculpting as the transient crater within the water column collapses, followed by various degrees of rapid sediment infilling. Ocean impacts and seafloor craters pose serious challenges for study, and we have difficulty hypothesizing, recognizing, and characterizing their physical products and signatures.

A number of impact products are known to be associated with impact events but are not diagnostic as they are also produced by natural geophysical forces other than cosmic impact (French and Koeberl 2010). Breccias containing impact melts and other shocked products are clearly indicative of impact; however, most breccia layers at impact sites are indistinguishable from breccias caused by dozens of other sedimentary, igneous, and metamorphic processes unless they also contain diagnostic shock indicators. Kink banding in muscovite and biotite micas, consisting of single or multiples sets of banding transverse to the prominent basal cleavage, commonly occurs at those impact sites containing micas, but can also be produced by tectonic deformation. Melt-bearing rocks of pseudotachylite and pseudotachylitic breccias containing veinlets or large inclusion-bearing bodies of melt can be formed by either impact cratering or by tectonic forces.

Mosaicism in quartz can also lead to issues in process identification (French and Koeberl 2010). Smaller sub-grain constituents of larger uniform crystals can exhibit crystal lattices significantly misoriented to each other that, without detailed analysis, can appear similar to impact shocked quartz.

Impact spherules are also problematic (French and Koeberl 2010) in that they often contain no evidence of shock processes or high-temperature origin and are potentially indistinguishable from some volcanic droplets and lapilli. Artificially produced spherules are becoming increasingly common from various metallurgical processes and industrial fly ash from coal-fired power plants. There are many types of spherules formed by processes that appear similar to impact spherules. This does not consider the constant rain of extraterrestrial particles similar to microspherules accreted on the Earth every day in the form of interplanetary dust from comet sublimation, asteroid collisions, atmospheric meteorite ablation, and interstellar sources (Grün et al. 2001). Ice core data suggests that an average of $0.22 \mathrm{kt}$ of dust in the range of 0.45 to $20 \mu \mathrm{m}$ rains on Earth each year (Karner et al. 2003). Fortunately, other impact products such as grains of shocked carbonates and quartz are found in 
some distal ejecta layers (e.g., Chicxulub impact; Smit 1999; Schulte et al. 2009), which help to signal the impact origin of the deposits.

It should be clear by now that the identification of cosmic impact structures and impact products is challenging. But so was, for example, knowledge of the methods and application of radiocarbon dating, archaeomagnetism, pollen analysis, and faunal analysis to archaeology during their formative years within the discipline. The key for archaeologists in terms of coming to grips with cosmic impact is to become familiar with basic concepts and terminology, and to form productive partnerships with the specialists such as petrologists and geochemists who have the requisite training and equipment to help with the identification of the products and physical effects of impact.

These data illustrate that the current emphasis by planetary scientists on the use of just a few standard criteria by which to validate impact structures and events (e.g., impact craters; shocked quartz; high levels of iridium), has proven inadequate for identifying and categorizing most cosmic impact events, including large magnitude events during the Quaternary Period. Dozens of candidate impact structures and impact events have been proposed by researchers and are in various stages of modeling, data collection and evaluation (Masse 2007; Gusiakov 2012). Many more have been determined or at least declared not to represent valid impacts due to perceived flaws in impact structure descriptions and the identification of impact features in rocks and minerals (e.g., French and Koeberl 2010). The status of some impact candidates will remain uncertain until the range of impact products is more fully explored and debated.

The occurrence and distribution of spherules and other possible impact-related small particles within archaeological contexts (e.g., Courty et al. 2008) are important arenas for studies in the archaeology of cosmic impact. For example, the presence and nature of nanodiamonds as a potential product of the hypothesized Younger Dryas impact is the subject of ongoing debate (e.g., Kennett et al. 2009; Kennett 2010; Kurbatov et al. 2010; Tian et al. 2011; van Hoesel et al. 2012; Israde-Alcántara et al. 2012). This debate has ramifications for the future identification and understanding of some Quaternary Period impact events.

The study of cosmic impact products can benefit from the focus within the archaeology discipline on site formation processes (e.g., Schiffer 1987) and other considerations of the nature of sample and object context. To a limited degree, this strategy has been fruitfully applied to the Younger Dryas impact debate. The products of recent cosmic impacts should not be expected to be uniform in character and distribution but rather comport to confounding processes, natural and cultural, analogous to the complex nature of the archaeological record. Their study and explication within the archaeological record requires an examination of both archaeological site formation processes and the factors of initial production and natural distribution of the cosmic impact products themselves.

\section{Physical Effects of Cosmic Impact}

Cosmic impact effects vary greatly depending on the size, speed, composition, and angle of the impactor, along with target location. We do have some idea about the general effects of terrestrial impact on Earth (e.g., Melosh 2007, 2011); no two 
impacts will yield identical effects and products. Researchers can model general effects including thermal radiation as the projectile and target material are converted to incandescent gas or plasma; seismic shaking at and away from the impact site; the likely creation of an impact crater for most larger-sized impactors; the deposition of ejecta from the impact; and the airburst created by displacement, compression, and heating of the air near the impact which produces ballistic shock waves.

\section{Globally Catastrophic Impact Effects-The Chicxulub Case}

The publication of the Cretacious-Paleogene "K-Pg" (originally defined as the Cretaceous-Tertiary or "KT") boundary iridium anomaly and its implications for a cosmic impact end of the dinosaurs (Alvarez et al. 1980) represents the first time that science began to seriously consider the potential effects of cosmic impact on the Earth. Prior to the 1950s, it was erroneously assumed that the numerous crater-like features on the Moon represented the calderas of extinct volcanoes rather than impact craters.

The K-Pg impact some 65 million years ago and its resultant $c a$. 150-km-diameter Chicxulub crater on the Yucatan peninsula and the Gulf of Mexico are modeled to be the result of impact by a 10-km-diameter asteroid. The $\mathrm{K}-\mathrm{Pg}$ impactor generated an impact energy release of $10^{8} \mathrm{Mt}$ (100 million megatons), 5 billion times greater than Hiroshima/Nagasaki. Because of its link with the demise of the dinosaurs, the $\mathrm{K}-\mathrm{Pg}$ boundary impact has become the most studied cosmic impact event by the planetary sciences; the Earth Impact Database (Planetary and Space Science Centre 2011) lists nearly 500 references for the impact. Despite the reality of the worldwide clay iridium layer (Alvarez et al. 1980; Smit 1999) and the enormous Chicxulub crater (Hildebrand et al. 1991), it has only been within the past decade that science has come to embrace the definitive direct link between the impact and extinction (e.g., Schulte et al. 2010), although this acceptance has been facilitated by more than two decades of productive research and debate.

Kring (2000) has provided a lucid summary overview of the effects caused by the Chicxulub impact in the Yucatan peninsula and shallow waters of the Gulf of Mexico. The ejecta blanket extirpated all life within several hundred kilometers of the crater, and the shock wave, air blast, and heat of the impact killed additional plants and animal outside of the ejecta blanket. A rain of ballistic ejecta fragments created spot fires over much of the world. Forests were leveled within a 1,000-2,000-km-diameter area from central Mexico to the Gulf States in the United States. Tsunamis 100$300 \mathrm{~m}$ high ripped up seafloor sediments down to a depth of 5,000 $\mathrm{m}$. The tsunami waves subsequently crashed into the Gulf States penetrating more than a hundred kilometers, with the backwash producing a huge forest debris deposit within the Gulf of Mexico. Richter scale magnitude 10 earthquakes led to the seismic slumping of coastlines.

Most devastating were global effects produced by ejecta and the vapor-rich plume injected through the atmosphere into space, and dispersed over the Earth (Kring 2000). Modeling popularized by the media in the early 1980s suggested that a substantial portion of the injected dust particulates were submicron in size; intense darkness would have persisted for months, with photosynthesis being shut down for up to one year (Pollack et al. 1983). Sulfate aerosols and nitric acids would have 
produced devastating acids rains causing deforestation and killing organisms in lakes and other susceptible bodies of water. The cumulative effects of the $\mathrm{K}-\mathrm{Pg}$ impact resulted in the extinction of approximately $65 \%$ of biological species on Earth.

Based on the evidence from the 24-km-diameter Boltysh crater in eastern Ukraine and the hypothesized very large Shiva crater off the western coast of India, it has been argued that the effects of the $\mathrm{K}-\mathrm{Pg}$ boundary event are due to multiple simultaneous impacts or a cluster of several large impacts over a few thousand or tens of thousands of years (Chatterjee 1997; Chatterjee and Rudra 2008). Given the present uncertainties surrounding the proposed Shiva crater, the multiple $\mathrm{K}-\mathrm{Pg}$ impact combined effects scenario is not compelling (Schulte et al. 2010).

\section{Threshold Globally Catastrophic Impact Effects}

Our use of the term "threshold globally catastrophic impact" is a heuristic device to establish a hypothetical point along the continuum of impact energy release values at which the physical effects are thought to be powerful enough to affect all of the Earth. As previously noted, a threshold globally catastrophic impact is modeled to occur on average once per million years and yields approximately one million $\left(10^{6}\right) \mathrm{Mt}$ of energy $\left(4.184 \times 10^{21} \mathrm{~J}\right), 100$ times less powerful than the modeled Chicxulub impact but 50 million times greater than Hiroshima/Nagasaki. It is possible that many or most threshold globally catastrophic effects can be triggered by smaller impacts with energy releases between $10^{5}-10^{6} \mathrm{MT}$.

The May 1980 Mount St. Helens volcanic eruption has been estimated at $24 \mathrm{Mt}$, including both the kinetic energy of the ejecta and thermal energy (U.S. Geological Survey 2000). The devastating March 2011 Japan Honshu earthquake had a mainshock energy release value measured at $9.1 \times 10^{17} \mathrm{~J}$ (Ide et al. 2011), slightly more than 217 Mt. The famous 1883 eruption of Krakatau (Krakatoa) volcano in Indonesia that killed more than 36,000 people (Winchester 2003) has been estimated at $370 \mathrm{Mt}$ (Myagkov 1998). The December 2004 Indonesian Sumatra earthquake, which led to the subsequent tsunami that killed 230,000 people, has been estimated at $460 \mathrm{Mt}$ (U.S. Geological Survey 2011). The legendary Thera volcanic eruption, which in the 17 th century BC tore apart Santorini Island in the Mediterranean Sea and contributed to the end of Minoan civilization, has been estimated at around 600-1,200 Mt (Floyd McCoy, personal communication to W. B. M. 2011). The largest recorded earthquake, the 1960 Chile 9.6 magnitude event, has been estimated at 3,600 Mt (French 1998: Table 2.1). The largest historic volcanic eruption, that of Indonesia's Tambora in 1815 which killed over 71,000 people, has been estimated at 20,000 Mt, including both the kinetic energy of the ejecta and thermal energy (French 1998: Table 2.1-his estimates for Mt. St. Helens and Krakatau are $310 \mathrm{Mt}$ and 3,700 Mt, respectively). All of these events are minuscule when compared with the destructive power of a threshold globally catastrophic cosmic impact.

The largest known Quaternary Period natural disasters, other than cosmic impacts, were the volcanic eruptions at Yellowstone, Wyoming $\sim 2.1 \mathrm{Ma}$, and the $\sim 74 \mathrm{ka}$ eruption of Toba in Indonesia. Their energy release would have been much larger than that of Tambora, but somewhat smaller than the largest Cenozoic Period supervolcano eruptions (e.g., the La Garita, Colorado event which produced the Fish Canyon Tuff around $27.8 \mathrm{Ma}$ ) which have been modeled with a maximum energy 
release of $10^{22} \mathrm{~J}$, or 2.39 million megatons (Mason et al. 2004), slightly more than twice that of a threshold globally catastrophic cosmic impact. The Yellowstone and Toba Ultra-Plinian eruptions, with energy releases presumably between $10^{5}-10^{6} \mathrm{Mt}$, would have produced their own unique regional and globally catastrophic consequences (e.g., Jones 2010).

Planetary scientists typically model the rates of occurrence of large volcanic eruptions as being considerably more frequent than that of cosmic impacts with similar energy releases (Mason et al. 2004), and therefore representing a much greater hazard. We set aside for the moment the issue of the frequency of large cosmic impacts (addressed below), other than to note that our data suggest that the frequencies of the two processes (eruption vs. cosmic impact) actually may be similar. More relevant here is the likelihood that major cosmic impacts have the potential to trigger a cascade of physical effects (e.g., earthquakes; tsunamis; sustained hurricanes and other atmospheric disturbances; storm surges; flooding) with a cumulative energy much greater than that of the initial impact itself, and seemingly greater than the potential physical effects associated with comparable large-scale volcanic eruptions.

Based on the Earth Impact Effects Program (Collins et al. 2005; Marcus et al. 2010), the following effects are expected for a terrestrial threshold globally catastrophic impact in sedimentary rock of a stony asteroid $\left(2,500 \mathrm{~kg} / \mathrm{m}^{3}\right)$ approximately $2.93 \mathrm{~km}$ in diameter, with an impact velocity of $16 \mathrm{~km} / \mathrm{s}$ and an impact angle of $45^{\circ}$. The impact will form a final crater $33.7 \mathrm{~km}$ wide and $854 \mathrm{~m}$ deep, melting and vaporizing a volume of rock around $26.4 \mathrm{~km}^{3}$. Even at locations $500 \mathrm{~km}$ from the impact site (slightly more than the distance from Richmond, Virginia to New York City, and slightly less than the distance between Los Angeles and Phoenix, Arizona or from Buenos Aires to Rio Cuarto in central Argentina), the impact effects are extraordinary. The impact fireball will appear nearly six times larger than the Sun, with seven minutes of radiant flux causing first degree burns over exposed portions of the human body. Approximately $100 \mathrm{~s}$ after the impact, the ground will be shaken by a Richter scale magnitude earthquake of $~ 8.6$. Impact ejecta will arrive about $5.5 \mathrm{~min}$ after impact, blanketing the location with a $1.8-\mathrm{cm}$ thick layer of dust and rock fragments averaging about $3.1 \mathrm{~mm}$ in diameter. Slightly more than $25 \mathrm{~min}$ after impact, the air blast wave will arrive with hurricane force winds of around $206 \mathrm{~km} / \mathrm{h}$. Most wood frame buildings will collapse, and about $30 \%$ of all trees will be blown down, the remainder being stripped of leaves and occasional branches. The Earth Impacts Effect Program does not consider the potential meteorological and climatic effects of vapor and particulate plume injection into and through the atmosphere.

Bad as this may seem, a threshold globally catastrophic deepwater oceanic impact may produce even more destructive effects. The modeling of oceanic impact is currently much less robust than that for terrestrial impact, but it is certain that in addition to the fireball, impact crater, ejecta blanket, earthquakes, and air pressure blast wave, there will also be mega-tsunami potentially far greater than the largest tsunami produced by underwater earthquakes and volcanic eruptions (Gusiakov 2007; Bryant 2008; Gusiakov et al. 2010). There has been debate over whether or not some coastal chevron dune deposits may represent the product of impact mega-tsunami wave action (Scheffers et al. 2008; Bourgeois and Weiss 2009; Gusiakov et al. 2010). No one disagrees that large oceanic impact events can produce mega-tsunami waves; 
the question is how large would the tsunami be for a given event and what the geophysical evidence might look like.

The most destructive aspect of a threshold globally catastrophic deepwater oceanic impact may be the lofting of a vast amount of water vapor and particulates into and through the upper atmosphere, modeled at up to ten times the mass of the impactor (Toon et al. 1997). The upper atmosphere contains an average of less than $0.5 \%$ water vapor. The injection of the impact plume, and its rapid dispersal by diabatic heat transfer processes and by various strong atmospheric winds, will likely result in torrential rainout lasting for days or even a few weeks causing devastating worldwide floods. These floods would be particularly pronounced in river valleys and valley basins. The excess water vapor and blockage of sunlight by the particulates may foster massive cyclonic storms (Masse 2007). These hypothesized storms would produce hurricane force winds and generate rainfall drawn in part from the oceanic reservoir, resulting in further flooding and in storm surges that can devastate coastal areas. This condition would persist until enough water vapor and particulates are removed from the atmosphere by rainout to stabilize the atmosphere at near preimpact conditions.

The physical record of oceanic impacts is currently almost impossible to extract due to the difficulty of working in ocean environments and the variety and complexity of effects. We parenthetically note that a globally catastrophic impact on or over thick glacial ice may result in a water vapor and particulate plume similar to that for a deepwater oceanic impact. An impact on or over the northwestern portion of the Laurentide ice sheet conceivably could have triggered the apparent freshwater pulse into the Arctic Ocean from Canada's 1,800-km-long McKenzie River system (Kennett 2011), which has been suggested as playing a vital role in the onset of the Younger Dryas climate event (Murton et al. 2010).

The considerable disturbance to the tightly coupled oceanic-atmospheric circulation system caused by globally catastrophic deepwater impacts not only produces meteorological effects but may also initiate climatic perturbations that can last for years, decades, and even centuries (MacCraken 2007). The nature of these perturbations depends on factors including the location of the impact (e.g., latitude and water depth) and other currently poorly understood variables. The long-term climatic effects of threshold globally catastrophic terrestrial impacts are likely dependent on a similar range of specific impact variables.

\section{Regional Impact Effects}

The potential effects of smaller $\left(10^{3}-10^{5} \mathrm{Mt}\right)$ oceanic impacts are even more poorly understood. We can assume that mega-tsunami wave propagation is possible, although modeling has indicated that deepwater impacts caused by asteroids less than $500 \mathrm{~m}$ in diameter $\left(\mathrm{ca} .3 \times 10^{3} \mathrm{Mt}\right)$ will not trigger long-distance mega-tsunami effects (Gisler et al. 2011).

The impact fireball, crater formation (except for airbursts), associated ejecta blanket, associated earthquakes, and the air pressure blast wave will still have large-scale consequences, particularly for impacts near land, but the degree to which deepwater impact plume injection into the upper atmosphere may result in widespread meteorological or climatic effects is unknown. Some researchers have 
hypothesized that both terrestrial and oceanic impact events as small as $10^{2}-10^{4} \mathrm{Mt}$ may trigger physical processes leading to significant depletion of the ozone, therefore allowing enhanced levels of ultraviolet radiation to reach the Earth's surface on regional or even worldwide scales (Birks et al. 2007; Pierazzo et al. 2010).

The limited knowledge about the effects of this size and energy level of impact poses difficulties to model its likely consequences for human populations. In our discussion of the Argentine Rio Cuarto asteroid impact we specify the effects of a probable regionally catastrophic terrestrial impact. Physical evidence of the impact and our own archaeological and anthropological analyses suggest that the impact exceeded 1,000 Mt. We emphasize that our data are not sufficiently robust to constitute definitive proof of the magnitude of the impact. Rather, our twofold purpose in focusing on Rio Cuarto is to use it as a model for discussing how a $10^{3}-10^{4} \mathrm{Mt}$ terrestrial impact might affect hunter and gatherer societies, and to stimulate future field and laboratory studies by archaeologists to better define the nature of this specific event.

\section{Local Impact Effects-The Barringer Crater, Tunguska, Sikhote Alin, and Carancas} Events

In order to understand the potential effects of small impact events, we turn to comparisons with four well-studied confirmed impacts: the formation of Arizona's Barringer Crater some 49 ky ago; the 1908 Siberian Tunguska impact; the Sikhote Alin meteorite shower that took place in Siberia in 1947; and the 2007 Peruvian Carancas meteorite impact.

Canyon Diablo, Arizona Arizona's 1.2-km-diameter Barringer Crater, often referred to as Meteor Crater, traditionally has been modeled (e.g., Kring 1997) as the impact of a roughly 50-m-diameter iron asteroid yielding an energy release originally calculated at around 20-40 Mt (1,000-2,000 times that of Hiroshima/Nagasaki); more recent studies indicate a smaller energy release of around $10 \mathrm{Mt}$ (Kring 2007). Melosh and Collins (2005) have modeled the impactor as a slow-moving $(12 \mathrm{~km} / \mathrm{s})$ pancake-like mass of iron fragments approximately $200 \mathrm{~m}$ in diameter. More recently, Artemieva and Pierazzo $(2009,2011)$ have modeled the preatmospheric impactor as a sphere between 46 and $66 \mathrm{~m}$ in diameter traveling at $18 \mathrm{~km} / \mathrm{s}$ (an average value for Earth-crossing asteroids), which then lost $30-70 \%$ of its mass due to atmospheric mechanical ablation and fragmentation, hitting the ground as a tight swarm of fragments in excess of $15 \mathrm{~km} / \mathrm{s}$. At least $50 \%$ of the main impactor was ejected during crater excavation, and dispersed downrange as molten spheroids and shrapnel composed of highly shocked fragments.

Based on modeling experiments using a 20-Mt energy calculation, Kring (1997) estimated that this small object would have produced hurricane force wind velocities as far as $40 \mathrm{~km}$ away from the impact crater, and over $1,000 \mathrm{~km} / \mathrm{h}$ at a distance of $5 \mathrm{~km}$. The airblast would have totally flattened trees out to a radius of about $16-$ $22 \mathrm{~km}$ from the impact crater, and damaged an area of 4,100 to 8,500 $\mathrm{km}^{2}$. Depending on the trajectory and angle of the impactor, the damage from overpressure created by the ballistic shock wave may have extended beyond the $40-\mathrm{km}$ radius in the direction of the projectile trajectory. 
The modeled severity of damage to animals around the Barringer Crater impact site is particularly notable. Large animals subjected to an impact shock wave and associated high overpressures would endure severe compression and differing degrees of thermal radiation exposure from the impact fireball. This situation would damage joint tissues and result in hemorrhaging and edema in the lungs, air emboli in blood vessels in the heart and brain, and fibrin emboli in the blood. There would have been $100 \%$ lethality within a radius of about $3 \mathrm{~km}$ from the impact crater, and serious lung damage within a radius of about 7-9 $\mathrm{km}$ from the impact crater. In terms of the air blast wave and high wind velocities, there would have been a casualty rate of approximately $50 \%$ for human-sized animals between 9 and $14 \mathrm{~km}$ from the impact crater, with higher casualties being reached in more heavily obstructed areas (e.g., woodlands and forests) as trees fall and as animals are slammed against trees and boulder outcrops as to opposed to more open savanna grasslands. Objects such as broken branches and rocks would have become deadly missiles in winds reaching or exceeding a velocity of $300 \mathrm{~km} / \mathrm{h}$.

Tunguska, Siberia The June 30, 1908 Tunguska impact (Krinov 1966; Steel 1995; Longo 2007; Rubtsov 2009) resulted in an energy release similar to that of the Barringer Crater impact, but differs in having been primarily an airburst rather than a ground strike. The Tunguska impactor was likely a small stony asteroid that, upon entering the atmosphere, exploded as an airburst 6-10 km above the ground surface. There are many disagreements about the nature of the impactor, pre-atmospheric size of the object, magnitude of energy release, and frequency of comparable impacts on Earth (Rubtsov 2009).

The difficulty of access to the impact location in the Podkamennaya Tunguska river basin prevented field investigation until two decades after the impact. This coupled with difficulties in the identification of impact signatures and products (other than the visibly affected local forest) have led to the formulation of a number of controversial and even bizarre theories that attempt to challenge the cosmic impact nature of the event (e.g., see discussions in Kolesnikov et al. 2007; Longo 2007; Rubtsov 2009). In our opinion, the overall evidence of eyewitness accounts and other objective criteria readily contradict these alternative theories.

The Tunguska impactor traditionally has been modeled as an object about 60 $70 \mathrm{~m}$ in diameter which yielded an energy release of between 10 and $15 \mathrm{Mt}$ (500-750 times that of Hiroshima/Nagasaki), and an original estimated frequency of around $1.5 \mathrm{ky}$ on average for the Earth to experience comparable impacts. The tendency in recent years has been for planetary scientists to expand this average frequency, including the 2-3-ky estimate calculated by Stuart and Binzel (2004). This traditional model has been challenged by recent simulation at Sandia National Laboratory in which the size ( $c a .30 \mathrm{~m}$ diameter), magnitude ( $c a .4-5 \mathrm{Mt}$ ) and frequency ( $c a .100$ 200 years on average between impacts) have been greatly reduced (Boslough and Crawford 2008; see, however, Rubtsov 2009).

No discernable crater has been identified for the Tunguska event (Lake Cheko has been proposed but not conclusively demonstrated to be of impact origin; see Gasperini et al. 2007; cf. Collins et al. 2008). The airburst leveled $2,150 \mathrm{~km}^{2}$ of forest, with trees snapped off or uprooted and hurled many meters from their original locations. Trees were stripped of their branches, and tree fall was generally radially aligned in a 
concentric pattern from the epicenter of the blast. One exception was at the epicenter whose branchless trees remained standing because they were not subjected to as great of transverse forces as were those away from the center of the blast. Trees in the general center of the blast radius $\left(c a .200 \mathrm{~km}^{2}\right)$ were charred, but did not completely burn due to the subsequent air pressure blast wave that extinguished the fire.

Evenki ( Evenks, Tungus) reindeer herders just outside the central core of the blast and tree fall zone were injured by heat and being tossed by the air pressure blast wave; some herders lost consciousness (Krinov 1966; Baxter and Atkins 1976). At the time of impact, around 7:15 a.m. local time, two Evenki brothers having returned at dawn from a long hunting trip were sleeping in their skin tent along the Avarkitta River approximately $30 \mathrm{~km}$ to the south-southeast of the impact epicenter (Suslov 2006; Rubtsov 2009:3). They were suddenly awaked by ground tremors and the noise of the wind. As they attempted to get out of their tent there was a great clap of thunder and the wind knocked down the tent and raised its skin flaps. Trees were falling down around them with their pine needles ablaze while branches and moss on the ground burned as well. It had been a sunny cloudless morning. A "second Sun" (i.e., the airburst fireball) appeared to the observers to rise above the mountain where the trees had already fallen followed by additional flashes of light and thunder. The brothers attempted to stand up but were knocked down by the wind. Other Evenki witnesses interviewed in 1926 told similar stories (Suslov 2006). Tents were blown away; clothing, blankets, and fishing nets caught on fire; smoke filled the air; and several people became at least momentarily unconscious.

A witness at the Vanavara trading post about $58 \mathrm{~km}$ southeast of the impact epicenter, noted that the sky appeared to split in half with the northern half being covered with fire (Baxter and Atkins 1976:91; Rubtsov 2009:3). The heat in the direction of the impact was such that clothing seemed to be on fire. A sudden blast of wind knocked the witness down after which he briefly lost consciousness. Upon recovering he was helped by his wife who had been indoors at the time of initial impact. There were loud noises in the sky like guns or stones falling. The ablating Tunguska impactor was observed along a path more than $650 \mathrm{~km}$ in length, and detonations were heard more than $800 \mathrm{~km}$ from the site across an area greater than 2,000,000 $\mathrm{km}^{2}$.

Most scientific treatments of the impact event imply that there were no human fatalities from the Tunguska event. However, three Evenki are documented as having indirectly died from the impact (Suslov 2006). One old man (Lurbuman) at a camp near the edge of the tree fall zone apparently died of a heart attack a few hours after the impact upon hearing from his son about the extent of the devastation. A shaman, Uyban, became unconscious and died an unspecified time after the impact. Ivan Machakugyr, who lived with his wife near the confluence of the Dilyushmo and Khushma rivers about $35 \mathrm{~km}$ from the blast epicenter, sustained a severe compound fracture on one arm from a falling tree during the impact; he apparently subsequently died of shock and loss of blood from his wounds. Dogs and a large number of reindeer were also stated as having been killed by the impact. It is possible that these animals were physically more vulnerable than the semi-sheltered adult humans.

The occurrence of a Tunguska-like airburst over a densely populated area is statistically very unlikely, but its effects would be devastating. A 10-Mt point source airburst at a height of $5 \mathrm{~km}$ over metropolitan New York has been modeled to result in 
3.9 million deaths, 4.7 million injuries, and 1.5 trillion dollars of property loss (Mignan et al. 2011).

An interesting sociological aspect of the Tunguska impact is the fact that the Evenki people considered the event to have been the visitation of their fire god (Krinov 1966; Baxter and Atkins 1976; Rubtsov 2009). The impact site area was considered sacred and seemingly evil, and Evenki shamans discouraged their people from going near the tree fall zone. Such avoidance of a region in which a major catastrophe has occurred may be a common reaction among traditional cultures (Masse et al. 2007; Piccardi and Masse 2007). Siberian anthropologist Innokenty Suslov (2006) noted that he had to be indirect and circumspect in his 1926 questioning of Tunguska witnesses. The impact observations were among topics forbidden for general discussion by Evenki religious "taboos."

Smaller Tunguska-like airburst events may have occurred over remote portions of Brazil in 1930 (Bailey et al. 1995; McFarland 2009) and Guyana in 1935 (Steel 1996), but are poorly known and largely unstudied. A mid-Pleistocene impact event dated to around $481 \mathrm{ky}$ ago is present as an extraterrestrial dust horizon in various Antarctic ice cores (Misawa et al. 2010). The event has been modeled as a large Tunguska-like airburst over Antarctica based on aggregates of chemically similar microspherules found in sediment traps in the Transantarctic Mountains (van Ginneken et al. 2010).

Sikhote Alin, Siberia The February 1947 Sikhote Alin impact in eastern Siberia (Krinov 1966, 1971; Steel 1995; Gallant 2002) is perhaps the closest modern analog that we have to Campo del Cielo. Sikhote Alin is by no means equivalent, and was evidently much less energetic.

Sikhote Alin was a coarse iron-nickel asteroid or asteroid fragment. The preatmospheric entry mass has been estimated at around $900,000 \mathrm{~kg}$, with about $100,000 \mathrm{~kg}$ surviving the atmospheric entry fall. The energy release is estimated at $\sim 1$ Mt (50 times Hiroshima/Nagasaki). It may have disintegrated in two or three separate detonations as it traveled through the atmosphere, with the lowest being less than $5 \mathrm{~km}$ above the ground surface. It is this latter explosion that actually formed a combined crater and strewn field that covered an area about $1 \times 2 \mathrm{~km}$.

Of the approximately 122 documented craters, the largest (Crater 1) had a diameter of around $28 \mathrm{~m}$ and a depth of $6 \mathrm{~m}$ from the top of the rim to the floor. At the time of initial investigation in 1947, the bottom and lower inner slopes of Crater 1 exhibited eight small pits indicating the formation of the crater by a small cluster of impactor fragments. Because of the slow speed of the ground impact throughout the crater field, the larger meteorites tunneled several meters into the ground and did not explode (penetration funnels similar to Crater 5 and Craters 7-20 at Campo del Cielo); a number of small meteorite fragments were found imbedded in trees. The forest was covered with snow at the time of impact. There is no evidence of either ignition fires or the creation of glass melts due to the small size and slow speed of the impacting object; the presence of snow and winter temperatures could have muted the potential for ignition fire.

The mass of the largest surviving meteorite is $\sim 1,500 \mathrm{~kg}$. The blast pressure wave was felt at a distance of more than $150 \mathrm{~km}$ from the crater strewn field. The bright descending meteorite was seen and the detonations heard more than $300 \mathrm{~km}$ from the 
impact site. A smoke train up to $32 \mathrm{~km}$ in length was seen in the sky for several hours after the impact.

Carancas, Peru Late in the morning of September 15, 2007, a small stony meteorite impacted approximately $3 \mathrm{~km}$ northwest of the small hamlet of Carancas, Peru (Le Pichon et al. 2008; Kenkmann et al. 2009; Tancredi et al. 2009). The impact occurred in a shallow dry arroyo with the ground water table being about $1.5 \mathrm{~m}$ below surface. Tancredi et al. (2009) provide descriptions of the event by nearby villagers. Witnesses, mainly to the east of the east to west traveling object, saw a bright fireball and heard explosive sounds. Villagers at Carancas itself heard a large explosion and observed a rapidly expanding mushroom cloud of dust, disseminated water droplets, and fine particles covering a large portion of the sky. A prominent smoke train from the atmospheric transit of the impactor was observed in the sky after the impact.

This is the youngest known impact crater on Earth and the smallest in terms of impact sites characterized by a single impact crater (some crater strewn fields formed by iron meteorites, such as Sikhote Alin, have numerous smaller craters). The Carancas impact crater is nearly circular and measured approximately $14 \mathrm{~m}$ in diameter between rim crests, and $2.4 \mathrm{~m}$ in depth from the lowest rim when first studied shortly after its formation. The average height of the crater rim above the target ground level is $54 \mathrm{~cm}$.

Scattered material in and around the crater indicates that the meteorite pulverized and fragmented upon impact. Several kilograms of meteoritic material were collected in the days following the impact. Based on surviving fragments, the meteorite is an ordinary chondrite. Tancredi et al. (2009) suggest that the original mass of the preatmospheric object was between 7 and 12 tons, with a diameter of between 1.6 and $2.0 \mathrm{~m}$, a velocity of between 12 and $17 \mathrm{~km} / \mathrm{s}$, and an atmospheric entry angle between $45^{\circ}$ and $60^{\circ}$. The diameter of the ablated meteorite at impact was about $0.6-1.1 \mathrm{~m}$, with a mass between 0.3 and 3 tons, an impact velocity of between 3 and $6 \mathrm{~km} / \mathrm{s}$, and an impact energy release between 1 and 3 tons of TNT. Kenkmann et al. (2009) rejected the notion that the crater was the result of a hypervelocity impact, and modeled the impact velocity significantly lower than Tancredi et al. (2009). Nevertheless, Harris et al. (2008a, 2008b) and Tancredi et al. (2009) specifically noted impact melt breccias mixed with the melted impactor along with shocked minerals indicative of a high-speed impact (4-6 km/s). In order to survive entry to low altitudes at high speeds, Schultz et al. (2008a) proposed that the object had fragmented high in the atmosphere but reorganized into a shape that reduced aerodynamic drag.

Most researchers agree that there are several unusual aspects to this impact that deviate from expectations for meteorites of this composition and small size. The stony meteorite remained largely intact during its traverse through the atmosphere (typically stony meteorites less than about $25 \mathrm{~m}$ in diameter fragment and do not survive atmospheric passage); it did not form a meteorite strewn field; and it was capable of producing an impact crater.

Ejecta from the impact traveled more than $350 \mathrm{~m}$, with a fragment damaging the metal roof of a storage shed located $120 \mathrm{~m}$ from the crater. A man riding a bicycle about $100 \mathrm{~m}$ from the crater fell and reported dizziness from the explosion, but his eardrums were not ruptured. A bull about $200 \mathrm{~m}$ from the crater fell and broke a horn. 
A man standing about $400 \mathrm{~m}$ from the crater heard the explosion and saw the expanding dust cloud, but did not fall or experience any injury. The Carancas area has a low population density. Kenkmann et al. (2009) note that given a mean world population density of 50 inhabitants per square kilometer, had the impact occurred in an area of average population density it could have adversely affected approximately ten individuals. They modeled the probability of a Carancas-like event occurring on average every 10 years somewhere on the Earth.

\section{Quaternary Period Record of Cosmic Impact}

Lists of identified and scientifically confirmed cosmic impacts are poor indicators of the actual numbers of past impacts of all magnitudes during the Quaternary Period. The highly regarded Earth Impact Database (Planetary and Space Science Centre 2011), maintained by the University of New Brunswick, contains just 32 confirmed impact structures for the past 3 million years, and only 39 total confirmed impacts during the past 35 million years (Table 1). This database does not include airbursts, such as the Tunguska event. Also missing are meteoritic strewn fields without identifiable craters, such as the huge Australasian tektite strewn field that as previously discussed may represent a globally catastrophic oceanic impact event around 800,000 years ago.

It is important to remember that the Earth Impact Database is a dynamic document and is periodically updated (through consensus review and other relevant practices and standards) to reflect new findings as they are verified. A recent study (Jourdan et al. 2011) suggests that India's Lonar crater dates to around $570 \pm 47 \mathrm{ky}$, an order of magnitude older than listed in the Earth Impact Database (see also Table 1), a date that may eventually supplant the original date estimate. In a similar vein, our paper suggests that the age of the Rio Cuarto crater field should match the dating for the Holocene impact glasses (3-6 BP) rather than the more general "less than 100,000 years" now used in the Earth Impact Database.

Few confirmed terrestrial impact structures, including those dating to the Quaternary Period, have been accurately and precisely dated (Jourdan et al. 2012). In fact, as illustrated in Table 1, the vast majority of impacts, including the larger impacts, have not even been identified or at least confirmed. The absence of any confirmed impacts between 300 and $900 \mathrm{ky}$ ago, 1.4 and 3.0 million years ago, and particularly between 5.0 and 15 million years ago and 15.1 and 35.3 million years ago well illustrate the difficulty of identifying past cosmic impact events, a difficulty that increases as one moves back in time.

Few currently confirmed impact structures represent larger scale events, even during the Quaternary Period. As indicated in Table 1, the largest confirmed events of the past three million years are three $10^{4} \mathrm{Mt}$ events. These include Zhamanshin in Kazakhstan 900 ky ago, Bosumtwi in Ghana 1.1 million years ago, and possibly Rio Cuarto in Argentina only 6-3 ky ago. Of the other 29 confirmed impact structures, New Quebec in Canada ( $c$ a. 1.4 million years ago) is between $10^{2}$ and $10^{3} \mathrm{Mt}$, while all others are less than $20 \mathrm{Mt}$. Only one globally catastrophic impact structure has been confirmed for the past 15 million years, Kara-Kul in Tajikistan dating about 5 million years ago. It is emphasized that the energy release values listed in Table 1 are 
Table 1 Confirmed impact structures on the Earth dating to the past 35.3 million years

\begin{tabular}{|c|c|c|c|c|}
\hline $\begin{array}{l}\text { Impact structure } \\
\text { name }\end{array}$ & $\begin{array}{l}\text { Location of } \\
\text { impact structure }\end{array}$ & $\begin{array}{l}\text { Diameter in km of largest } \\
\text { crater (and numbers of } \\
\text { known associated craters) }\end{array}$ & $\begin{array}{l}\text { Crude estimate of } \\
\text { energy release } \\
\text { (megatons) }\end{array}$ & $\begin{array}{l}\text { Date of impact or } \\
\text { estimated years } \\
\text { before present }\end{array}$ \\
\hline Carancas & Peru & $0.014(1)$ & $<1$ & AD 2007 \\
\hline Sikhote Alin & Russia & $0.027(122)$ & $\sim 1$ & AD 1947 \\
\hline Wabar & Saudi Arabia & $0.116(3)$ & $\sim 1$ & AD 1704 \\
\hline Sobolev & Russia & $0.053(1)$ & $<1$ & $<1,000$ \\
\hline Haviland & United States & $0.015(1)$ & $<1$ & $<1,000$ \\
\hline Whitecourt & Canada & $0.036(1)$ & $<1$ & $<1,100$ \\
\hline Kaalijärv & Estonia & $0.110(9)$ & $\sim 1-2$ & $2,800-2,400 ?$ \\
\hline Henbury & Australia & 0.157 (11) & $\sim 1-2$ & $<4,700$ \\
\hline Campo del Cielo & Argentina & $0.115(20)$ & $\sim 1-2$ & $4,800-4,100$ \\
\hline Kamil & Egypt & $0.045(1)$ & $<1$ & $<5,000$ \\
\hline Boxhole & Australia & $0.170(1)$ & $\sim 1$ & $\sim 5,400$ \\
\hline Rio Cuarto & Argentina & $4.500(11)$ & $\sim 10^{3}-10^{4}$ & $6,000-3,000$ \\
\hline Macha & Russia & $0.300(1)$ & $\sim 1$ & $<7,000$ \\
\hline Ilumetsa & Estonia & $0.080(3)$ & $<1$ & $7,400-7,000$ \\
\hline Morasko & Poland & $0.100(8)$ & $\sim 1-2$ & $<10,000$ \\
\hline Tenoumer & Mauritania & $1.900(1)$ & $<10$ & 21,400 \\
\hline Barringer & United States & $1.190(1)$ & $\sim 10$ & 49,000 \\
\hline Odessa & United States & $0.168(7)$ & $\sim 1-2$ & $<50,000$ \\
\hline Xiuyan & China & $1.800(1)$ & $<10$ & $>50,000$ \\
\hline Lonar & India & $1.830(1)$ & $<10$ & 52,000 \\
\hline Amguid & Algeria & $0.450(1)$ & $\sim 1-2$ & $<100,000$ \\
\hline Tswaing & South Africa & $1.130(1)$ & $<10$ & 220,000 \\
\hline Kalkop & South Africa & $0.640(1)$ & $\sim 1$ & 250,000 \\
\hline Dalgaranga & Australia & $0.024(1)$ & $<1$ & 270,000 \\
\hline Wolfe Creek & Australia & $0.875(1)$ & $<1$ & $<300,000$ \\
\hline Zhamanshin & Kazakhstan & $14.000(1)$ & $\sim 5 \times 10^{4}$ & 900,000 \\
\hline Veevers & Australia & $0.080(1)$ & $<1$ & $<1,000,000$ \\
\hline Monturaqui & Chile & $0.460(1)$ & $\sim 1-2$ & $<1,000,000$ \\
\hline Bosumtwi & Ghana & $10.500(1)$ & $\sim 2 \times 10^{4}$ & $1,070,000$ \\
\hline New Quebec & Canada & $3.440(1)$ & $\sim 5 \times 10^{2}$ & $1,400,000$ \\
\hline Talemzane & Algeria & $1.750(1)$ & $<10$ & $<3,000,000$ \\
\hline Aouelloul & Mauritania & $0.390(1)$ & $\sim 1-2$ & $3,000,000$ \\
\hline El'gygytgyn & Russia & $18.000(1)$ & $\sim 10^{5}$ & $3,500,000$ \\
\hline Roter Kamm & Namibia & $2.500(1)$ & $\sim 10^{2}$ & $3,700,000$ \\
\hline Kara-Kul & Tajikistan & $52.000(1)$ & $\sim 3.5 \times 10^{7}$ & $<5,000,000$ \\
\hline Karla & Russia & $10.000(1)$ & $\sim 2 \times 10^{4}$ & $5,000,000$ \\
\hline Bigach & Kazakhstan & $8.000(1)$ & $\sim 6 \times 10^{3}$ & $5,000,000$ \\
\hline Steinheim & Germany & $3.800(1)$ & $\sim 6 \times 10^{2}$ & $15,000,000$ \\
\hline Ries & Germany & $24.000(1)$ & $\sim 3.5 \times 10^{5}$ & $15,100,000$ \\
\hline Chesapeake Bay & United States & $40.000(1)$ & $\sim 5.1 \times 10^{7}$ & $35,300,000$ \\
\hline
\end{tabular}

Adapted and modified from the Earth Impact Database (Planetary and Space Science Centre 2011). The energy release values are roughly estimated from modeling and assumptions contained within the Earth Impact Effects Program (Marcus et al. 2010). The values suggested for the Campo del Cielo and Rio Cuarto impact events are based on the present study 
heuristic estimates roughly calculated by the authors from the Earth Impact Effects Program (Marcus et al. 2010). We do not know all of the actual values for variables that would have factored into the energy release for each impact event (e.g., impactor entry angle and speed, impactor composition, the presence of ancillary craters subsequently erased by geophysical processes). The energy release values for some impacts could be several times larger than listed in Table 1.

We recommend that archaeologists become familiar with scientifically confirmed and accepted impacts (e.g., Planetary and Space Science Centre 2011) along with previously discarded impact structure and impact event proposals. Particular attention should be given to new and ongoing proposals and debates, including that for the Younger Dryas. A useful tool for learning about many of these hypotheses and debates is the Expert Database on Earth Impact Structures or EDEIS (Gusiakov 2012), maintained by Viacheslav Gusiakov, director of the Tsunami Laboratory at the Institute of Computational Mathematics and Mathematical Geophysics, Siberian Division of the Soviet Academy of Sciences. The EDEIS lists a total of 1,082 confirmed and hypothesized impact structures and events (Gusiakov 2012). Another valuable set of discussions can be found in the Asteroid and Comet Impact Hazards website (http://impact.arc.nasa.gov/) maintained by David Morrison, senior scientist at the NASA Astrobiology Institute, NASA Ames Research Center. The staff of the Earth Impact Database is apparently working on a list of unconfirmed craters for future inclusion in their website (see FAQ in Planetary and Space Science Centre 2011).

Table 2 depicts the estimated numbers of impacts during a 3 million year interval (e.g., the terminal Pliocene epoch and Quaternary Period) and a 15 ky interval (e.g., the terminal Pleistocene and subsequent Holocene). Table 2 provides a rough and conservative estimation of the magnitude, periodicity, and numbers of cosmic impacts during the two "average" intervals are heuristic estimates roughly calculated by the authors from the Earth Impacts Effects Program (Marcus et al. 2010). These hypothesized events are simplistically modeled for this exercise as the impact of a variably sized stony asteroid with the projectile density of $2,500 \mathrm{~kg} / \mathrm{m}^{3}$, speed of $16 \mathrm{~km} / \mathrm{s}$, an impact angle of $45^{\circ}$, and a target of sedimentary rock with a density of $2,500 \mathrm{~kg} / \mathrm{m}^{3}$.

This model conservatively depicts a threshold globally catastrophic impact with an occurrence interval of 4.6 million years rather than the 1 million year figure noted earlier in the paper and used by many other planetary scientists. Table 2 also simplistically assumes that cosmic impact is a completely random process with respect to the timing and distribution of occurrence, which as noted earlier for comets may not be the case. Taken together, the actual numbers of impacts during the "average" 3 million and $15 \mathrm{ky}$ intervals are likely much larger at all levels of magnitude. By adjusting the average interval of a threshold globally catastrophic impact from 4.6 to 1.0 million years and then adjusting the values for each level of decreasing magnitude, the resulting adjusted figures are perhaps better representative of the average numbers of impact events. The National Research Council of the National Academies (2010) report Defending Planet Earth has adopted even more conservative interval estimates for impact rates. They use an average interval estimate of $700 \mathrm{ky}$ for $1-\mathrm{km}-$ diameter impacts on Earth. This contrasts with $380 \mathrm{ky}$ for our Earth Impacts Effects Program model (ca. $3.94 \times 10^{4} \mathrm{Mt}$ ), and $82.6 \mathrm{ky}$ for our adjusted model. 
Table 2 Average numbers of cosmic impacts during a three million year period and a fifteen thousand year period

\begin{tabular}{|c|c|c|c|c|}
\hline Approximate energy release & $\begin{array}{l}\text { Projectile diameter } \\
\text { (kilometers or } \\
\text { meters) }\end{array}$ & $\begin{array}{l}\text { Average interval } \\
\text { between events }\end{array}$ & $\begin{array}{l}\text { Average number } \\
\text { of events per } \\
3,000,000 \text { years }\end{array}$ & $\begin{array}{l}\text { Average number } \\
\text { of events per } \\
15,000 \text { years }\end{array}$ \\
\hline $\begin{array}{c}10^{6} \mathrm{Mt}(50,000,000 \text { times }> \\
\text { Hiroshima/Nagasaki) }\end{array}$ & $2.93 \mathrm{~km}$ & $\begin{array}{l}4.6 \text { million years } \\
{[1 \text { million years }]}\end{array}$ & $\begin{array}{l}0.67 \text { events } \\
{[3.8 \text { events }]}\end{array}$ & $\begin{array}{l}0.0034 \text { events } \\
{[0.016 \text { events }]}\end{array}$ \\
\hline $\begin{array}{c}10^{5} \mathrm{Mt}(5,000,000 \text { times }> \\
\text { Hiroshima/Nagasaki) }\end{array}$ & $1.36 \mathrm{~km}$ & $\begin{array}{l}780,000 \text { years } \\
{[169,570 \text { years }]}\end{array}$ & $\begin{array}{l}3.9 \text { events } \\
{[16.6 \text { events }]}\end{array}$ & $\begin{array}{l}0.02 \text { events } \\
{[0.09 \text { events }]}\end{array}$ \\
\hline $\begin{array}{c}10^{4} \mathrm{Mt}(500,000 \text { times }> \\
\text { Hiroshima/Nagasaki) }\end{array}$ & $637 \mathrm{~m}$ & $\begin{array}{l}170,000 \text { years } \\
{[36,960 \text { years }]}\end{array}$ & $\begin{array}{l}18 \text { events } \\
{[83 \text { events }]}\end{array}$ & $\begin{array}{l}0.09 \text { events } \\
{[0.41 \text { events }]}\end{array}$ \\
\hline $\begin{array}{r}10^{3} \mathrm{Mt}(50,000 \text { times }> \\
\text { Hiroshima/Nagasaki) }\end{array}$ & $306 \mathrm{~m}$ & $\begin{array}{l}73,000 \text { years } \\
{[15,870 \text { years }]}\end{array}$ & $\begin{array}{l}42 \text { events } \\
{[193 \text { events }]}\end{array}$ & $\begin{array}{l}0.21 \text { events } \\
{[0.97 \text { events }]}\end{array}$ \\
\hline $\begin{array}{l}10^{2} \mathrm{Mt}(5,000 \text { times }> \\
\text { Hiroshima/Nagasaki) }\end{array}$ & $168 \mathrm{~m}$ & $\begin{array}{l}21,000 \text { years } \\
{[4070 \text { years }]}\end{array}$ & $\begin{array}{l}144 \text { events } \\
{[662 \text { events }]}\end{array}$ & $\begin{array}{l}0.72 \text { events } \\
{[3.3 \text { events }]}\end{array}$ \\
\hline $\begin{array}{l}10 \mathrm{Mt} \text { (500 times> } \\
\text { Hiroshima/Nagasaki) }\end{array}$ & $65 \mathrm{~m}$ & $\begin{array}{l}1500 \text { years } \\
{[330 \text { years }]}\end{array}$ & $\begin{array}{l}2000 \text { events } \\
{[9200 \text { events }]}\end{array}$ & $\begin{array}{l}10.0 \text { events } \\
{[46.6 \text { events] }}\end{array}$ \\
\hline $\begin{array}{l}1 \mathrm{Mt} \text { (50 times }> \\
\text { Hiroshima/Nagasaki) }\end{array}$ & $32 \mathrm{~m}$ & $\begin{array}{l}213 \text { years } \\
{[46 \text { years }]}\end{array}$ & $\begin{array}{l}14,085 \text { events } \\
{[64,790 \text { events }]}\end{array}$ & $\begin{array}{l}70.4 \text { events } \\
{[324 \text { events] }}\end{array}$ \\
\hline
\end{tabular}

Adapted from modeling and assumptions in the Earth Impact Effects Program (Marcus et al. 2010). Hypothesized events are modeled as the impact of a variably sized stony asteroid with the projectile density of $2500 \mathrm{~kg} / \mathrm{m}^{3}$, speed of $16 \mathrm{~km} / \mathrm{s}$, an impact angle of $45^{\circ}$, and a target of sedimentary rock. Figures in brackets represent adjusted values based on a threshold globally catastrophic impact of $10^{6} \mathrm{Mt}$ occurring on average once every 1 million years rather than every 4.6 million years

There is no reason to assume that all of the larger magnitude impacts $\left(\geq 10^{3} \mathrm{Mt}\right)$ including globally catastrophic impacts - would have occurred prior to the past $15 \mathrm{ky}$. Although of low probability, it is possible that more than one impact greater than 1,000 Mt occurred during the past $15 \mathrm{ky}$. Our data suggest that Rio Cuarto may be one such event.

\section{Recognizing and Proving Cosmic Impact Events and their Population-Level Effects}

Scientific proof depends on both evidence and judgment criteria. Evidence is data which is deemed relevant and that is intended to account for the facts in issue. Such data may include information extracted from the testimony of witnesses (e.g., observers of impact events), records and documents (oral and written information about the observed impact events; stratigraphic and paleoenvironmental data), objects (impact structures and impact products; the archaeological record), or some specified relation between objects. Judgment criteria are the standards on which the evaluation of a certain body of evidence, relative to the facts in issue, is based. These criteria specify, on the basis of consensual and pragmatic choices guided by the state of the art in each particular discipline, how useful or relevant each piece of 
information is for determining the likelihood of the occurrence of a hypothesized fact or event.

Evidence can be direct or circumstantial (Bates 1985:2). Direct evidence is evidence of the facts in issue themselves without the need for intervening inference or additional evidence, constituted either by the testimony of a witness who observed the event or the production of an admissible document which constitutes the fact in issue. Circumstantial evidence is evidence of facts that are not in issue, from which a fact in issue may be inferred. Typically, circumstantial evidence presents a series of facts that, when linked together, indirectly support a claim. This kind of evidence is subject to interpretation so the conclusions drawn upon it may be, to some degree, contentious. In the historical sciences (e.g., geology, paleontology, and archaeology) whose aim is to explain natural phenomena in terms of long past causes (Cleland 2002), it is usually impossible to collect direct evidence about past events, so they must rely almost entirely on circumstantial evidence to test hypotheses. This makes the development of judgment criteria a most critical and pressing issue.

Currently, there is a marked asymmetry in the development of criteria to reasonably prove, on the one hand, the past occurrence of a cosmic impact event and, on the other hand, the range of the effects of such an unpredictable incident on contemporary human populations. The first issue usually depends on the demonstrated presence of one or more of the known physical correlates of an impact event like impact structures, meteorite or tektite strewn fields, and other rock and mineral features whose impact signatures are present in higher numbers than those expected by pure chance. Even without the presence of known impact structure features, it is still possible to make a strong case for the presence of an impact event on the basis of detailed observations, quantitative measurements, and stratigraphic associations of likely impact products (French and Koeberl 2010).

Regarding the effects at the human population level of a past cosmic impact event, no evidential lines nor judgment criteria have yet been explicitly formulated. It currently is extremely difficult to clearly specify what would serve as unambiguous evidence for the occurrence of population-level effects of a cosmic impact. There is an almost complete lack of information about what exactly such effects might be, what material correlates would constitute their likely signature, and how such correlates might be meaningfully approached from an archaeological stand point. This situation results from the current unawareness of most of the archaeologists about the potential role of cosmic impacts as a driving force behind human evolution and the fact that the NEO research community has not shown interest in the development of explicit models and fieldwork programs to systematically look at the potential role of cosmic impact in humankind's past.

The environmental and ecological effects of an impact event depends on the size, mass, composition, speed, and angle of the impactor, along with target location (i.e., the atmosphere, the continental or the oceanic crust). A single impact including those substantially below the threshold of global catastrophe can trigger a complex combination of natural destructive forces such as shock waves, fireballs, earthquakes, tsunamis, wildland fires, high-speed winds, torrential rainfall, and coastal storm surges capable of producing significant environmental and ecological change and disruption (Fig. 1), depending on proximity to the impact. The magnitude of the effects of such impact-related catastrophes on human populations will in turn depend 
IMPACT EVENT AND ITS EFFECTS

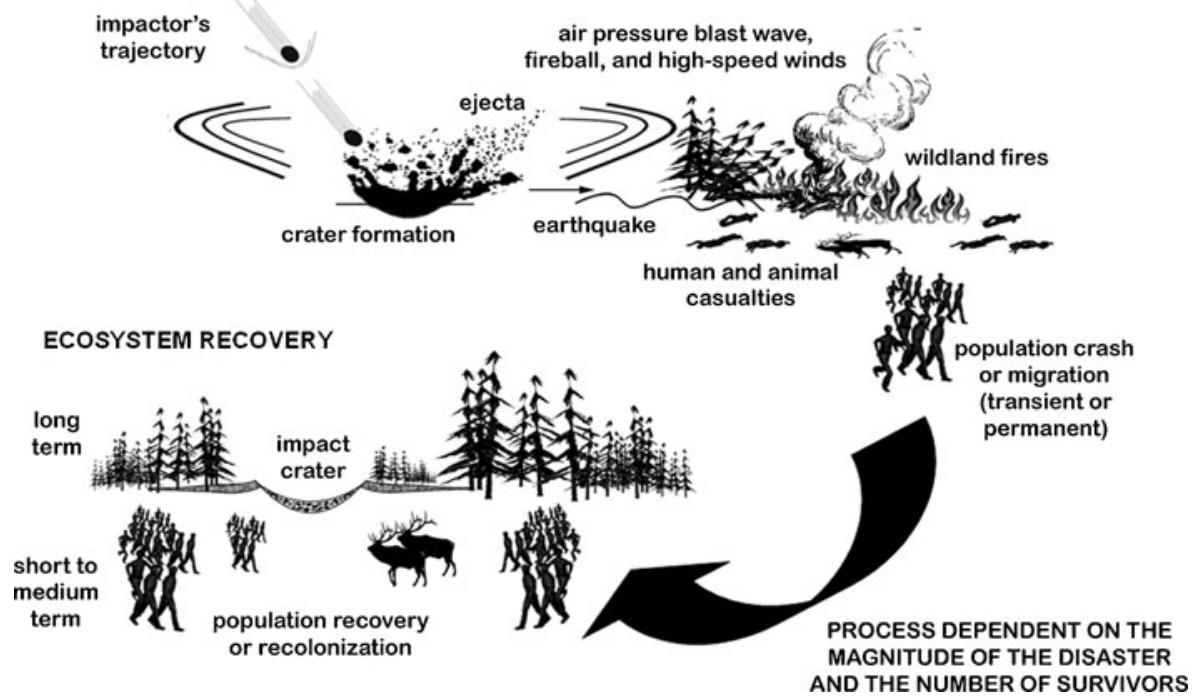

Fig. 1 Schematic representation of the likely effects of a terrestrial, regional level $\left(10^{3}-10^{5} \mathrm{Mt}\right)$, cosmic impact and the conditions that regulate the rate of ecosystem recovery. Although the figure illustrates a crater-forming impact, it also applies to the effects of an airburst

on population size and density, spatial distribution of individuals and groups at a regional or superregional scale, and aspects of the organization at different levels or spheres (e.g., social, economic, informational). All these factors determine the degree of vulnerability, i.e., the susceptibility of any given population to suffer harm (Leary and Beresford 2009).

A number of authors (e.g., Folke et al. 2002, 2004; Adger 2006; Kasperson et al. 2005; Leary and Beresford 2009) characterize vulnerability as having three basic dimensions: (1) exposure to stresses, perturbations and shocks; (2) sensitivity of organisms - including people-places, and ecosystems to stress or perturbation, comprising their capacity to anticipate and cope with the stress; and (3) resilience or adaptive capacity of exposed organisms, places and ecosystems in terms of their ability to absorb shocks and perturbations, maintain function and, eventually, restore the previous state of affairs. It is expected that the vulnerability of human populations varies across the entire range of levels of socio-political integration. Sheets (1999), from a comparative archaeological study on the effects of explosive volcanic eruptions on ancient egalitarian, ranked, and stratified Mesoamerican societies, suggests that the negative influence of such hazards on the persistence of human groups tends to increase along with the degree of organizational complexity of each society. Smallscale mobile hunter-gatherer societies living at low population densities and with a very low investment in the production of "built environments" seem to be more resilient to environmental and ecological perturbation than larger and more densely packed, sedentary, and infrastructurally rooted social groups (Fitzhugh 2012).

It is reasonable to think that resilience, even for hunter-gatherers, is strongly limited or constrained by the magnitude of the natural disaster to which a population or society is exposed. When the magnitude of the catastrophe is low (i.e., local-scale 
impact), it is expected to affect organization rather than demography. When the magnitude is high (i.e., regional-scale impact), both organization and demography are likely to exhibit significant responsive change. In such a situation, changes at the population level may range from the simple and transient spatial redistribution of people to a demographic decline or crash leading to either a range contraction or, in the most severe cases, to population extinction (Fig. 1). The magnitude of the disaster also affects the rate of ecosystem recovery and habitat recolonization. In natural catastrophes, the quickness of the recovery tends to be inversely proportional to the size of the impacted area and directly proportional to the number of survivors (del Moral and Grishin 1999:139).

The detection of signals of past demographic events and processes is a muchdebated issue in archaeology, one that has experienced a recent growth in theory and method, and their application (see discussion in Chamberlain 2006). Currently, the most promising line of inquiry about past demographic fluctuations is the study of radiocarbon datasets collected from large geographic areas (e.g., Housley et al. 1997; Bocquet-Appel and Demars 2000; Gkiasta et al. 2003; Gamble et al. 2004; Barrientos and Perez 2005; Barrientos et al. 2005; Hamilton and Buchanan 2007; Buchanan et al. 2008, 2011; Riede 2009; Collard et al. 2010; Peros et al. 2010; Steele 2010; Bradtmöller et al. 2012; Wilmshurst et al. 2011). When properly treated (Gamble et al. 2004; Surovell and Brantingham 2007; Surovell et al. 2009a; Williams 2012), the temporal distribution of radiocarbon dates provides a useful tool to assess the changes in the intensity of the archaeological signal attributable to underlying demographic factors. However, this line of evidence - like many others in archaeology — is still ambiguous enough to impede distinguishing between significantly different alternatives like wholesale depopulation-whatever its cause - from population contraction or shrinkage. Even more important, it is almost silent about the causes of the demographic changes it attempts to detect. This fact, coupled with the inherent equifinality of certain demographic processes, constitute a real obstacle to any attempt to establish a link between a known confirmed cosmic impact event and a detected change in the archaeological signal of past populations. An additional complicating factor is the usually wide range of probable ages of any documented cosmic impact based on absolute dating methods other than radiocarbon (e.g., fission track, $\left.{ }^{40} \mathrm{Ar} /{ }^{39} \mathrm{Ar}\right)$. The resulting range of probable ages hinders our ability to pinpoint the temporal position of the impact event and to correlate it with inferred associated population loss in the archaeological signal of the putatively affected population. Masse (2007:58) has noted that even if two thirds of a regional population were killed by a natural disaster such as an impact event, by holding emigration and immigration constant it would take the survivors less than 80 years to recover the pre-impact population levels assuming a very modest population increase of $2 \%$ per year beginning the sixth year after the disaster. Lacking high precision dating, the catastrophic population loss would be difficult to resolve without recourse to other indicators of the event.

Given the current state of our knowledge we should use as many different lines of evidence as possible to assess the nature and magnitude of the effects of any past cosmic impact events on contemporary human populations, taking into account both the scale and the inferred organizational properties of the implied social groups. In the following discussion, we use such an approach to appraise the relevance and 
reliability of the evidence advanced for each confirmed mid-Holocene Argentine asteroid impact.

A great deal of work remains to be done in terms of modeling and the establishment of methods for evidence judgment, criteria development, and hypothesis testing by which to evaluate the role of cosmic impact in human evolution and culture history. Essential for this undertaking is the attainment of an adequate understanding about the complexities of cosmic impact effects. A good place for archaeologists to begin is with studies relating to the perceived sociological, economic, and environmental effects of future cosmic impact (e.g., Chesley and Ward 2006; Bobrowsky and Rickman 2007), and general treatments of natural hazard risk and modern disaster management (e.g., Bryant 2004; Gad-el-Hak 2008; Beer 2010; Bailey 2011). Useful comparisons also can be gleaned from studies of the $\sim 74 \mathrm{ka}$ Toba event (e.g., Jones 2010) and other volcanic eruptions, although there are no cosmic event products comparable to volcanic ash in its dual role as event horizon marker and as an aid in the preservation of direct evidence of event environmental and cultural effects. Archaeologists should also familiarize themselves with the nascent subdiscipline(s) of disaster anthropology and archaeology (e.g., Oliver-Smith and Hoffman 1999; Hoffman and Oliver-Smith 2002; Torrence and Grattan 2002; Gould 2007; Fitzhugh 2012), which not only describe the potential expanding roles of anthropological and archaeological method and practice in dealing with past and present disasters, but also endeavors to put a human face on the victims of disaster.

The archaeological study of disaster in part owes its existence to the now classic volume edited by Sheets and Grayson (1979) resulting from the innovative collaboration between archaeologists and volcanologists on the role of volcanic eruption in human history. It is ironic that the NEO research community study of the effects of cosmic impact on the Earth and the anthropological/archaeological study of natural disaster had their seminal beginnings so close in time (Sheets and Grayson 1979; Alvarez et al. 1980). After four decades of independent and non-overlapping lines of inquiry, it is finally time to bring the two fields of study together to look at the role of cosmic impact in humankind's past.

\section{The Geophysical Evidence for the Mid-Holocene Argentine Asteroid Impacts}

The Earth Impact Database (Planetary and Space Science Centre 2011) lists a worldwide total of 182 confirmed impact structures. Nine of these are in South America, including the recent Carancas impact in Peru. Our focus is on Argentina's two mid-Holocene asteroid impact events, Campo del Cielo and Río Cuarto.

\section{Campo del Cielo Crater and Strewn Field}

The Campo del Cielo crater field in northeastern Argentina $\left(27^{\circ} 8^{\prime} \mathrm{S}, 61^{\circ} 8^{\prime} \mathrm{W}\right)$ (Fig. 2) was first mentioned in 1576 in Spanish colonial reports (Álvarez 1926; Marvin 2006). This portion of the Gran Chaco is semi-arid, hot, very flat, and covered equally by savanna, scrub, and dense thorn forests. The crater field contains at least 20 small, generally elongated impact craters within a northeast-trending ellipse (N61.5 ${ }^{\circ} \mathrm{E}$ ), $4 \mathrm{~km}$ wide and $19.2 \mathrm{~km}$ long (Cassidy et al. 1965; Cassidy and Renard 


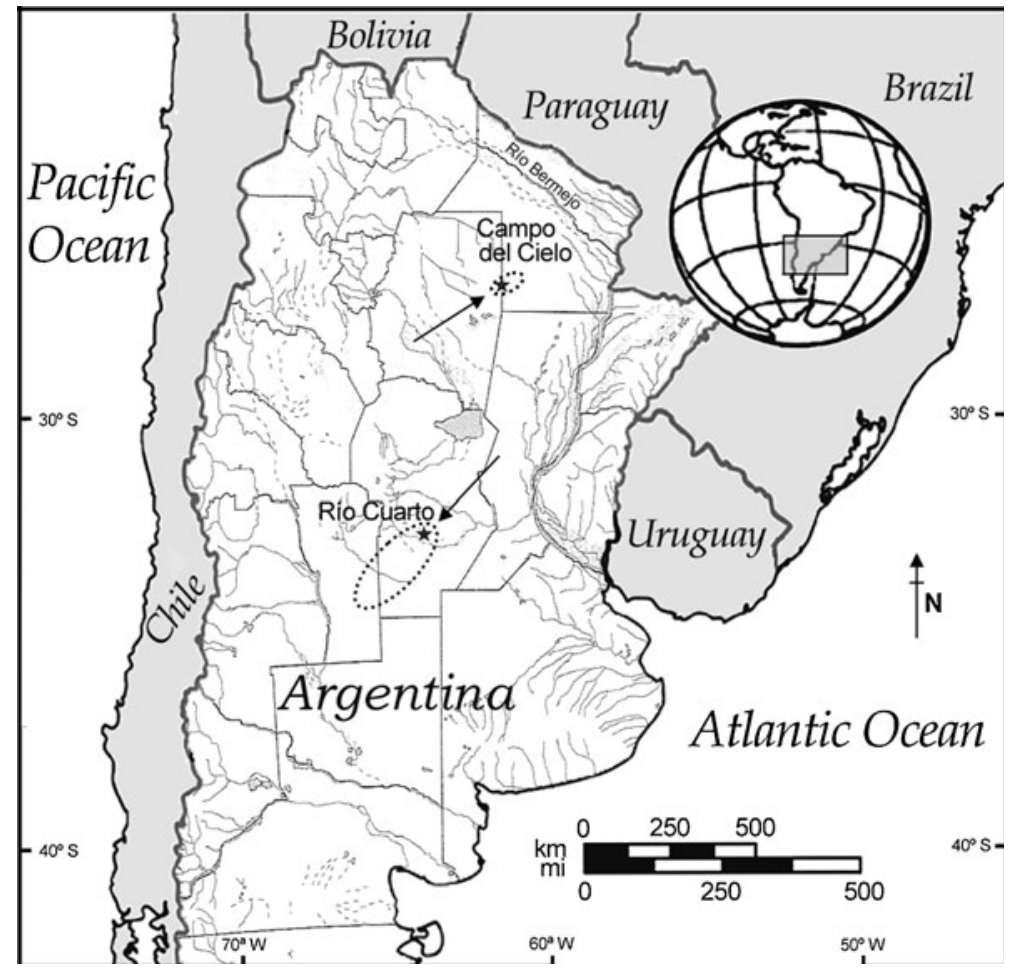

Fig. 2 Geographic distribution of mid-Holocene Argentine impact events. The map depicts the locations of crater fields (stars) along with the approximated distribution of the Campo del Cielo meteorite strewn field and the Rio Cuarto Holocene glass melts (dotted lines). Arrows mark the approximate pre-impact flight direction of the impacting objects after their entry to the atmosphere

1996; Liberman et al. 2002; Wright et al. 2007; Vesconi et al. 2011). The impact infall angle was quite shallow, calculated at less than $10^{\circ}$ from the horizontal. The main concentration of craters is at the southwestern end of the ellipse. The impact crater field covers an area of approximately $45 \mathrm{~km}^{2}$.

The largest crater ("Laguna Negra," Crater 3) is $115 \times 91 \mathrm{~m}$ based on the crater rim, and the present greatest depth for any of the craters is more than $5 \mathrm{~m}$ ("Hoyo Rubín de Celis," Crater 2) from the top of the rim to the bottom of the crater; the depths of most craters are less than $3 \mathrm{~m}$ due to sediment infilling. Figure 3 illustrates the general nature of Crater 2, which is nearly circular and measures $72 \times 69 \mathrm{~m}$. The largest known surviving fragment of the original iron-nickel meteorite ("El Chaco") from Crater 10, is roughly $2 \mathrm{~m}$ in diameter and weighs an estimated 36,000 kg (Fig. 4).

Craters $1-4$, the four largest and least elongated, were formed by ground explosions spread along a 6-km line (Wright et al. 2007; Vesconi et al. 2011). Fifteen of the 16 smaller craters do not exhibit evidence of explosive impact but instead are meteorite penetration funnels. Crater 6 (Fig. 5), approximately $7.5 \mathrm{~km}$ northeast of the nearest explosion crater (Crater 3) shows characteristics of both a penetration funnel and an explosion crater. The explosion craters at Campo del Cielo are larger and more nearly circular; they contain few or no meteorite fragments inside the crater; there are many shocked fragments occurring outside the crater, particularly Crater 3 
Fig. 3 Excavation for meteorite fragments detected by magnetic graviometer on the rim of Crater 2, Campo del Cielo. The opposite crater rim can be observed just beyond the vegetationcleared impact basin [courtesy of William Cassidy and Shawn Wright]

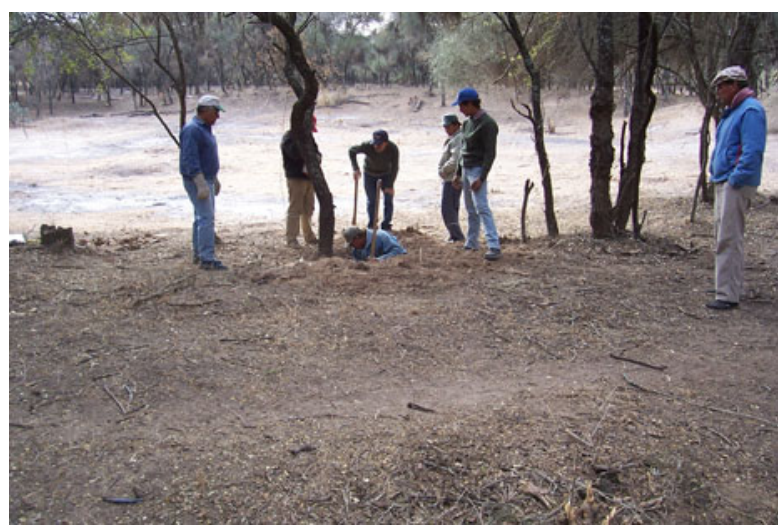

(Cassidy et al. 1965: Fig. 2); and the impacting projectile is disrupted at impact and does not survive. The penetration funnels are smaller and more elongate; most meteorite fragments remain in the crater; there are few or no shocked fragments outside of the crater; and the main part of the projectile survives and is recoverable. Crater 6, while having the general characteristics of a penetration funnel, is notably different from the other three excavated penetration funnels in not containing a carpet of fallback breccia and in having a smaller percentage of the impactor fragment survive the impact, both suggestive of explosion. The range of crater types at Campo del Cielo from hypervelocity explosion craters to non-hypervelocity penetration funnels serve as a reminder that an impact event is not necessarily uniform and can exhibit a continuum of energies and products (Vesconi et al. 2011).

Five of the penetration funnels have been excavated (Craters 6, 9, 10, 13, 17). Excavation of Crater 17 (Figs. 6 and 7) yielded a meteorite weighing 7,850 kg and a dozen smaller fragments. Calculated impact velocities for the excavated craters range from 1.7 to $4.3 \mathrm{~km} / \mathrm{s}$. Analysis of impact effects yielded a pre-atmospheric entry velocity for the Campo del Cielo meteoroid of $22.8 \mathrm{~km} / \mathrm{s}$, a diameter greater than $6.0 \mathrm{~m}$, and mass minimally at $840,000 \mathrm{~kg}$. No impact glass melts have been recovered from the Campo del Cielo crater field, likely indicative of the small size and relatively

Fig. 4 William Cassidy standing next to the El Chaco meteorite fragment extracted from Crater 10, Campo del Cielo [courtesy of William Cassidy and Shawn Wright]

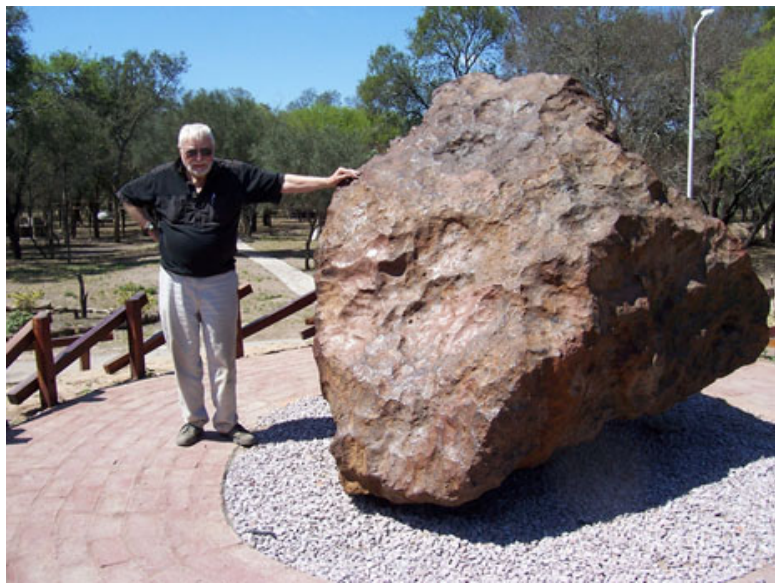


Fig. 5 Trenching at Crater 6, Campo del Cielo. The top edges of the trenches along the rim indicate the contours of the filled-in impact basin. The dimensions of the basin are $28.5 \times 25.5 \mathrm{~m}$, with the maximum depth of the basin (below the sediment infill) being $6.7 \mathrm{~m}$ below the top of the rim [courtesy of William Cassidy and Shawn Wright]

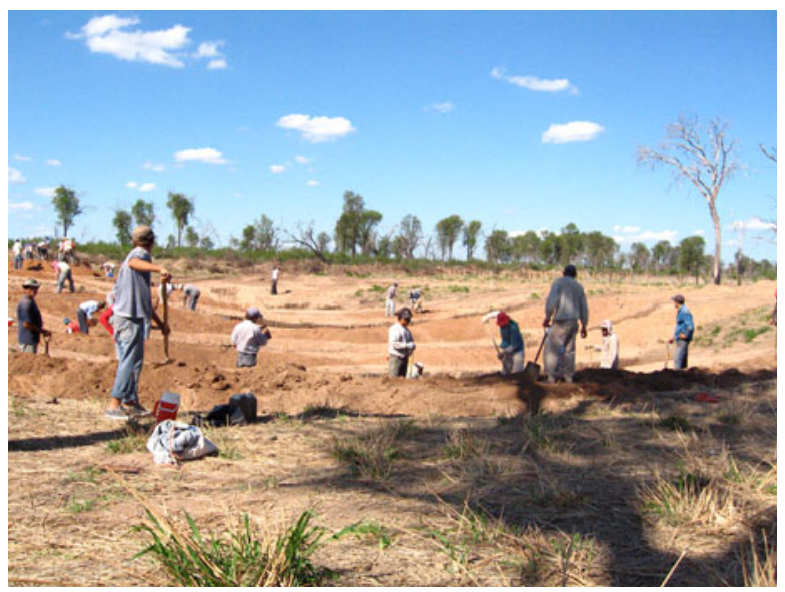

slow speed of the impactors. An elliptical strewn field of small meteorites extends about $60 \mathrm{~km}$ beyond the craters, covering an area approximately $448 \mathrm{~km}^{2}$ in extent (assuming an ellipse $9.5 \times 60 \mathrm{~km}$ ).

The results of preliminary numerical modeling of the energetic effects associated with the formation of Crater 3 (which for the purposes of the model was calculated at $103 \mathrm{~m}$ in diameter) are useful for considering potential effects on contemporaneous human populations (Echaurren 2007). The size of the pre-impact meteorite fragment was calculated at $3.34 \mathrm{~m}$, with an impact velocity of $3.41 \mathrm{~km} / \mathrm{s}$ and an angle of impact at $11.07^{\circ}$. The impact produced approximately 341 meteorite fragments $0.49 \mathrm{~m}$ in diameter that were ejected $308 \mathrm{~m}$ from the crater rim at a velocity of $298.8 \mathrm{~m} / \mathrm{s}$. The dust cloud produced by the impact had a diameter of $1.09 \mathrm{~km}$ and persisted in the atmosphere for more than $9 \mathrm{~h}$. The total energy released by the Crater 3 impact is estimated at between 25.4 to $29.81 \mathrm{kt}$, slightly larger than that for the Nagasaki weapon.

Three charcoal specimens have been recovered from Campo del Cielo. Two samples are argued to bracket the impact, whereas the other is believed to date the impact event (Cassidy and Renard 1996: Table 4). The most recent sample was recovered from Crater 1 post-impact infill, yielding a ${ }^{14} \mathrm{C}$ age of $800 \pm 150 \mathrm{BP}$. The University of Washington Quaternary Isotope Laboratory Calib Radiocarbon Calibration Program (Calib 5.0.2) yields a calibrated $(2 \sigma)$ date range of AD 9001431. The earliest sample, from a soil horizon buried by the ejecta blanket of Crater 2 , yields a ${ }^{14} \mathrm{C}$ age of $5800 \pm 200 \mathrm{BP}$, calibrated $(2 \sigma)$ at $5209-4264 \mathrm{BC}(7158-6213 \mathrm{cal}$ $\mathrm{BP})$. The third sample was recovered from the beginning of the penetration funnel at the bottom of Crater 10, and is suggested to represent an impact ignition fire (Cassidy and Renard 1996). This suggestion is enhanced by the location of Crater 10 near the middle of the distribution of explosive craters (Wright et al. 2007: Fig. 1). The Crater 10 sample yields a ${ }^{14} \mathrm{C}$ age of $3945 \pm 85 \mathrm{BP}$, calibrated $(2 \sigma)$ at $4789-4095 \mathrm{BP}(2840-$ $2146 \mathrm{BC}$ ), which for convenience we round to $c a$. 4800-4100 cal BP.

\section{Rio Cuarto Crater Field and Glass Melt Distribution}

Impact melt breccias near Río Cuarto, in central Argentina ( $\left.32^{\circ} 50^{\prime} \mathrm{S}, 64^{\circ} 12^{\prime} \mathrm{W}\right)$ (Fig. 2) occur in several elongate, rimmed depressions. The age and stratigraphic 
Fig. 6 Wall profile of Crater 17, Campo del Cielo. The line of sticks marks the contact between the base of the impact basin and pre-impact soils. The field notebook on the stick near the left edge of the photograph provides a rough scale [courtesy of William Cassidy and Shawn Wright]

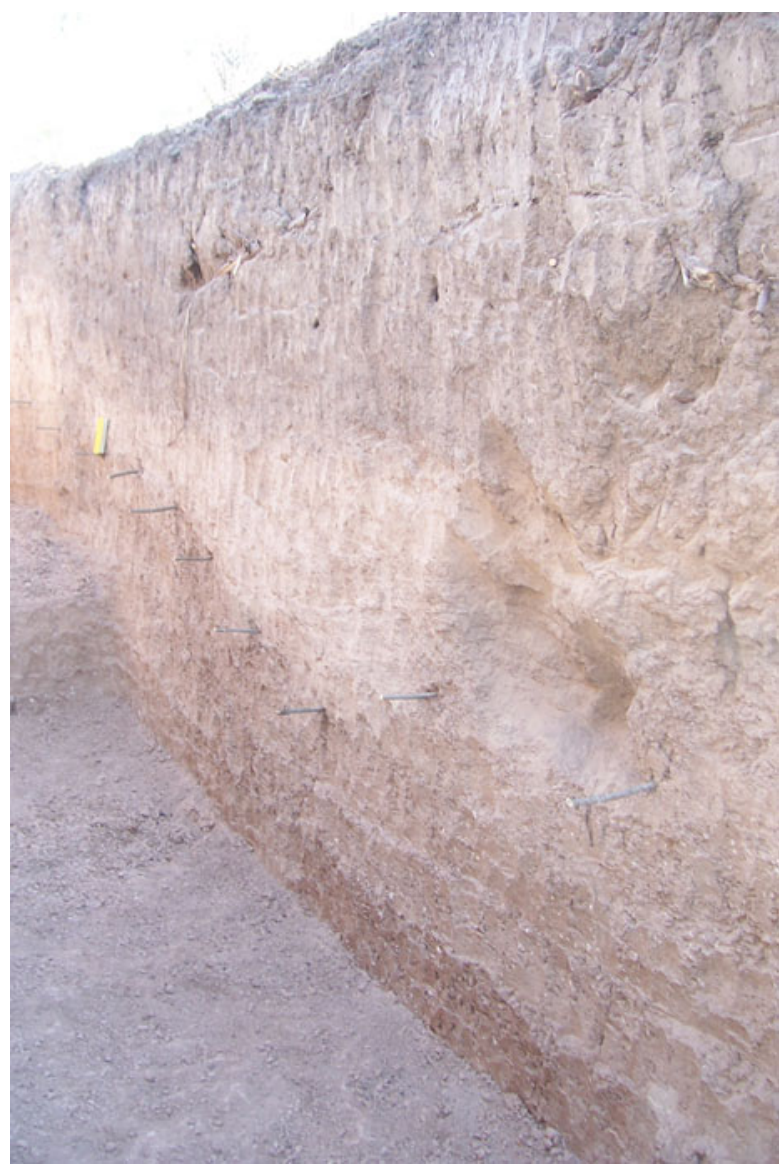

occurrence of the impact materials indicated a Holocene impact attributed to a shallow angle asteroid (Schultz and Lianza 1992; Schultz et al. 1994). The impact is modeled to have resulted in at least 11 elongated shallow craters (Fig. 8); the largest is about $1.1 \times 4.5 \mathrm{~km}$.

Fig. 7 Excavation of the $7,850 \mathrm{~kg}$ Felix Basualdo meteorite fragment from its penetration funnel at Crater 17, Campo del Cielo. The meteorite was detected by the use of systematic magnetic graviometer grids across the crater. The loose small chunks on top of the meteorite are fragments that were found adjacent to the main mass [courtesy of William Cassidy and Shawn Wright]

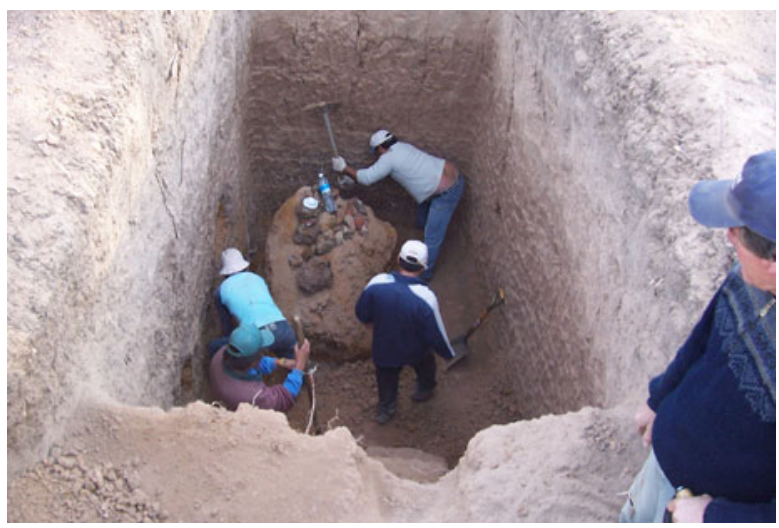


Fig. 8 Aerial view of hypothesized Rio Cuarto impact Craters $\mathrm{D}$ (right) and E, looking northeast. Both craters are approximately $3.5 \mathrm{~km}$ in length [courtesy of Peter Schultz]

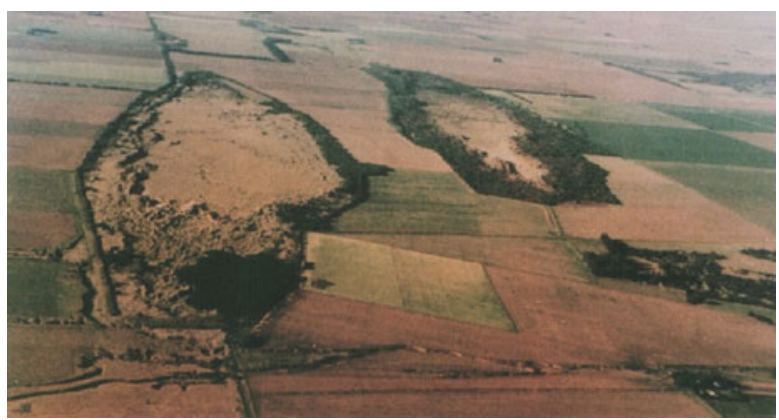

The region contains extensive deposits of loess and dune sand that can be readily altered by wind (Schultz and Lianza 1992; Iriondo 1997). This fact has led to a series of alternate interpretations proposed in response to the original claims of impact formation for the Río Cuarto elongated depressions. Cione et al. (2002) argued for a non-impact origin, and stated that Argentine geologists have long supported the midHolocene eolian formation of these depressions (e.g., Cantú and Degiovanni 1984; Blarasín and Sánchez 1987), pointing out that the alignments match prevailing wind patterns during the period(s) of their formation. Bloom (1992) has argued that the glass melts (Fig. 9) - locally referred to as escorias or slag-like rocks - are unlikely to be of impact origin. He suggests that natural and anthropogenic fires, such as the burning of fields as part of the agricultural cycle, can produce the melts described by Schultz and Lianza (1992) (see also San Cristóbal 1999). Nevertheless, the melt breccias retrieved from Rio Cuarto exhibit key impact indicators and melting/quenching impossible to achieve by fires (Schultz et al. 2004). Alberto Cione (personal communication to G. B. 2007, 2008) has recently noted that some melts could have an impact origin, but advocates additional analytical work to examine the conclusions of Schultz et al. (2004).

Using aerial photography, Bland et al. (2002) also suggest that the Río Cuarto structures are part of a widespread set of several hundred elongated eolian depressions associated with parabolic sand dunes that formed in the Argentine Pampas during the mid-Holocene. Unlike Bloom (1992) and Cione et al. (2002),

Fig. 9 Specimen of Rio Cuarto Holocene impact glass melt. The scale is $1 \mathrm{~cm}$ in length [courtesy of Peter Schultz]

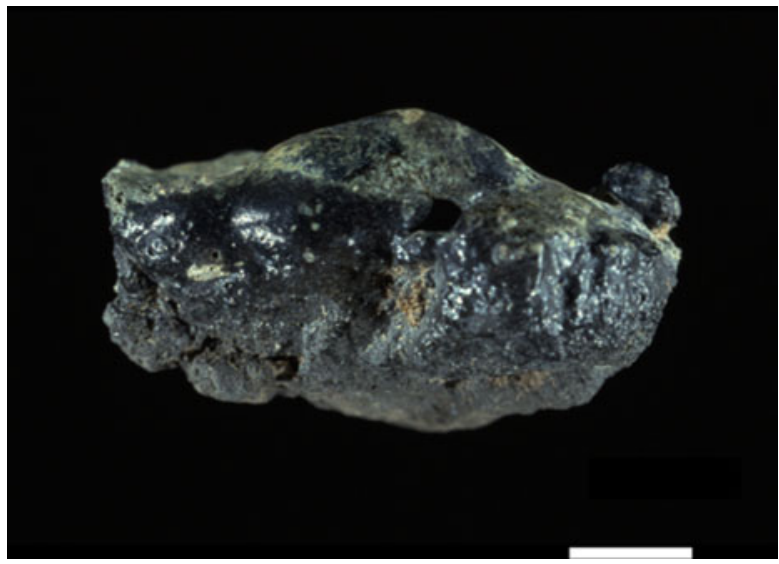


Bland et al. (2002) support the impact origin of the Río Cuarto glasses; however, their interpretation is that the Rio Cuarto glasses represented the distal ejecta of a mid-Pleistocene ( $c$. 480 ky BP) impact occurring several hundred kilometers away.

Prior to and coincident with these alternative claims, Schultz et al. (2004) were part of a systematic NSF-funded study to understand the nature and distribution of the impact glasses found in the Argentine loess. Their ongoing research includes detailed petrological and electron microprobe analyses, along with geochemical analyses (X-ray florescence and instrumental neutron activation analysis) of the Argentine glass melts. They demonstrated that temperatures in excess of $1,700{ }^{\circ} \mathrm{C}$ would be necessary to completely melt all constituents including quartz grains. The specimens exhibit rapid quenching of the melt, a condition unlikely in a field fire or wildland fire. The glasses are in stratigraphically restricted contexts, unlike the expected more widespread and haphazard distribution if they were instead the result of lightning or field fires.

Masse and Masse (2007) note that the physics of wildland fire - and by analogy agricultural field fire-argues against the anthropogenic burning of fields as the origin of the glass melts as suggested by Bloom (1992) and San Cristóbal (1999). Pyne et al. (1996:21) state that the theoretical maximum temperatures that can be achieved by the burning of combustible gases generated from wildland fuels is around $1,900-2,200{ }^{\circ} \mathrm{C}$. However, these values are never reached in actual fires, and Pyne and his colleagues note that the maximum actually measured for an exceptionally intense fire is about $1,650{ }^{\circ} \mathrm{C}$. An examination of U. S. Forest Service records indicates that the hottest measured crown fire is about $1425^{\circ} \mathrm{C}$ with most maximum values being below $1,200{ }^{\circ} \mathrm{C}$ (Ted Bunch, personal communication to W. B. M. 2011); associated ground temperatures would be considerably less. Most wildland fires more typically burn at average temperatures of 700-980 ${ }^{\circ} \mathrm{C}$ (Pyne et al. 1996:22). The burning of fields in preparation for agriculture, including the presence of smoldering fires, should yield temperatures approximating this range. These temperature values are considerably below the melt threshold for the quartz and clay constituents of the Río Cuarto glass melts (Schultz et al. 2004).

In their initial exhaustive analysis of the melt glasses from the Pampas, Schultz et al. (2004) identified melts from five separate Quaternary impacts with four of the impacts dating back to the Pleistocene period between $570 \pm 100 \mathrm{ky}$ BP (corresponding to the material identified by Bland and his colleagues) and $114 \pm 26 \mathrm{ky} \mathrm{BP}$, along with a single Holocene glass melt strewn field. Schultz et al. (2006) also identified two separate late Miocene vesicular impact glasses from the Pampas, for a current total of eight distinct late Cenozoic impact melt breccia deposits dating between 9.24 Ma and 3-6 ky BP (Schultz et al. 2006; Harris and Schultz 2007). The presence of so many melt-producing impacts in such a small area (ca. $500,000 \mathrm{~km}^{2}$ ) over such a short period of time is remarkable (Schultz et al. 2004).

Despite clear impact signatures in the melt breccias (Harris and Schultz 2007), only two sets of potential impact structures have been defined as yet for the eight late Cenozoic glass melt horizons in the Argentine pampas. These include the hypothesized 2.8-km-diameter mid-Pleistocene La Dulce Crater (Harris et al. 2007) and the Río Cuarto craters. A crater has not yet been defined for a mid-Pliocene impact 
(Schultz et al. 1998) possibly associated with rapid regional faunal change (Vizcaino et al. 2004).

The robust documentation of the Holocene age of the most recent impact glass (Fig. 9) is based on three dating techniques (Schultz et al. 2004): geological context (stratigraphy and preservation state) - 10-4 ky BP; fission track dating-2,300土 1,600 BP; and radiometric ${ }^{40} \mathrm{Ar} /{ }^{39} \mathrm{Ar}$ dating-6,000 $\pm 2,000 \mathrm{BP}$. The combined suite of dating techniques yields a date range for the Rio Cuarto impact of approximately 6-3 ky BP.

The Holocene Río Cuarto glass melts are traceable along the corridor depicted on Fig. 2 (P. Schultz, personal communication to W. B. M. 2008), forming a rough ellipse about $175 \mathrm{~km}$ wide and $350 \mathrm{~km}$ in length $\left(48,106 \mathrm{~km}^{2}\right)$. A direct relationship between the Rio Cuarto structures and the perceived distribution of glass melts is possible given the orientation of the crater field and apparent path of the impactor as determined by Schultz and his colleagues (see also Masse 1998: Fig. 4). Peter Schultz (personal communication to W. B. M. 2008) cautions that this distribution is very preliminary, being affected by sand dunes and other factors that make the actual boundary difficult to delimit.

Schultz and his colleagues (e.g., Schultz and Lianza 1992; Schultz et al. 2004) favor a scenario in which the Río Cuarto structures were created by ground level detonation with impact blast winds being driven by the initial contact and by force of the ejection of downrange debris, similar to a moving nuclear blast. They stress that the Río Cuarto craters differ from the broad, arcuate system of longitudinal dunes to the east due to the presence of rims and the glass melts; this observation in our view requires better quantification. Recent work by Harris and Schultz (2007) indicates the presence of quartz planar deformation features and coesite in several late Cenozoic impact breccias, along with other indicators of impact. It is unclear from their preliminary studies how the materials specifically relate to the Río Cuarto craters and the Holocene glass melts. Regardless of the debate about the structures themselves, the evidence for an impact in the Holocene is compelling.

\section{The Archaeology and Anthropology of the Argentine Asteroid Impacts}

If we fully understood the physics and the physical effects of the Campo del Cielo and Río Cuarto Argentine impacts, it might be a relatively straightforward process to estimate the effects on the contemporaneous human populations. We do not completely understand these two events. To understand the potential cultural effects of the Rio Cuarto and Campo del Cielo impacts we must turn to anthropological and archaeological methods and data.

Catastrophe Myths and Oral Histories of the Gran Chaco and Southern Argentina

There is a growing awareness that myths can include a record of observed historic natural and cultural events (e.g., Vitaliano 1973; Blong 1982; Barber and Barber 2004; Piccardi and Masse 2007; Cashman and Giordano 2008; van der Slujis 2009; Snyder et al. 2011). Without detailing individual case studies supporting this 
argument, we provide the following definition as a starting point to examine the content of South American myths:

Myth is a structured narrative...derived from oral transmission, and typically created or assembled and perpetuated by knowledge specialists who use supernatural elements and images in order to categorize and explain observed natural phenomena and events that are of perceived vital importance or of special relevance to the social order and well-being of a given culture [Masse et al. 2007:17].

Traditional performance-based oral histories, when passed down from generation to generation by trained knowledge specialists in prescribed settings (Vansina 1985; Whiteley 2002; Masse et al. 2007), can be accurately maintained for hundreds and even thousands of years. For example, Echo-Hawk (2000) has cogently argued that some Native American migration traditions likely capture aspects of the transition between Pleistocene and Holocene climatic conditions; and it is widely recognized that Klamath and other Northwestern myths capture aspects of the cataclysmic eruption of Oregon's Mount Mazama and the formation of Crater Lake more than 7,500 years ago (e.g., Vitaliano 1973, 2007; Deloria 1995; Barber and Barber 2004). The accuracy of orally transmitted myth details is perhaps best illustrated with reference to documented historic natural events such as total solar eclipses, the passage of great comets, and volcanic eruptions captured and detailed in Hawaiian myth storylines and tied into the relative chronology of royal chiefly genealogies (Masse et al. 1991; Masse et al., in preparation; Masse 1995, 2012; Masse et al. 2007). In this sense, and under special conditions, pertinent detailed myths can be reasonably considered as eyewitness accounts of specific natural events orally transmitted across generations, therefore approaching the status of direct evidence of a past phenomenon.

Observed remarkable comets and meteorite falls likely played a prominent role in the creation of myths and cosmological oral traditions for many cultures worldwide, some of which may capture the observations of catastrophic cosmic impact (e.g., Clube and Napier 1982, 1990; Masse 1998, 2007; Baillie 1999, 2007b; McCafferty and Baillie 2005; Rappenglück et al. 2010). South American mythology is no exception.

South America has a rich legacy of oral traditions and mythology (e.g., Levi-Strauss 1969, 1973; Bierhorst 1988). Particularly valuable for our interests in cosmic impact is a set of 4,259 myths from 20 major tribal groups (representing 31 indigenous societies) east of the Andes gathered by the University of California at Los Angeles (Wilbert and Simoneau 1992). Masse and Masse (2007) analyzed these myths, concentrating on those that describe local, regional, or "worldwide" natural catastrophes that led to the deaths of members of a given cultural group. Of specific interest is a set of 284 myths (Table 3 ) that have as their primary motif a major cataclysm stated as having led to the deaths of most or all members of one or more cultural groups - referred to as having led to new creations of humanity. While one might scoff at the rational basis of such "new creations," these cultural groups were small or at least organized into clusters of a few hundred or at most several thousand people. Rare large-scale cataclysms such as Plinian volcanic eruptions, cosmic impacts, wildland fires, and torrential monsoons of unusual duration could decimate such groups. 
Table 3 Number of individual UCLA Folk Literature Collection myths containing specified 'world calamity' motifs for each cultural group in the Collection (from Masse and Masse 2007)

\begin{tabular}{|c|c|c|c|c|c|c|}
\hline Culture \& location & $\begin{array}{l}\text { World flood } \\
\text { [earliest in } \\
\text { myth cycle] }\end{array}$ & $\begin{array}{l}\text { Great cold } \\
\text { [after flood } \\
\text { myth] }\end{array}$ & $\begin{array}{l}\text { World fire } \\
\text { [middle of } \\
\text { myth cycle] }\end{array}$ & $\begin{array}{l}\text { Sky fall- } \\
\text { darkness [latest } \\
\text { in myth cycle] }\end{array}$ & $\begin{array}{l}\text { Great darkness } \\
\text { [latest in myth } \\
\text { cycle] }\end{array}$ & Total \\
\hline
\end{tabular}

\section{NORTHWEST}

\begin{tabular}{|c|c|c|c|c|c|c|}
\hline Cuiva & 13 & - & - & 4 & - & 17 \\
\hline Guajiro & 9 & - & - & - & 1 & 10 \\
\hline Sikuani & 10 & - & - & - & - & 10 \\
\hline Warao & 3 & - & - & - & - & 3 \\
\hline Yaruro & 10 & - & - & - & - & 10 \\
\hline \multicolumn{7}{|l|}{$\begin{array}{l}\text { GUIANA } \\
\text { HIGHLANDS }\end{array}$} \\
\hline Yanomani & 17 & - & - & 11 & 2 & 30 \\
\hline \multicolumn{7}{|l|}{$\begin{array}{l}\text { BRAZILIAN } \\
\text { HIGHLANDS }\end{array}$} \\
\hline Bororo & 4 & - & 1 & - & - & 5 \\
\hline Gê & 11 & - & 6 & - & 1 & 18 \\
\hline \multicolumn{7}{|l|}{ GRAN CHACO } \\
\hline Ayoreo & 17 & - & 2 & - & 1 & 20 \\
\hline Caduevo & - & - & - & - & - & 0 \\
\hline Chamacoco & 10 & - & 1 & 1 & - & 12 \\
\hline Chorote & 10 & - & 7 & 1 & - & 18 \\
\hline Maka & 2 & - & - & - & 1 & 3 \\
\hline Mataco & 12 & - & 5 & - & 1 & 18 \\
\hline Mocoví & 7 & - & 3 & - & - & 10 \\
\hline Chulupí (Nivaklé) & 6 & 1 & 6 & 9 & - & 22 \\
\hline Toba & 24 & 5 & 27 & - & 12 & 68 \\
\hline \multicolumn{7}{|l|}{ PATAGONIA } \\
\hline Tehuelche & 2 & - & - & - & - & 2 \\
\hline \multicolumn{7}{|c|}{ TIERRA DEL FUEGO } \\
\hline Selk'nam & 1 & - & - & - & - & 1 \\
\hline Yamana & 3 & 1 & 2 & - & 1 & 7 \\
\hline TOTAL & 171 & 7 & 60 & 26 & 20 & 284 \\
\hline
\end{tabular}

The myth categories are organized according to perceived relative chronology apparent in the Gran Chaco region

These 284 myths were divided into five general categories of cataclysm, which for the nine cultural groups in the Gran Chaco (Fig. 10) were further divided into a relative chronological sequence as noted in some of the myths. The earliest catastrophe was a "world flood" that also seemed to be correlated with a period of "great cold." This was followed at a later point in time by a "world fire," which in turn was followed most recently by a period of "sky fall" and "great darkness."

Masse and Masse (2007) suggested that the stories of sky fall and the great darkness in the Gran Chaco were likely associated with a massive Plinian eruption 


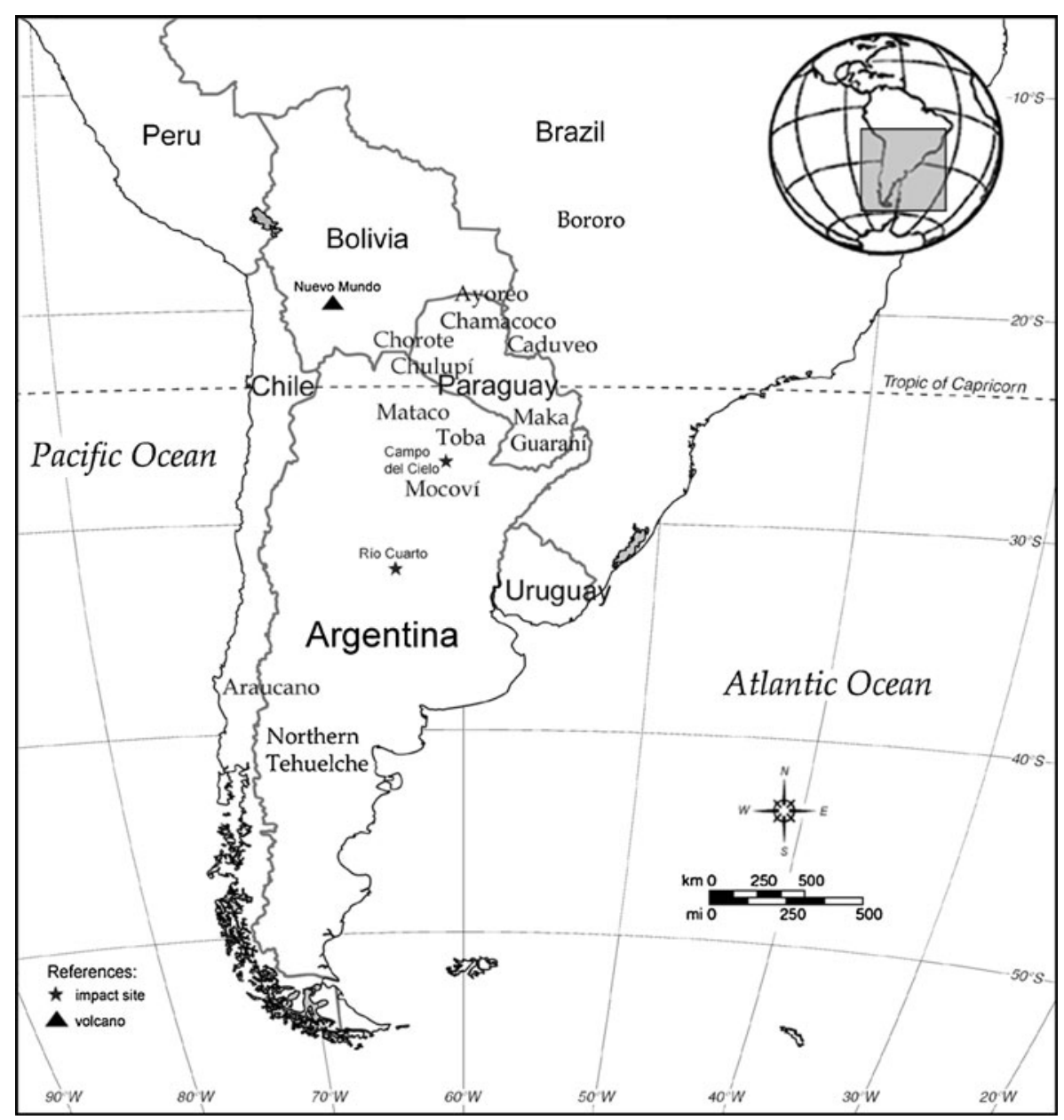

Fig. 10 Geographic location of the ethnographic groups whose world fire and meteorite impact myths are described in the text. Note the close proximity of the Toba, Mocoví, and Mataco tribes to the Campo del Cielo crater field

of the Nuevo Mundo volcano in Bolivia (Fig. 10) - the easternmost Holoceneactive volcano in the central Andes. Nuevo Mundo ash deposits have been traced as far as Potosi, $200 \mathrm{~km}$ to the east, although their overall distribution seemingly has not been mapped. This event occurred before the arrival of the Spanish in South America and not earlier than the terminal Pleistocene or Holocene due to the young appearance of the associated deposits (de Silva and Francis 1991). The Gran Chaco myth chronology suggests that the eruption occurred after the Campo del Cielo and Rio Cuarto impacts of 6-3 BP, but this conclusion needs to be verified by actual chronometric dating of the ash deposits. The South American sky fall and great darkness myths exhibit many remarkable parallels to the imagery in the mythology collected by geologist Russell Blong (1982) on the major seventeenth century eruption of the Long Island volcano off the coast of Papua New Guinea. 
The world flood and the great cold have been tentatively linked to a hypothesized globally catastrophic Indian Ocean comet impact that has been modeled to have occurred in 2807 BC (Masse 1998, 2007; Abbott et al. 2007; Gusiakov et al. 2010), but this hypothesis is outside the scope of the present paper.

South American world fire myths are distributed in those areas most subject to devastating droughts and large-scale fires - the Brazilian Highlands and the Gran Chaco. The Brazilian cerrado is a massive mosaic of mixed grassland, shrub, and forest occupying much of the Brazilian Highland region. The cerrado has been termed "the natural epicenter for Brazilian fire" (Pyne et al. 1996:685), whose configuration traditionally has been maintained through deliberate annual burning by tribes such as the Gê. Gran Chaco tribal groups, such as the Toba, are noted for their burning of grasslands and brush as a common hunting technique (Métraux 1946:13).

Many Gran Chaco myths specifically ascribe a non-lightning and non-volcanic celestial cause for the world fire (the nearest Holocene-active volcanoes are many hundreds of kilometers to the west). Toba cosmology is very specific as to the meteoritic cause of the world fire:

Moon...is a pot-bellied man whose bluish intestines can be seen through his skin. His enemy is a spirit of death, the celestial Jaguar. Now and then the Jaguar springs up to devour him. Moon defends himself with a spear tipped with a head carved of the soft wood of the bottletree..., which breaks apart at the first impact. He also has a club made of the same wood which is too light to cause any harm. The Jaguar tears at his body, pieces of which fall on the earth. These are the meteors, which three times have caused a world fire [Métraux 1946:19].

The following is an example of a Toba meteorite impact myth (Métraux 1946:33; in Wilbert and Simoneau 1982a:68):

The people were all sound asleep. It was midnight when an Indian noticed that the moon was taking on a reddish hue. He awoke the others: "The moon is about to be eaten by an animal." The animals preying on the moon were jaguars, but these jaguars were spirits of the dead. The people shouted and yelled. They beat their wooden mortars like drums, they thrashed their dogs...They were making as much noise as they could to scare the jaguars and force them to let go their prey. Fragments of the moon fell down upon the earth and started a big fire. From these fragments the entire earth caught on fire. The fire was so large that the people could not escape. Men and women ran to the lagoons covered with bulrushes. Those who were late were overtaken by the fire. The water was boiling, but not where the bulrushes grew. Those who were in places not covered with bulrushes died and there most of the people were burnt alive. After everything had been destroyed the fire stopped. Decayed corpses of children floated upon the water. A big wind and a rain storm broke out. The dead were changed into birds. The large birds came out from corpses of adults, and small ones from the bodies of children.

For the Mocoví tribe, the world fire is ascribed to the Sun falling, with the storyline as for the Toba suggesting more than a single episode for the event [Métraux 
1946:34]. At least one Toba myth somewhat similarly identifies the heat of the Sun as the being the cause of the world fire (Métraux 1946:36, Wilbert and Simoneau 1982a:69-70), although for this particular myth only a single village was involved rather than the entire world.

Masse and Masse (2007) suggest that the three Toba world fires refer to the Campo del Cielo impact, the Río Cuarto impact, and possibly an airburst event in the Brazilian Highlands. The Toba, Mataco, and Mocoví tribes are historically situated nearest to and directly downrange from the Campo del Cielo crater and strewn fields. The Río Bermejo is in the center of the distribution of these three tribes, about $230 \mathrm{~km}$ north of the impact zone (Fig. 2). The Río Cuarto crater field is about $900 \mathrm{~km}$ south of the Río Bermejo. The Brazil impact is based on Gê world fire myths, and the fear of meteors and meteorites expressed by the adjacent Bororo tribe. This suspected impact may relate to a cohesive set of myths from the Chorote and Chulupí (Nivaklé) tribes who describe a slow-moving fire coming from the north (Wilbert and Simoneau 1985, 1987).

The Toba and Mocoví stories about fragments of the Moon or Sun falling down and causing a world fire comprise a second cohesive set of world fire myths (Wilbert and Simoneau 1982a; 1988; 1989). Key elements are the presence of meteorite fragments, the witnessing of the impactor or impact fireball (Sun or Moon falling), the timing of the event at night or perhaps at dawn, and the fact that the fire moved quite rapidly. These elements are strongly suggestive of the Campo del Cielo impact event, and are similar to eyewitness accounts of the historic Tunguska and Sikhote Alin impacts events described earlier.

Another set of traditions regarding the Campo del Cielo impact, but seemingly separately derived from the UCLA myth collection, was recorded by medical doctor and historian Antenor Álvarez in his book on the Campo del Cielo impact site (Álvarez 1926). Of specific interest is the following brief statement regarding the mythology surrounding the impact site, as translated in Cassidy and Renard (1996:443):

The meteorite of the Chaco was known since earliest American antiquity through stories from the Indians who inhabited the provinces of Tucumán. (These indians) had trails and easily traversed roadways that departed from certain points more than 50 leagues away, converging on the location of the bolide. The indigenous tribes of the district gathered here in useless and vague veneration to the God of the Sun, personifying their god in this mysterious mass of iron, which they believed issued forth from the magnificent star. And there, in the stories of the different tribes of their battles, passions and sacrifices, was born a beautiful, fantastic legend of the transfiguration of the meteorite on a certain day of the year into a marvelous tree, flaming up on a certain day of the year into a marvelous tree, flaming up at the first rays of the sun with brilliant radiant lights and noises like one hundred bells, filling the air, the fields and the woods with metallic sounds and resonant melodies to which, before the magnificent splendor of the tree, all nature bows in reverence and adoration of the Sun.

Cassidy and Renard (1996) speculate that this story captures the eyewitness observation of the meteorite entering the atmosphere brighter than the Sun, and its 
subsequent fragmentation and the cacophony of sound produced by multiple atmospheric sonic booms and impact explosions.

Giménez Benítez et al. (2000) have questioned virtually all aspects of the Álvarez statement. Their skepticism stems from (1) inconsistencies found in their review of the few published sources mentioned elsewhere by Álvarez in his book; (2) the lack of mention of Campo del Cielo and its meteorites in general ethnographies of the regions; and (3) interviews conducted in 1999 with two apparently knowledgeable individuals (in terms of myths and astronomical lore) at the Mocoví settlement of Toldería Cacique Catán near Campo del Cielo, whose information seemingly did not replicate the information in Álvarez (1926). In addition, Giménez Benítez and his colleagues were unable to obtain confirmation that meteoritic iron was used for the making of weapons (arrow points; bolas) as suggested by Álvarez. They also note that archaeological collections from the region do not contain meteoritic iron tools, although it is unclear as to whether or not unaltered meteorite fragments may be present. Their comments indicate that prior to the time of their research in the late 1990s little archaeological research had been conducted in and around the Campo del Cielo and meteorite strewn field.

We applaud the efforts of Giménez Benítez et al. (2000) and support the notion of a skeptical approach to assessing the nature and content of the Álvarez statement. We suggest, however, that the accuracy of the Álvarez statement is still an open question. The Mocoví are relatively recent emigrants from the middle Bermejo River to their present location adjacent to and east of the Campo del Cielo crater field (Wilbert and Simoneau 1988). The ancestors of other indigenous groups, such as the Toba and Mataco possibly were more advantageously situated to view the direct effects of the impact. More critical is the extremely small sample size of two interviewees, made even smaller by the fact that they are relatives and likely shared the same sources of oral history transmission. And the Mocoví experienced a large degree of acculturation during the nineteenth and twentieth centuries as noted by Giménez Benítez et al. (2000) and others (e.g., Wilbert and Simoneau 1988). Also, most past ethnographers and their resultant ethnographies are somewhat limited by their own knowledge and interests; astronomy and other similar esoteric information were often undervalued and underrepresented. Even given these issues, there are enough suggestive details provided by the interviewees to Giménez Benítez et al. (2000) to indicate that the potential exists to elicit additional relevant details through expanded interviews with the Mocoví and other nearby tribal groups. We agree with Giménez Benítez and his colleagues that additional ethnographic and archaeological research would likely be productive.

A final myth considered here possibly relates to the Campo del Cielo myth set, although it could instead relate to the Río Cuarto impact. This Mataco myth does not appear to describe a volcanic tephra or pyroclastic ashflow event in that it refers to something in the south and not the west where Holocene volcanoes are located. It also describes the complete large-scale burning of the forest, an event not typically associated with volcanic eruption - areas of pyroclastic ash flow adjacent to the volcano appear to more typically vaporize or carbonize forests than to burn them:

Once, a very long time ago, the life-style of the Mataco developed into near anarchy... All was chaos. Then one day a big black cloud gathered in the south, and lightning and thunder began. When the cloud had covered the entire sky it 
began to rain a bit here and there, but the drops that fell were not like rain but like fire. The people tried to jump into the river to save themselves, but the water was boiling. Tokhuah [a Mataco trickster character] was among them, but he saved himself because he could go wherever he wished, and he decided to go underground. All died but a very few, and they did not know why they had survived. Bits of fire continued to fall from the sky and everything, including the entire forest, burned; nothing remained except a few people here and a few there. They did not understand why they were still alive and what they were to do next [Fock, in Wilbert and Simoneau 1982b, p. 126].

This myth likely describes cosmic impact processes, such as would have been generated by the Río Cuarto and Campo del Cielo impacts.

With the possible exception of this one myth, none of the Gran Chaco world fire myths appear to directly relate to the Río Cuarto impact. This is not surprising given the long distance between the Gran Chaco and the Río Cuarto crater field, and the fact that Río Cuarto impactor flight effects would have been most pronounced further to the south and west of the Río Cuarto crater field.

It is puzzling and unexpected that the myths of Patagonian Tehuelche tribes, whose ancestors could have been in a geographic position close to the impact area, appear to have no storylines about the Rio Cuarto impact (Wilbert and Simoneau 1984b), particularly in light of the fact that the witnessed impact of a small iron meteorite in southern Patagonia is represented by several myths. The absence of stories linkable with the Río Cuarto event could be due to the limited number of myths collected from the Tehuelche, particularly from northern Tehuelche (Gününa-këna) sources. For the Araucano or the araucanized populations from Neuquén, however, there is a myth that relates the origin of two Andean lakes - Lacar and Lolog — with the fall from the sky of the two rebel sons of God, thrown down by the furious, outraged divinity (Koessler-Ilg 2000:15-16). Although this story does not mention human or animal casualties associated with the storied event, it may recall a witnessed cosmic impact east from the Andes; its relationship with Campo del Cielo or Río Cuarto is unclear.

\section{Modeling the Cultural and Human Biological Effects of the Argentine Asteroid Impacts}

What does the physical evidence for impact, along with the mythology, tell us about the likely effects of the Campo del Cielo and Río Cuarto impacts?

The Campo del Cielo crater field and even the strewn field would have been dangerous zones. People in these areas likely would have been seriously injured or killed by crater formation and by the shrapnel from the atmospheric detonation that led to the strewn field. There may have been an air pressure blast wave and other effects created by the low entry angle of the impactor, but these are difficult to judge without more detailed modeling.

Based on perceived effects, the impact energy release of Campo del Cielo was likely between that for Sikhote Alin and Tunguska, ca. 1-2 Mt. Because of the considerable size of the crater and strewn field, the detonation(s) may have been higher in the atmosphere than that for Sikhote Alin; alternatively, the low angle of the impactor may have contributed to the length of the impacted area ellipse (W. Cassidy, 
personal communication to W. B. M. 2009). A fireball was created by the atmospheric detonation (mythology indicates the presence of a fireball and associated debris cloud), but impact ground temperatures apparently were insufficient to create glass melts.

Planetary scientists have debated the capacity of impacts to start ground ignition fires (e.g., Jones and Lim 2000; Jones 2002; Svetsov 2002; Durda and Kring 2004). Witnessed meteorite falls, mythology, and the limited archaeological record of impact sites support the notion that wildland fires are caused by some smaller impacts, including Campo del Cielo. A key would be fuel availability and suitable weather/ climatic conditions for the spread of the fire. William Cassidy (personal communication to W. B. M. 2009), while supportive of the notion that ground ignition fires were potentially triggered by the Campo del Cielo impact, has appropriately cautioned that the remarkable visual nature of a meteor observed immediately prior to impact may unduly exaggerate oral traditions regarding any resultant wildland fire. The line of explosion craters (Craters 1-4) is $6 \mathrm{~km}$ long (with Crater 6 possibly extending that line an additional $7.5 \mathrm{~km}$ ), together with enhanced shock effects due to the low angle of impact, may have facilitated the rapid spread of potentially devastating wildland fires.

Gad-el-Hak (2008: Table 2.1) has devised a five-step nonlinear logarithmic scale by which to compare various natural and man-made disasters. Disaster scope for his scale is based on either of two criteria, the first being the numbers of casualties and the second being the size of the affected geographic area. Despite the uncertainties regarding potentially associated wildland fires, Campo del Cielo fits within the middle of the next to highest disaster scope category, that of an "enormous disaster" $\left(>100 \mathrm{~km}^{2}\right.$ and $<1,000 \mathrm{~km}^{2}$ ). We conservatively suggest an average fatality risk of $50 \%$ for any humans who may have been present within the boundaries of the $493 \mathrm{~km}^{2}$ Campo del Cielo impact crater and strewn field, presumably a higher percentage in the crater field and lower in the meteorite strewn field.

The Río Cuarto impact event is both qualitatively different from and quantitatively larger than Campo del Cielo, and likely several magnitudes larger than the Tunguska event. The way we presently understand the modeling and interpretations of Peter Schultz and his colleagues and those of their critics, there seemingly are four different rough scenarios by which to interpret Río Cuarto. We present them in order of increasing likelihood based on our initial review of the physical and archaeological/ anthropological data.

Scenario 1 assumes that there was no impact (Bloom 1992; Bland et al. 2002; Cione et al. 2002) and that the hypothesized craters and Holocene glass melt strewn field are solely the products of wind action and field burning, respectively (as originally suggested by Bloom 1992 and San Cristóbal 1999). This seems to us the least likely of the four scenarios for the reasons discussed above.

Scenario 2 dismisses the impact origin of the hypothesized Río Cuarto crater field (Bloom 1992; Bland et al. 2002; Cione et al. 2002), and assumes that the Holocene glass melt strewn field represents distal ejecta from an unidentified crater or set of craters (Bland et al. 2002). While possible given the potential of smaller impact craters to be masked over time by geological processes such as blowing sand and loess (Masse 2007), a mid-Holocene impact crater responsible for such a large distribution of melts seems unlikely to be still undiscovered, especially given the attention brought to this region by the initial publication of the hypothesized impact 
two decades ago (Schultz and Lianza 1992) and the recent availability of tools such as Google Earth for the visualization of potential craters.

Scenario 3 views the Holocene glass melts as the in situ residue of an airburst, rather than as ejecta from a cratering event. As previously noted, the largest modeled airbursts could impact surface areas greater than 100,000 $\mathrm{km}^{2}$ (Wasson 2003), a figure twice that of the tentatively defined Río Cuarto Holocene glass melt field.

Scenario 4, which in part is based on extensive modeling and simulation associated with oblique projectiles (e.g., Schultz 1991), accepts the Río Cuarto crater field as originally defined (Schultz and Lianza 1992) and views the distribution of Holocene glass melts as most likely representing impactites spread out by the explosive contact that created the craters. If the relationship between the crater field location and orientation and the defined Holocene glass melt distribution (Figs. 2, 3 and 4) at all approaches reality - and Peter Schultz (personal communication to W. B. M. 2008) wisely cautions that there is still much work to be done to verify this apparent relationship - then this would strongly suggest that the craters and melts are intimately related. The low angle of entry also may have caused devastation on the ground by the bow shock wave in front and below the impactor for many kilometers prior to actual impact.

It is difficult for us to choose between Scenario 3 (airburst) and Scenario 4 (Río Cuarto cratering impact), but both better fit our existing data than do the first two. The airburst and cratering impact scenarios seemingly imply $10^{3}-10^{4} \mathrm{Mt}$ of energy release based on modeling programs, such as Earth Impact Effects Program (Collins et al. 2005; Marcus et al. 2010), likely resulting in devastation over tens of thousands of square kilometers. Not only would the Rio Cuarto devastation be considerably larger than that of the Campo del Cielo impact, but also the mortality in these areas should be much greater than that calculated for the Campo del Cielo impact, perhaps approaching $90 \%$ fatalities within the $48,106 \mathrm{~km}^{2}$ elliptical impact path. That this conservative figure is not set at $100 \%$ takes into account topography and other situational and physical variations of the impact event. There were blast survivors at or near ground zero in Hiroshima and Nagasaki who survived due to unusual locations or situations (Wheeler 1983:120-135). An 11-year-old boy survived virtually unscathed when he dove into a pool of the Urakami River at the very instant of the initial Nagasaki thermal blast wave. Similarly, a nun at Saint Francis Convent scattering fertilizer in a field, was saved when she tripped and fell into an eight-foot deep ditch. In both cases their unprotected companions were instantly killed. These two examples are instructive in that the Gran Chaco world fire myths are dominated by stories of people saving themselves by being in holes in the ground or in lagoon waters.

According to the aforementioned scale of Gad-el-Hak (2008), Río Cuarto is likely well past the threshold for the highest category $\left(>1,000 \mathrm{~km}^{2}\right)$, that of a "gargantuan disaster" deserving further modeling effort. On the basis of the data published by Binford (2001), some approximations about relevant parameters of the kind of societies likely involved in the Rio Cuarto impact can be made. From his database of 339 hunter-gatherer groups, we isolated the 19 that inhabit the area between $32^{\circ}$ and $36^{\circ}$ of latitude (both north and south) in order to calculate the approximate number of individuals and cultural groups or societies that could be directly affected by the impact. The hunter-gatherer societies that lived at that latitudinal strip during 
historical times (6 at different parts of Australia, and 13 in the American Southwest) (Table 4) exhibited a quite restricted residential mobility (0-9 annual movements, with a median of 0.1 and a interquartile range between 0 and 7), a diet mainly composed by gathered resources (with a median of $50 \%$ ), and a highly variable total population size (a median of 2,124 people, with a interquartile range between 889 and 3,500 people) and population density (a median of 18.0 inhabitants $/ 100 \mathrm{~km}^{2}$, with a interquartile range between 5.12 and 43.75 inhabitants $/ 100 \mathrm{~km}^{2}$ ).

The uncritical use of these data may be misleading since the hunter-gatherer societies living in central Argentina at the time of the impact event are believed to have been mostly low density at the regional scale of analysis (Barrientos and Perez 2005, and discussion below). Taking this into account, some filtering of the data was necessary in order to get more realistic approximations. First, we performed - after standardizing the quantitative data $-a k$-means cluster analysis using three of the variables coded by Binford (2001:117) (total population or TLPOP, population

Table 4 Ethnographic hunter-gatherer societies living between $32^{\circ}-36^{\circ}$ North and South Latitude

\begin{tabular}{|c|c|c|c|c|c|c|c|c|c|}
\hline $1^{\mathrm{a}}$ & $2^{\mathrm{a}}$ & $3^{\mathrm{a}}$ & $4^{\mathrm{a}}$ & $5^{\mathrm{a}}$ & $6^{\mathrm{a}}$ & $7^{\mathrm{a}}$ & $8^{\mathrm{a}}$ & $9^{\mathrm{a}}$ & $10^{\mathrm{a}}$ \\
\hline $\begin{array}{l}\text { Australia-New } \\
\text { South Wales }\end{array}$ & Wongaibon & $32.14 \mathrm{~S}$ & 5.12 & 3589 & 70,110 & 35.00 & 40.00 & 25.00 & 0.00 \\
\hline $\begin{array}{l}\text { Australia-New } \\
\text { South Wales }\end{array}$ & Barkindji & $32.40 \mathrm{~S}$ & 15.43 & 3008 & 19,500 & 25.00 & 40.00 & 35.00 & 0.00 \\
\hline USA-California & Diegueno $^{\mathrm{b}}$ & $32.44 \mathrm{~N}$ & 18.10 & 3000 & 16,600 & 25.00 & 55.00 & 20.00 & 7.00 \\
\hline USA-Texas & Chiricahua Apache ${ }^{b}$ & $32.52 \mathrm{~N}$ & 1.16 & 1425 & 122,850 & 40.00 & 60.00 & 0.00 & 0.00 \\
\hline USA - California & Cupeno $^{\mathrm{b}}$ & $33.26 \mathrm{~N}$ & 48.80 & 195 & 400 & 25.00 & 75.00 & 0.00 & 0.10 \\
\hline USA-Arizona & Yavapai $^{\mathrm{b}}$ & $33.37 \mathrm{~N}$ & 1.48 & 600 & 40,500 & 35.00 & 60.00 & 5.00 & 9.00 \\
\hline USA - California & Luiseno & $33.42 \mathrm{~N}$ & 67.90 & 5500 & 8120 & 15.00 & 60.00 & 25.00 & 2.00 \\
\hline USA-California & Cahuilla & $33.59 \mathrm{~N}$ & 43.75 & 3675 & 8400 & 25.00 & 75.00 & 0.00 & 4.00 \\
\hline USA-California & Gabrielino & $34.00 \mathrm{~N}$ & 64.90 & 5000 & 7700 & 10.00 & 40.00 & 50.00 & 0.10 \\
\hline USA-California & Serrano $^{b}$ & $34.52 \mathrm{~N}$ & 17.58 & 3500 & 19,900 & 40.00 & 60.00 & 0.00 & 7.00 \\
\hline $\begin{array}{l}\text { Australia_-South } \\
\text { Australia }\end{array}$ & Karuna $^{\mathrm{b}}$ & $34.56 \mathrm{~S}$ & 18.00 & 1296 & 7200 & 20.00 & 45.00 & 35.00 & 8.00 \\
\hline USA-California & Chumash & $34.63 \mathrm{~N}$ & 118.20 & 2124 & 1800 & 5.00 & 25.00 & 70.00 & 0.10 \\
\hline $\begin{array}{l}\text { Australia - Western } \\
\text { Australia }\end{array}$ & Mineng $^{\mathrm{b}}$ & $34.95 \mathrm{~S}$ & 7.00 & 889 & 12,700 & 30.00 & 40.00 & 30.00 & 0.00 \\
\hline $\begin{array}{l}\text { Australia-South } \\
\text { Australia }\end{array}$ & Jaralde $^{\mathrm{b}}$ & $35.06 \mathrm{~S}$ & 40.00 & 200 & 500 & 15.00 & 45.00 & 40.00 & 0.00 \\
\hline USA-California & Kawaiisu Shoshoni ${ }^{\mathrm{b}}$ & $35.37 \mathrm{~N}$ & 11.90 & 500 & 4200 & 40.00 & 60.00 & 0.00 & 9.00 \\
\hline USA-California & Salinan & $35.47 \mathrm{~N}$ & 37.40 & 3500 & 9400 & 20.00 & 50.00 & 30.00 & 0.00 \\
\hline USA-Texas & Kiowa Apache ${ }^{\mathrm{b}}$ & $35.83 \mathrm{~N}$ & 4.14 & 1908 & 46,000 & 90.00 & 10.00 & 0.00 & 0.00 \\
\hline Australia_-Victoria & Tjapwurong & $35.86 \mathrm{~S}$ & 35.00 & 2450 & 7000 & 20.00 & 35.00 & 45.00 & 0.00 \\
\hline USA-Arizona & Walapai $^{\mathrm{b}}$ & $35.95 \mathrm{~N}$ & 3.86 & 1000 & 25,900 & 35.00 & 65.00 & 0.00 & 4.00 \\
\hline
\end{tabular}

Data and denomination of variables from Binford (2001)

a 1 (STATE); 2 (NAME); 3 (LATITUDE); 4 (DENSITY); 5 (TOLPOP); 6 (AREA); 7 (HUNTING); 8 (GATHERING); 9 (FISHING); 10 (NOMOV)

${ }^{\mathrm{b}}$ Case included in the analysis 
density per $100 \mathrm{~km}^{2}$ or DENSITY, and the average number of annual residential moves or NOMOV) in order to analytically separate two more internally homogeneous groups. The analysis discriminated between a first cluster of 8 cultural groups with higher total population, higher population density and lower residential mobility, and a second cluster composed by 11 groups with lower total population, lower population density, and higher residential mobility. The members of the latter cluster were selected for further analysis (Table 4).

If we consider that the area directly affected by the impact was approximately an ellipse of $48,106 \mathrm{~km}^{2}$, and assuming an even distribution of population across the landscape, a median number of three (interquartile range between 1 and 11) cultural groups or societies with such characteristics may have been literally swept away by this sudden, unpredictable event. This implies a median number of about 1,000 individuals (interquartile range between 500 and 1,908) affected in some way by the impact, 900 of which $(90 \%)$ probably died. This number could even be much higher because it does not include the potential effects of fast-moving wildland fires radiating out from the impact zone, which would have killed additional individuals and further depleted the resources necessary for human maintenance and recovery. Such sudden devastation may have had more subtle and time-transgressive effects on the broader population, assuming it caused severe disruption to the spatial structure of the affected population, its demography, its resource base, and the degree of connectivity between demes or local groups controlling migration and gene flow rates. It is possible that small local populations living in more distant locations may have crashed or diminished in size as an indirect consequence of the impact. We reiterate that a cultural factor linked to major catastrophic events, including cosmic impacts, which may affect connectivity between populations is the consequent avoidance of the region that suffered the catastrophe - a seeming common reaction among traditional cultures (Piccardi and Masse 2007; Masse et al. 2007) — as illustrated by the reaction of the Evenki people to the Tunguska impact. Due to the many uncertainties, we emphasize that these figures should only be considered at best crude first estimates. We agree with Peter Schultz (personal communication to W. B. M. 2008) that much more fieldwork and modeling is necessary before truly understanding the nature of the Río Cuarto event and the extent of its devastation.

The two mid-Holocene cosmic impact events in Argentina had the potential of being very destructive. The Campo del Cielo impact event would have caused fewer than ten deaths based on our modeling. Gran Chaco mythology suggests that this death toll was actually considerably higher, perhaps more than 100 individuals due to one or more villages or campsites likely being within or adjacent to the crater and strewn field and the effects of the associated wildland fire. The Río Cuarto impact would seem to be both qualitatively different from and quantitatively larger than Campo del Cielo. Rio Cuarto most likely represents the primary cosmic impact contributor to any major environmental and population perturbation in central Argentina during the mid-Holocene, thus deserving a closer and more thorough examination. In the following sections, we assess the degree to which this impact event can be linked, at a supraregional level, with major variations in the frequency and distribution of different biocultural indicators of population stability. 
The Holocene Archaeological Signal in Central Argentina

We begin with the basic assumption that large regionally relevant radiocarbon datasets can be used to evaluate temporal variations in the intensity of the "archaeological signal," i.e., the fluctuating quantity of any specified indicator whose temporal variation in frequency convey information about past human activity at some selected spatial scale of analysis. Like other signals, the archaeological signal is affected by noise (i.e., unwanted perturbation added to the target signal) and distortion (i.e., change introduced in the general form of a signal, usually involving its total or partial degradation in such a way that the received signal differs from that sent out by the source). In archaeological research, human activity is the prime signal source targeted for investigation, so it is desirable to recognize and isolate the target signal from the background noise.

Taphonomy is one of the main tools on which archaeology can rely for this purpose, since it provides useful knowledge about the different agents operating on the formation of the deposits from where the information-bearing entities (e.g., lithic and faunal bone assemblages) are recovered (Hiscock 1985; Lyman 1994). Despite the advances in the recognition of the effects of different agents acting on archaeological deposits, it is clear that the criteria and procedures to accurately remove noise from the human signal are not yet fully developed. Regarding distortion, much of what Surovell and Brantingham (2007:1869) call "taphonomic bias," in the sense of time-dependent destructive processes affecting archaeological deposits, may qualify as a distortive force impinging on the archaeological signal. In archaeology, distortion is a much more intractable problem than noise. We cannot anticipate the original form of the signal since the signal emitted by cumulative human activity, measured in terms of the frequency of physical items per spatial or temporal unit, can be considered as random or stochastic. The procedure proposed by Surovell et al. (2009a) to correct temporal frequency distributions of radiocarbon dates, based on the examination of the ratio of archaeological to geological contexts and the posterior verification of results with some independent evidence, cannot be considered a true method for undistorting the archaeological signal. However, it represents an ingenious way to deal with the "taphonomic bias problem" that deserves further examination in different contexts of application. Other sources of distortion (e.g., chance in sampling or "research bias;" Surovell and Brantingham 2007; Surovell et al. 2009a) remain to be modeled and controlled.

The first step in our analysis consisted in assembling, after a thorough survey of the relevant literature published up to July 2011, five radiocarbon datasets corresponding to the same number of archaeologically/eco-geographically defined areas of central Argentina between approximately $30^{\circ}-39^{\circ}$ South Latitude (Fig. 11). These are: (1) Sierras Centrales $(n=62)$; (2) southeastern Pampas $(n=122)$; (3) southwestern Pampas $(n=35)$; (4) Diamante/Atuel river valleys $(n=93)$; (5) Payunia/northern Neuquen $(n=103)$. These areas are close to the impact site of Río Cuarto and the surrounding affected zone. It is expected that if this catastrophic event had any noticeable effect on human populations on a broad scale, the archaeological record from these areas may contain some signal of it. In order to ensure some degree of chronometric hygiene (in the sense of Spriggs 1989), we selected for inclusion in this exploratory study only those radiocarbon dates, both AMS and beta-counting that 


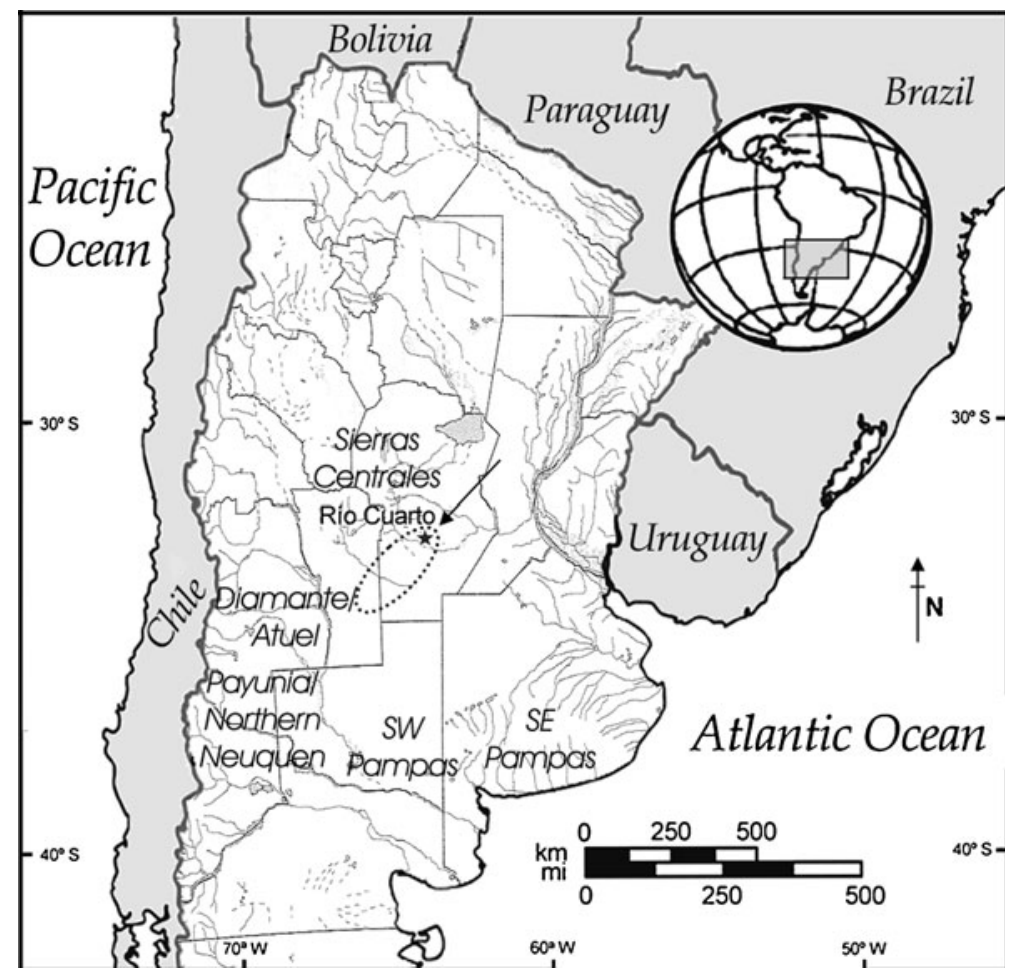

Fig. 11 Geographic location of the five regional radiocarbon dataset sampling areas in relation to the Rio Cuarto crater field (star) and glass melt strewn field (dotted line)

conformed to a minimal set of criteria. For that purpose, we first proceeded to filter the total database by eliminating all those determinations indicated as dubious in the original reports on a context-specific basis. In all those cases in which more than one determination was made on a single sample, we arbitrarily retained the oldest one. We also eliminated those dates not directly related to any particular archaeological assemblage (i.e., those corresponding to soil profiles not associated with archaeological materials). An additional criterion was to eliminate those radiocarbon dates with sigma $(\sigma)$ values (i.e., laboratory uncertainty) higher than $300{ }^{14} \mathrm{C}$ years. From a geographical standpoint, the total pooled sample of 415 dates come from 134 archaeological sites unevenly distributed across the entire study area. The diverse materials used for radiocarbon dating include, in order of representation: charcoal, human and animal bone collagen, macro-botanical remains, dung, mummified soft tissues (muscle), fresh water snail shell, and organic fraction of sediments from archaeological deposits. A minor fraction of the sample corresponds to unspecified materials. For the purpose of this research we took all the dates at face value, since to perform an in-depth analysis of the entire data set would be a prohibitively timeconsuming task, with no guaranteed results. This is mainly due to the lack of information in most of the original reports about pertinent issues such as sample pretreatment protocols, sample quality assessment, and the correction factor for isotopic fractionation. Despite the many factors - both known and unknown - that may impinge on the distribution of radiocarbon dates, we still consider the available 
dataset as a suitable source of data for detecting variations in the archaeological signal at the regional level of analysis along with an evaluation of the demographic, taphonomic, and sampling factors that contributed to its shape.

The second step was to evaluate the overall shape of the temporal frequency distribution of uncalibrated radiocarbon dates, looking for potential biases. Figure 12 shows that such a distribution is not uniform since the number of dates increases through time in a curvilinear fashion (smooth distance-weighted least squares curve; stiffness parameter $=0.5)$. This suggests that time-dependent destructive forces (e.g., erosion, diagenesis, weathering) may have affected the integrity of the archaeological record across this extensive geographic area, biasing the overall frequency distribution of radiocarbon dates simply because there are potentially more datable samples from more recent time periods relative to older ones. By varying the stiffness parameter to 0 , we can observe that the underlying structure of the frequency data becomes more apparent, showing that the second half of the mid-Holocene $\left(6-4{ }^{14} \mathrm{C}\right.$ ky BP) is, relative to other time periods, a particularly underrepresented lapse in terms of radiocarbon dated materials and, by implication, of deposited or preserved archaeological contexts. Research biases, like selective period-oriented archaeological sampling and dating do not seem to be major factors shaping the observed frequency distribution of radiocarbon ages, since such a selective approach to the archaeological record has not been a common documented practice, at least from a regional perspective. At the site-level, however, it is likely that in some cases the dating effort was unevenly allocated throughout the entire archaeological sequence, generally favoring the earliest occupations over the later ones (e.g., Diamante/Atuel river valleys, southeastern Pampas).

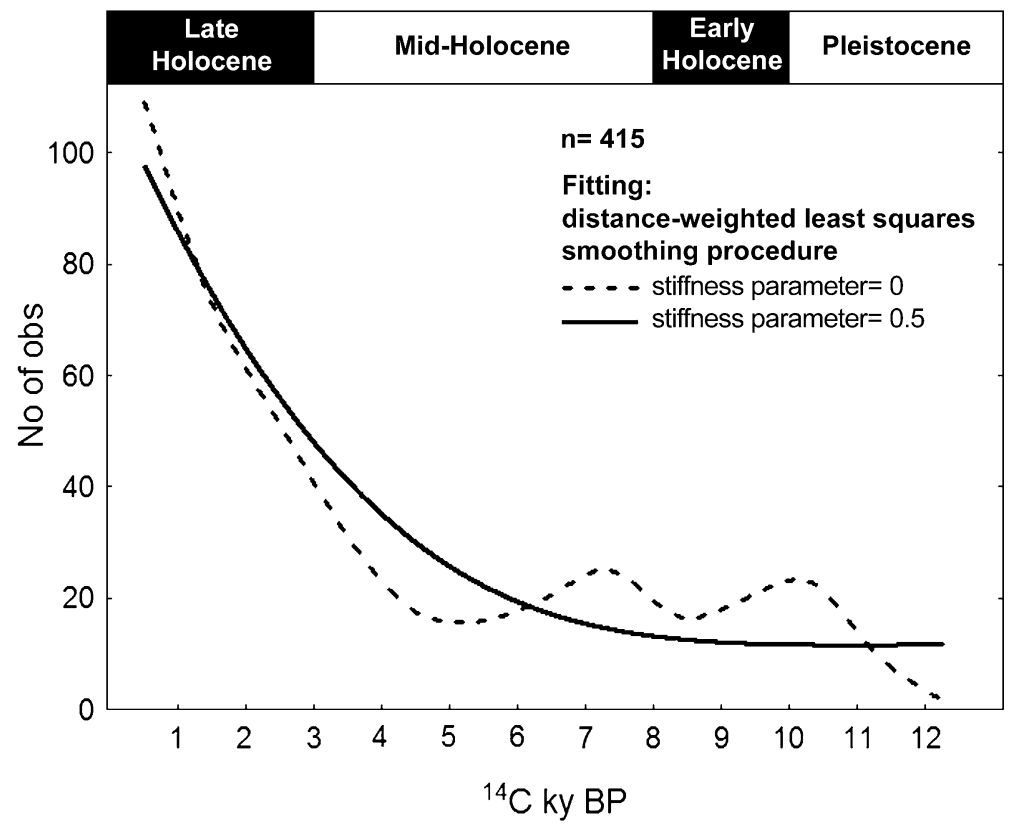

Fig. 12 Temporal frequency distribution of uncalibrated radiocarbon dates $(n=415)$ from central Argentina. The graph shows two curves adjusted to data (smooth distance-weighted least squares procedure) that vary in the value of the stiffness parameter 
The third step consisted in the calendar calibration of the radiocarbon dates and the generation of graphs representing the summed probability distribution of the whole dataset. The calibration was performed using the Cologne Radiocarbon Calibration \& Palaeoclimate Research Package (CALPAL-A), a software package that allows the simultaneous processing of large datasets. The results are represented in a 2-D dispersion calibration graph that shows the calendar probability distribution $(2 \sigma)$ of the ${ }^{14} \mathrm{C}$ ages (i.e., calibrated age distribution) (Weninger 1997). The calibration curve selected was the CalPal-2007-Hulu (Weninger and Jöris 2007), based on a tree ring section identical to INTCAL04 (Reimer et al. 2004), and extended into late Glacial by U/Th-coral data of Fairbanks et al. (2005), onto which are projected the varve grayscale Cariaco Basin data (Hughen et al. 2000) and the floating late Glacial Hohenheim Tree Ring Data (Kromer et al. 2004). The selected curve produces results that are identical-for all practical purposes-to the recently published INTCAL09-calibration (Bradtmöller et al. 2012). The differences with the results potentially derived from the use of the $\mathrm{SHCal04}$ curve, the recommended calibration curve for Southern Hemisphere radiocarbon measurements (McCormac et al. 2004), are deemed negligible at the present scale of analysis.

The fourth step of our analysis was the assessment of the curve representing the summed probabilities of the calibrated radiocarbon dates (Fig. 13). Operatively, we used its height as the parameter to evaluate the intensity of the archaeological signal. The higher peaks, caused by a local increase in the frequency of dates per time unit, were considered as representing increases in the intensity of the signal relative to lesser peaks or plateaus in the curve. In the same manner, any intercept of the curve with the horizontal axis was considered as a temporary loss of the signal either by demographic, taphonomic or sampling factors. Using the scale at the right of the graphic as reference, we delimited five vertical zones that qualify the archaeological signal represented by the curve of the summed probabilities of the calibrated radiocarbon ages as very low, low, moderate, high, and very high. What clearly emerges from Fig. 13 is that most of the signal for the mid-Holocene period $\left(8-3{ }^{14} \mathrm{C} \mathrm{ky} \mathrm{BP}\right.$, or ca. 8.8-3.1 cal ky BP) can be considered as low or very low, particularly for the

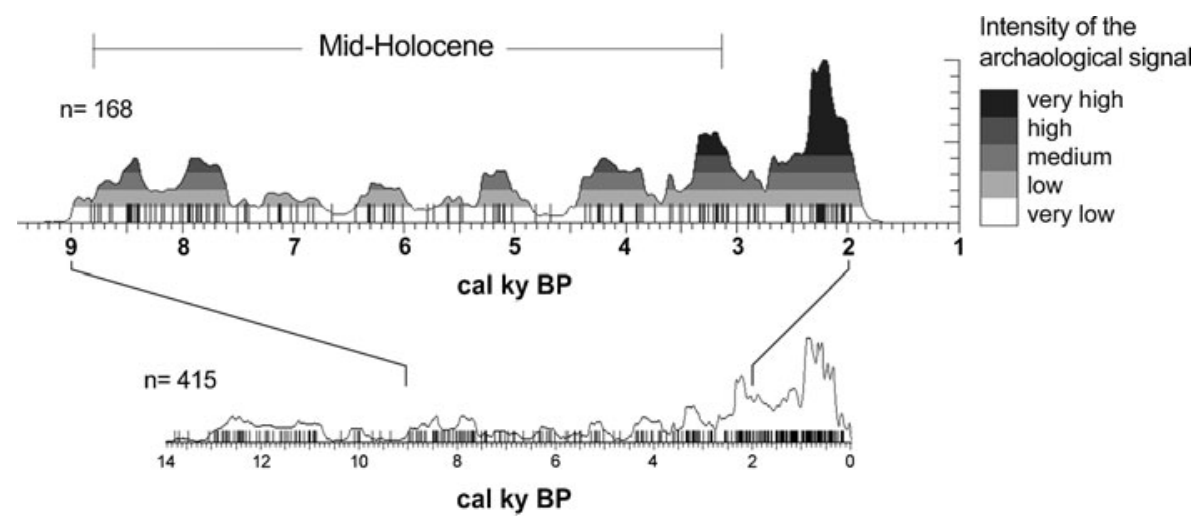

Fig. 13 Plot of the probability distribution of the calibrated radiocarbon dates on the calendaric time scale of the entire sample from central Argentina $(n=415)$ (below) and the subsample corresponding to the 92 cal ky interval $(n=168)$ (above). In order to qualify the intensity of the archaeological signal represented by the summed probability curve, a rank-order scale is indicated 
interval between 7.5 and 4.4 cal ky BP. The mid-Holocene thus appears, in general, underrepresented from an archaeological standpoint in an extensive zone of central Argentina. In the following section, we discuss the likely meaning of such underrepresentation and the potential role played by the Río Cuarto impact event.

\section{Climate, Ecology, and Taphonomic Bias as Factors Partially Explaining the Low} Measured Intensity of the Mid-Holocene Archaeological Signal

The paucity of archaeological evidence of mid-Holocene age for central Argentina is not a novel observation (Politis 1984; Barrientos 1997, 2009; Barrientos and Perez 2002, 2005; Barrientos et al. 2005; Gil 2005; Gil et al. 2005; Garvey 2008; Neme and Gil 2009). We acknowledge the potential role of taphonomic and research bias; this finding has been almost invariably interpreted as the result of some demographymediated process (e.g., group size reduction, local extinction) affecting land use intensity by hunter-gatherer populations. Moreover, such demographic changes were usually linked to major variations in the climatic and ecological conditions that occurred during the mid-Holocene.

In order to evaluate the hypothesized linkage between the intensity of the archaeological signal-mainly interpreted as a demographic epiphenomenon whose expression is inherently biased or distorted in often unknown and unclear ways - and climate, we plot the summed probabilities of the calibrated radiocarbon dates against different paleoclimatic proxies of regional significance. Scholars often disagree in fundamental ways regarding the climatic evolution of the Holocene in general and of the mid-Holocene in particular (e.g., Zárate 2002; Barrientos and Perez 2005), depending on the types of data used (e.g., biostratigraphic, pedo-sedimentary, palynological, isotopic). While there is a general consensus about warmer than today prevailing conditions for most of the mid-Holocene period in central Argentina (Hypsithermal), the existence of permanently wetter or alternating wetter-drier conditions for this time interval, particularly in the eastern portion of that area (i.e., the Pampas) is still currently debated (Bonadonna et al. 1995; Zárate et al. 1998; Iriondo 1999, 2006; Tonni et al. 1999; Carlini and Tonni 2000; Gil et al. 2005; Mancini et al. 2005; Quattrocchio et al. 2008; Tonello and Prieto 2010). For the southwestern portion of central Argentina (southern Mendoza and northern Neuquén) there is a stronger agreement between scholars about the prevailing warm and arid character of the climate during this time period (Zárate 2002), although with some temporal and spatial peculiarities (Neme and Gil 2009).

Figure 14 shows that the very low archaeological signal prevailing during most of the mid-Holocene coincides with generally warm, either wetter or drier-than-today, climatic conditions. Moreover, there seems to be a close inverse relationship between temperature and signal intensity. A single intriguing exception is that of the major decrease in the intensity of the archaeological signal between $c a .4 .4$ and 4.9 cal ky BP. This decrease does not have a clear relationship with any major climatic event with the possible exception of neoglacial activity recorded in Patagonia between $c a$. 5.2 and 4.5 cal ky BP (Mercer 1982) or between ca. 5.4-4.9 cal ky BP (Porter 2000) (see discussion in Douglass et al. 2005). It is included within the generally warmer period of the mid-Holocene close to the point of reversion in both temperature and 


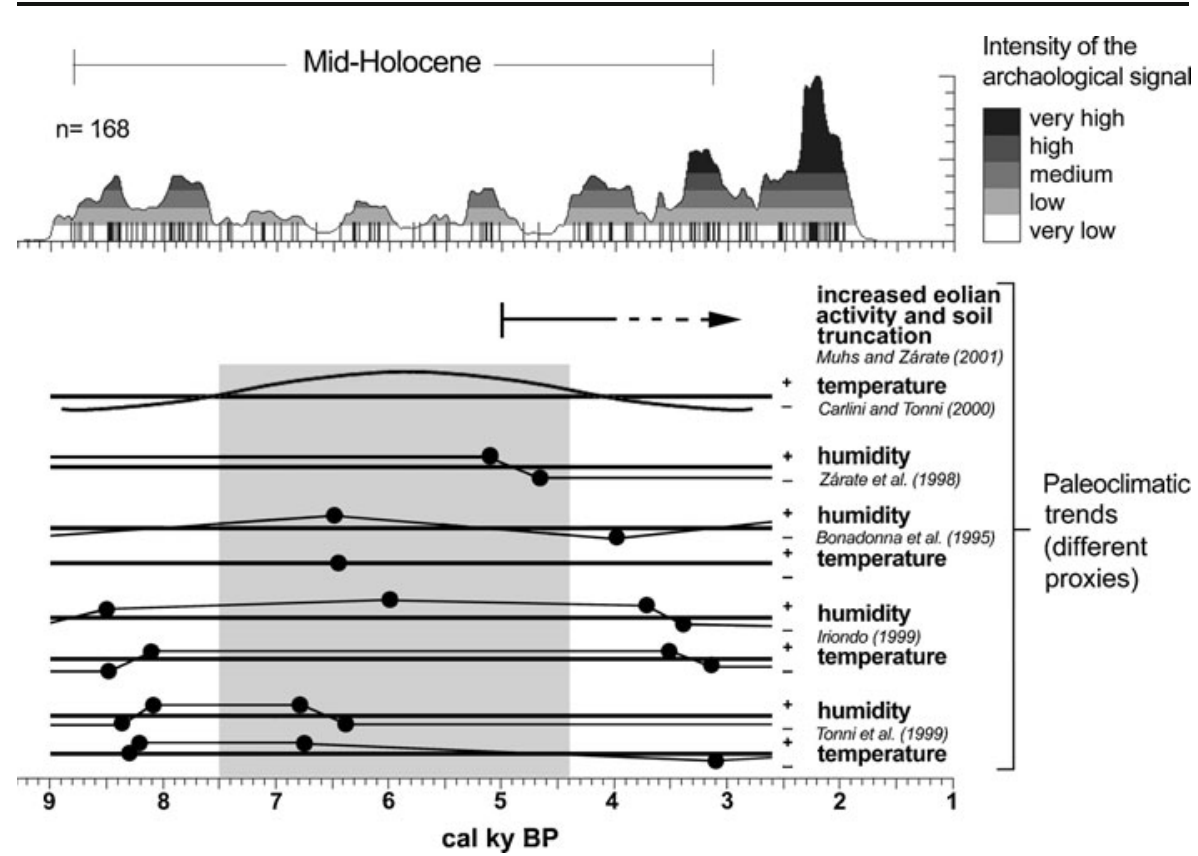

Fig. 14 Plot of the probability distribution of the calibrated radiocarbon dates on the calendaric time scale of the subsample from central Argentina corresponding to the 9-2 cal ky interval $(n=168)$ (above) and a multiproxy paleoclimatic chart for the eastern part of the same region (Pampas) (below)

humidity that occurred, in the Pampas at least, near the middle/late Holocene boundary (Zárate et al. 1998; Zárate 2005; Tonello and Prieto 2010).

The aforementioned decrease in the archaeological signal in Central Argentina also coincides with, and mostly precedes an increase in eolian activity. The latter was almost negligible during the Early and mid-Holocene but increased significantly after 5 cal ky BP, causing the truncation of soils at different localities in the Pampas, although the regional impact of this process has not yet been thoroughly assessed (Muhs and Zárate 2001). Soil erosion may have been responsible for an increased rate of archaeological site destruction at a supraregional level, thus partially contributing to the documented underrepresentation of the archaeological record from the midHolocene period in some areas.

Summarizing, the very low archaeological signal from mid-Holocene times appears to be strongly associated with at least two main, but not mutually exclusive, factors: (a) taphonomic bias, and (b) population responses to climate change. We address the second factor since a comprehensive discussion of the first one requires a great deal of field data that is not yet available.

Previously mentioned, in the mid-Holocene the archaeological signal seems at its low when warm climatic conditions prevail. On the contrary, the highest peaks of signal intensity are before and after the onset and end of this period (Figs. 13 and 14), coinciding with cooler climates (Bonadonna et al. 1995; Zárate et al. 1998; Iriondo 1999; Tonni et al. 1999; Carlini and Tonni 2000; Mancini et al. 2005). Taking this into account, it can be proposed that increases in temperature in central Argentina were limiting factors affecting human occupation of some environments, either 
associated with humid or subhumid-semi-arid conditions. This does not necessarily imply that humans were by themselves sensitive to those raises in temperaturealthough it might also be the case-but simply that human populations may have demographically responded to variations in the ecological conditions triggered by temperature increases.

It can be argued that human demography in this area may have been tightly related to the demography of the main animal resource, the guanaco (Lama guanicoe) (Politis 1984; Barrientos and Perez 2005). As the zooarchaeological record shows, this ungulate was the main terrestrial staple for Holocene hunter-gatherer populations, not only in Central Argentina (Politis and Salemme 1990; Martínez and Gutiérrez 2004; Medina and Rivero 2007; Gutiérrez and Martínez 2008; Neme and Gil 2009), but also in other regions of the Southern Cone of South America like Patagonia and Tierra del Fuego (Barberena et al. 2009; Morrison 2010). The guanaco inhabits a diversity of habitats differing in their degree of humidity, including desert and xeric shrublands, montane grasslands, savanna grasslands and shrublands, and temperate forests (Dinerstein et al. 1995; González et al. 2006:160). Relative to temperature, guanaco is a species that typically inhabits temperate/ cold environments, such as the Bonaerensian hills, Patagonian steppes, and Andean highlands (MacDonagh 1949; Ringuelet and Aramburu 1957; Cabrera and Yepes 1960); however, there are populations adapted to the Chaco, one of the hottest, almost arid, ecosystems in South America (Romero 1927; Villalba and Bonacic 2006). It is generally believed that the remarkable success of the guanaco to colonize and survive in such a diversity of habitats is mainly due to their flexible social behavior and ecophysiological adaptations to harsh environments (González et al. 2006:158-59).

Guanacos and humans in southern South American environments seem to have behaved like co-evolving components of predator-prey systems at the microevolutionary level (L'Heureux 2008), therefore human demography may have been particularly sensitive to guanaco demography. The empirical rationale behind this assertion is that in general the cycles of the prey seem to determine the cycles of the predators but not conversely (Mayr 1997; however, see Kay 1998). It is plausible that guanacos and many other mammalian species in temperate zones like central Argentina were sensitive to post-Pleistocene raises in temperatures, particularly during the mid-Holocene. Quantitative estimates of mid-Holocene warmth $(\mathrm{COH}-$ MAP 1988) suggest that Earth was perhaps 1 or $2{ }^{\circ} \mathrm{C}$ warmer than today. Most of this warmth may represent summer warmth rather than year-round warmth. If guanacos were also sensitive to increases in humidity as some authors propose (Politis and Tonni 1980; Politis et al. 2011; cf. Loponte 1996-1998; 2008), the combined effects of warmer and wetter conditions in portions of central Argentina or at certain times during the mid-Holocene may have been even more intense for the demography of this species,. These factors may constitute a major ecosystem regulator, affecting cycles of prey population contraction and expansion, thus impinging over local or regional carrying capacity and human demography. Similar trends were also observed, for the same period, in the Great Basin of North America (e.g., Grayson 2000; Byers and Broughton 2004; Louderback et al. 2011), a somewhat comparable environment to that of much of central Argentina and northern Patagonia (Morello 1984). 
Research about temperature sensitivity in guanaco primarily focuses on responses to cold conditions (e.g., "winter stress;" Raedeke 1976; Merino et al. 1993; Cajal and Ojeda 1994; Borrero 2001; Belardi and Rindel 2008). Information on heat resistance is scarce. Existing studies are mostly concerned with short-term individual responses to experimentally induced stress (Fowler 1989, cited by Ingram 1992). We are unaware of any data about the relationship between medium to long-term increases in temperature and population-level responses of guanaco. It has been proposed (McLean 1979, 1981, 1991) that climatic warming beyond the optimum temperature range for conception and estrual activity can significantly reduce mammalian fertility — and possibly that of other vertebrates like reptiles and birds (McLean 1994) leading to reduction in population numbers and, during abrupt climatic changes, collapse and population extinction. In either case, there is much that we need to learn about guanaco physiology and human-guanaco interaction from an ecological standpoint and within the frame of medium to long-term ecosystem and biome evolution. This includes modeling the interwoven effects of simultaneous mass mortality (e.g., a cosmic impact event) for guanacos and humans.

\section{Is Cosmic Impact a Credible Factor Affecting the Mid-Holocene Archaeological} Signal?

The prevalence of a low to very low archaeological signal in Central Argentina during much of the mid-Holocene can be largely explained in terms of taphonomic bias and climatic-ecological interactions affecting human organization and demography. Within this period, the interval 5.0-4.4 cal ky BP is characterized by a particularly depressed archaeological signal-even lower than previous moments of the midHolocene-that seems difficult to explain solely in those terms (Fig. 13). This interval coincides with the very final part of the Hypsithermal, a period in which the temperatures dropped near or below the current levels (Fig. 14), thus arguably favoring the recovery of mammalian populations. If taphonomic bias, sampling, and ecoclimate-mediated organizational/demographic changes do not seem to sufficiently account for the lowering in the archaeological signal at the 5.0-4.4 cal ky BP interval, might cosmic impact help to explain the observed phenomenon?

In order to connect the very low level of the archaeological signal between 5.0 and 4.4 cal ky BP with the Río Cuarto cosmic impact we need to check for temporal coincidences between the interval of interest and the estimated age of the impact event. Figure 15 shows the temporal distribution of the different published estimations of the age of the Río Cuarto impact in relation with the curve of the summed probabilities of the calibrated radiocarbon dates from the pooled sample from central Argentina. The individual estimations, derived from high-resolution ${ }^{40} \mathrm{Ar} /{ }^{39} \mathrm{Ar}$ dating, independent fission track analyses of well-preserved glasses (Schultz et al. 2004), and from radiocarbon dating of carbon found at the bottom of putative impact structures (Schultz and Lianza 1992; Bland et al. 2002), indicate a general middle to late Holocene age for the event. However, the composite age estimation proposed by Schultz et al. (2004:236) makes the impact more coincident with the middle/late Holocene boundary. At first glance, it is remarkable that the interval 5.0-4.4 cal ky BP is included within the range of the composite age estimated for the Río Cuarto impact event, coinciding with the middle of the proposed 6-3 cal ky BP date range. 


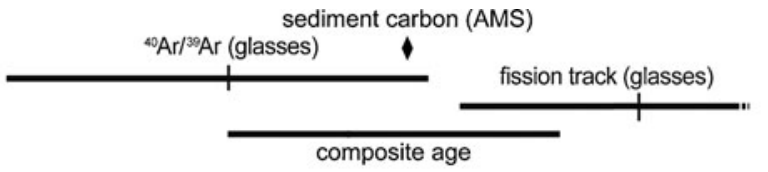

Age of the

Río Cuarto

Impact Event

(different methods)

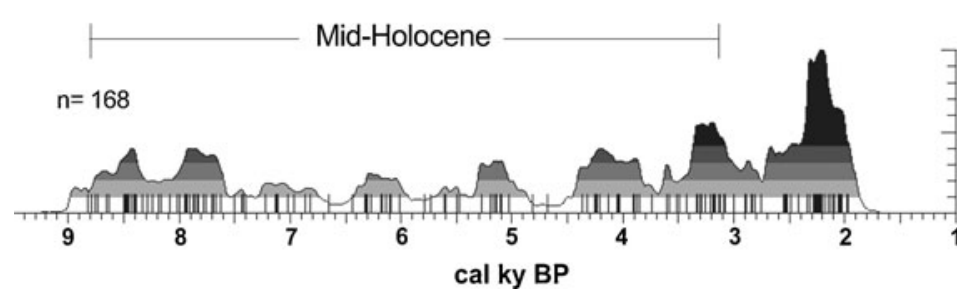

Intensity of the archaological signal

Fig. 15 Plot of the probability distribution of the calibrated radiocarbon dates on the calendaric time scale of the subsample from central Argentina corresponding to the 9-2 cal ky interval $(n=168)$ (below), and the probability distribution of the different ages obtained for Río Cuarto materials (impactites and carbon) (above)

The wide range of probable ages of a cosmic impact based on dating methods like fission track or ${ }^{40} \mathrm{Ar} /{ }^{39} \mathrm{Ar}$ impedes pinpointing the temporal position of the event with the sufficient precision to establish an indisputable association with any significant variation in the archaeological signal from a given spatial unit of analysis. This necessitates exploring other lines of archaeological evidence in search of significant changes that could also be linked to the putatively disturbing effects of the Río Cuarto impact.

In the context of small-scale and relatively mobile hunter-gatherers, significant changes in craniofacial morphology, temporal variation in cultural patterns of cranial vault deformation, and discontinuities in the use of persistent burial places (sensu Littleton and Allen 2007) might be informative about sudden biocultural change potentially associated with local or regional population-level disruption (Barrientos 1997, 2009). Figure 16 shows that the only indicator coinciding with the beginning of the 5.0-4.4 cal ky BP interval is the discontinuity in the use of Arroyo Seco 2 (AS2) as a persistent burial place (Politis et al. 2010). This is an inland, open air, and multicomponent site located at about $60 \mathrm{~km}$ from the Atlantic coast in the southeastern Pampas, that was intensively but intermittently used between $c a$. 9.04.8 cal ky BP for the inhumation of several tens of individuals (Barrientos 1997; Politis et al. 2010).

A major change in craniofacial morphology, partially associated with the replacement of the annular cranial vault modification ("A" in Fig. 16) by the tabular oblique variety ("TO" in Fig. 16) occur, at least in the eastern section of central Argentina, at around 3 ky calyears BP, at the lower limit of the composite age range estimated for the Río Cuarto impact event (Fig. 16). Barrientos and colleagues (Barrientos 1997; Barrientos and Perez 2002, 2005; Barrientos et al. 2005; Perez 2002a, 2002b, 2006) have suggested that in the southeastern Pampas of Argentina a population replacement may have taken place before or around $3 \mathrm{cal}$ ky BP since the differences between samples belonging to the early/middle Holocene transition and to the early late Holocene-demonstrated with both, traditional and geometric morphometrics - are too significant to be explained in terms of microevolutionary mechanisms operating on a single lineage in so short of a time period. The geographic provenance of the hypothesized entering population is unknown, but recent molecular studies carried out by Figueiro and Sans (2011) indicate 


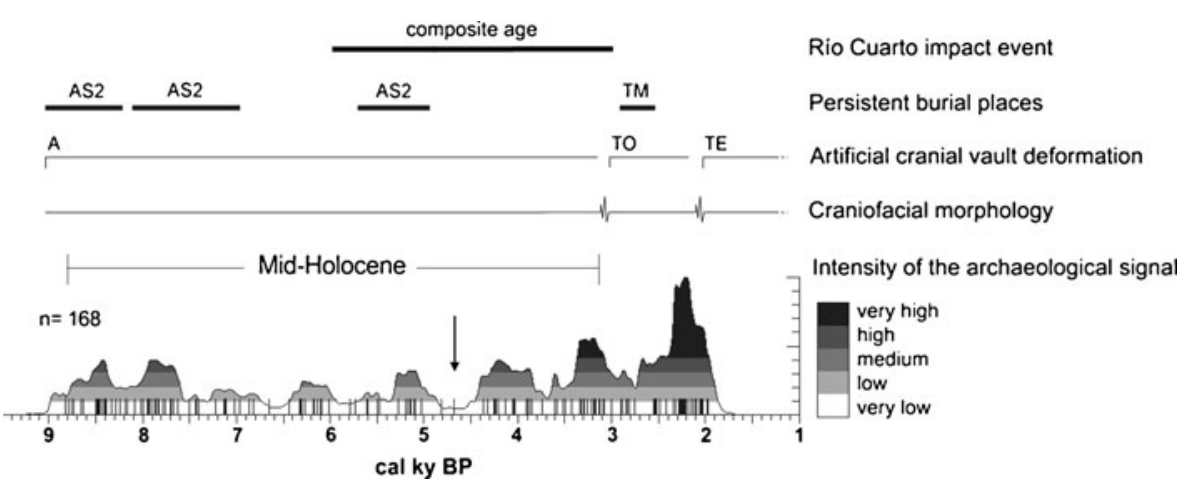

Fig. 16 Plot of the probability distribution of the calibrated radiocarbon dates on the calendaric time scale of the subsample from central Argentina corresponding to the 9-2 cal ky interval $(n=168)$ (below), the temporal distribution of different bioarchaeological indicators (middle), and the composite age range of the Río Cuarto impact event (above). The vertical arrow indicates the position of the 5.0-4.4 cal ky BP interval, characterized by a particularly depressed archaeological signal

a likely northern origin due to the presence in a sample from Laguna Tres Reyes 1 (ca. 2.75-2.1 cal ky BP) of the A2 mtDNA haplogroup, which is absent in older samples south of $35^{\circ} \mathrm{S}$. In fact, haplogroup A currently reaches its highest frequencies in northeastern Argentina (e.g., among the Mocoví and Guaraní, see Fig. 11), is relatively rare in Central Argentina, and is absent in native populations from southern Patagonia and Tierra del Fuego (Avena et al. 2010). Even accepting the timetransgressive nature of the population-level effects of a cosmic impact, the biocultural changes above referred seem to be too late to be reasonably linked with the Río Cuarto event (Fig. 16).

The current evidence does not allow for an undisputed claim about the existence of a tight causal relationship between the potentially highly disruptive Río Cuarto impact event and perceptible variations in the set of sensitive archaeological indicators of demographic and biocultural change explored in this paper. It is clear, however, that this particular catastrophic event cannot be ruled out as a causal factor for at least part of the variations in the archaeological record of midHolocene age in Central Argentina. More research combining the large-scale approach adopted in this paper with many and more detailed small-scale observations would shed light on this problem.

\section{Concluding Remarks}

The primary purpose of this paper has been to demonstrate that the study and science of cosmic impact is accessible to archaeologists and other historical sciences and has major relevance for research into and understanding of human cultural, social, and biological evolution. Cosmic impacts with regional effects $\left(10^{3}-10^{5} \mathrm{Mt}\right)$, such as Rio Cuarto, and threshold globally catastrophic effects $\left(10^{5}-10^{6} \mathrm{Mt}\right)$ would have played a significant role in Quaternary Period history, a fact that should become clearer once we have successfully defined the locations and timing of such large impacts. Equally important is the demonstration that even smaller more frequent impacts, such as Campo del Cielo, can play a vital role in local and regional culture history. Archaeologists can 
and should play a significant role in the identification and dating of geologically recent impacts and the description of their cultural effects.

We define the potential relationship between the occurrence of the two confirmed cosmic impacts in central and northeastern Argentina during the mid-Holocene and apparent changes in population dynamics on a broad spatial scale. While we cannot yet definitively support this connection, our initial review of a number of datasets $-{ }^{14} \mathrm{C}$, temporal patterns of biocultural variation, climate, the physical evidence of the impact events, and mythology_indicates that we cannot eliminate cosmic impact as a reasonable hypothesis accounting for some variations in the intensity of the archaeological signal in this portion of Argentina during the mid-Holocene. The data presented here contribute to strengthen this line of argument.

It was also our goal to explore how the tools and methods of archaeology might be profitably used to investigate culturally significant aspects of Campo del Cielo, Rio Cuarto, and other Quaternary Period impact events. We initially anticipated that a more precise date than 6-3 ky BP could be elicited for the Rio Cuarto impact event. The tiny radiocarbon signal between 5.0 and $4.4 \mathrm{cal}$ ky BP is suggestive but not yet compelling. Ironically, had archaeologists been involved from the outset in the scientific study of the Rio Cuarto and Campo del Cielo impact events, we might by now have more precise dating, which is needed for future testing of our models and interpretations.

At the very least, the microstratigraphic study of the impact crater and strewn field complexes and adjacent areas could have shed light on wildland fires and other physical effects associated with the impacts; however, dune migration within and outside of the Rio Cuarto structures (Peter Schultz personal communication to W. B. M. 2008, 2012) and extensive recent landscape modification due to modern agriculture (Fig. 8) indicate that considerable effort first needs to be put into the identification of intact geological deposits. William Cassidy (personal communication to W. B. M. 2009) has noted the frequent presence of pottery fragments on Campo del Cielo crater rims, which he thought possibly indicative of the use of craters for water collection (for use by local populations or transported to distant sites). There are other equally intriguing possibilities for the presence of such ceramics including as offerings associated with the putative pilgrimage trails to the crater field. In addition, it would be of interest to more intensively study the distribution of Campo del Cielo meteorites and Rio Cuarto Holocene glass melts in regional archaeological contexts, both as a means to help date the impacts themselves and to better understand the myriad potential social and psychological effects the impacts may have had on contemporary cultures and their descendents (Giménez Benítez et al. 2000; see also the account by McGhee 1996 on the use by Dorset, Thule, and Inuit people of the meteorites from northern Greenland as metal sources).

A great deal of research still remains to be done at various different fronts before we reach an acceptable understanding about the kind of relationships explored here. Continued enlargement of empirical databases and the concomitant development of explorative/comparative research are necessary. There is a need for an open-minded and dispassionate discussion about the role of cosmic impact in population and cultural dynamics. This requires the establishment of adequate and realistic standards of proof for research problems that address the effects of recent cosmic impacts on variously organized human populations. At present we must rely almost entirely on unspecific circumstantial evidence. Currently nothing resembles a "smoking gun," 
i.e., a specific find or set of finds about past human populations that can indisputably be attributed to direct or indirect effects of a confirmed cosmic impact. The identification of such an unambiguous signature will surely be a challenge for future research on this topic, particularly if we hope to use archaeological and cultural data as a tool to help the planetary sciences recognize and define other as yet unproven Quaternary and Holocene impact events.

Attention given by archaeologists to the recent history of cosmic impact can contribute to the planning required in response to the potential for future impact. This includes but is not limited to support for four topics in NEO research: risk assessment and the perception of risk, social perspectives on hazard, the potential catastrophic collapse of civil societies, and disaster preparedness (Bobrowsky and Rickman 2007). Unlike the requiem advocated for the Younger Dryas impact debate, the archaeological search for proofs about the effects of cosmic impact on past human populations should not be prematurely dismissed or abandoned.

The message that we want to communicate to our fellow archaeologists and to planetary scientists is past cosmic impacts were cataclysmic natural events that, despite widely differing magnitudes, would have had consequences for humans at each level of magnitude. Globally and regionally catastrophic cosmic impacts unquestionably occurred during the Quaternary Period and likely played a significant role in human biological and cultural evolution. Smaller and more numerous local impacts would have profoundly affected local population demographics and behavior. The continued study of the potential effects of past cosmic impacts on contemporaneous local and regional populations is therefore a most worthwhile endeavor.

Acknowledgments We thank Adolfo Gil, Raven Garvey and Gustavo Neme for giving us the opportunity in 2008 to present an earlier version of this paper in their symposium "Middle Holocene Behavioral Strategies in the Americas" at the 73rd Annual Meeting of the Society for American Archaeology in Vancouver, British Columbia, Canada. Peter Schultz shared information regarding Rio Cuarto and provided illustrations. William Cassidy contributed data and suggestions relating to Campo del Cielo, and along with Shawn Wright provided illustrations. Alberto Cione kindly discussed his own differing impressions about the Rio Cuarto event. Juan Bautista Belardi and Michael Masse for made important criticism and fruitful comments on an earlier version of this paper, while Dee Breger, Payson Sheets, Peter Bobrowsky, and particularly Michael Masse performed detailed editorial reviews of the present paper. Ted Bunch provided data and comment regarding temperature values for wildland fires and the general study of impact glass melts. Floyd McCoy reaffirmed our magnitude (megaton) energy release estimate for the Thera volcanic eruption. David Janecky brought our attention to several useful references. Johannes Wilbert kindly provided assistance with the mythology literature reviewed in the earlier Masse and Masse (2007) study. Several anonymous reviewers provided comments on drafts of the paper that helped to shape and focus our arguments. We alone bear responsibility for the final content of the paper.

\section{References}

A'Hearn, M. F. (2006). Whence comets? Science, 314, 1708-1709.

Abbott, D. H., Masse, W. B., Burckle, L., Breger, D., \& Gerard-Little, P. (2007). Burckle abyssal impact crater: Did this impact produce a global deluge? In S. P. Papamarinopoulos (Ed.), The Atlantic hypothesis: Searching for a lost land. Book of Proceedings of the International Conference Atlantis 2005 (pp. 179-190). Santorini: Heliotopos.

Adger, W. N. (2006). Vulnerability. Global Environmental Change, 16, 268-281. 
Álvarez, A. (1926). El meteorito del Chaco. Buenos Aires: Peuser.

Alvarez, L. W., Alvarez, W., Asaro, F., \& Michel, H. V. (1980). Extraterrestrial cause for the CretaceousTertiary extinction. Science, 208, 1095-1108.

Anderson, D. G., Goodyear, A. C., Kennett, D. J., \& West, A. (2011). Multiple lines of evidence for possible human population decline/settlement reorganization during the early Younger Dryas. Quaternary International, 242, 570-583.

Andronikov, A. V., Lauretta, D. S., Andronikova, I. E., \& Maxwell, R. J. (2011). On the possibility of a late Pleistocene extraterrestrial impact: LA-ICP-MS Analysis of the Black Mat and Usselo Horizon Samples. Meteoritics \& Planetary Science, 46(SI, Supplement 1), A11-A11.

Artemieva, N., \& Pierazzo, E. (2009). The Canyon Diablo impact event: projectile motion through the atmosphere. MAPS, 44, 25-42.

Artemieva, N., \& Pierazzo, E. (2011). The Canyon Diablo impact event: 2. projectile fate and target melting upon impact. Meteoritics \& Planetary Science, 46, 805-829.

Asher, D. J. S., Clube, S. V. M., Napier, W. M., \& Steel, D. I. (1994). Coherent catastrophism. Vistas in Astronomy, 38, 1-27.

Asphaug, E. (2009). Growth and evolution of asteroids. Annual Review of Earth and Planetary Sciences, 29, 413-448.

Avena, S. A., Parolin, M. L., Boquet, M., Dejean, C. B., Postillone, M. B., Alvarez Trentini, Y., et al. (2010). Mezcla génica y linajes uniparentales en Esquel (Pcia. de Chubut). Su comparación con otras muestras poblacionales argentinas. Journal of Basic \& Applied Genetics, 21, 1-14.

Bailey, M. (2011). Risk and natural catastrophes: the long view. In L. Skinns, M. Scott, \& T. Cox (Eds.), Risk (pp. 131-158). Cambridge: Cambridge University Press.

Bailey, M. E., Markham, D. J., Massai, S., \& Scriven, J. E. (1995). The 1930 August 13, Brazilian Tunguska event. Observatory, 115, 250-253.

Baillie, M. (1999). Exodus to Arthur: catastrophic encounters with comets. London: Batsford.

Baillie, M. G. L. (2007a). The case for significant numbers of extraterrestrial impacts through the Late Holocene. Journal of Quaternary Science, 22, 101-109.

Baillie, M. G. L. (2007b). Tree-rings indicate global environmental downturns that could have been caused by comet debris. In P. Bobrowsky \& H. Rickmann (Eds.), Comet/asteroid impacts and human society (pp. 105-122). Berlin: Springer.

Barber, E. W., \& Barber, P. T. (2004). When they severed earth from sky: how the human mind shapes myth. Princeton: Princeton University Press.

Barberena, R., Zangrando, A., Gil, A. F., Martínez, G. A., Politis, G. G., Borrero, L. A., \& Neme, G. A. (2009). Guanaco (Lama guanicoe) isotopic ecology in southern South America: spatial and temporal tendencies, and archaeological implications. Journal of Archaeological Science, 36, 26662675.

Barlow, N. G. (2010). What we know about Mars from its impact craters. Geological Society of America Bulletin, 122, 644-657.

Barrientos, G. (1997). Nutrición y dieta de las poblaciones aborígenes prehispánicas del sudeste de la Región Pampeana. Unpublished Doctoral Dissertation. Facultad de Ciencias Naturales y Museo, La Plata, UNLP.

Barrientos, G. (2009). El estudio arqueológico de la continuidad/discontinuidad biocultural: El caso del sudeste de la Región Pampeana. In R. Barberena, K. Borrazzo, \& L. A. Borrero (Eds.), Perspectivas actuales en arqueología argentina (pp. 189-214). Buenos Aires: CONICET-IMHICIHU.

Barrientos, G., \& Perez, S. I. (2002). La dinámica del poblamiento humano del Sudeste de la Región Pampeana durante el Holoceno. Intersecciones en Antropología, 3, 41-54.

Barrientos, G., \& Perez, S. I. (2005). Was there a population replacement during the Late Mid-Holocene in the Southeastern Pampas of Argentina? Archaeological evidence and paleoecological basis. Quaternary International, 132, 95-105.

Barrientos, G., Perez, S. I., Bernal, V., González, P. N., Béguelin, M., \& Del Papa, M. (2005). Changing views about the local evolution of human populations in the Argentine Pampas during the Holocene. In S. R. Zakrzewski \& M. Clegg (Eds.), Proceedings of the Fifth Annual Conference of the British Association for Biological Anthropology and Osteoarchaeology (BAR International Series 1383, pp. 93-104). Oxford: Archaeopress.

Bates, F. (1985). Principles of evidence (3rd ed.). Sydney: The Law Book.

Baxter, J., \& Atkins, T. (1976). The fire came by: the riddle of the great Siberian explosion. New York: Doubleday.

Beer, T. (Ed.). (2010). Geophysical hazards: minimizing risk, maximizing awareness. New York: Springer. 
Belardi, J. B., \& Rindel, D. (2008). Taphonomic and archeological aspects of massive mortality processes in guanaco (Lama guanicoe) caused by winter stress in Southern Patagonia. Quaternary International, $180,38-51$.

Bertini, I. (2011). Main Belt comets: a new class of small bodies in the solar system. Planetary and Space Science, 59, 365-377.

Bierhorst, J. (1988). The mythology of South America. New York: William Morrow.

Binford, L. R. (2001). Constructing frames of reference. An analytical method for archaeological theory building using ethnographic and environmental data sets. Berkeley: University of California Press.

Birks, J. W., Crutzen, P. J., \& Roble, R. J. (2007). Frequent ozone depletion resulting impacts of asteroids and comets. In P. Bobrowsky \& H. Rickmann (Eds.), Comet/asteroid impacts and human society (pp. 225-245). Berlin: Springer.

Bland, P. A., \& Artemieva, N. A. (2003). Efficient disruption of small asteroids by Earth's atmosphere. Nature, 424, 288-291.

Bland, P. A., Souza Filho, C. R., Jull, A. J. T., Kelley, S. P., Hough, R. M., Artemieva, N. A., et al. (2002). A possible tektite strewn field in the Argentinian Pampa. Science, 296, 1109-1111.

Blarasín, M. T., \& Sánchez, M. L. (1987). Secuencia evolutiva de dunas cuaternarias en el sector de Laguna Oscura, dpto. Río Cuarto. Provincia de Córdoba, República Argentina. In Décimo Congreso Geológico Argentino Actas 3 (pp. 297-300). Argentina: San Miguel de Tucumán.

Blong, R. J. (1982). The time of darkness: local legends and volcanic reality in Papua New Guinea. Seattle: University of Washington Press.

Bloom, A. (1992). A non-impact explanation for elongated depressions near Río Cuarto, Córdoba Province, Argentina. Geological Society of America Annual Meeting, Abstracts with Programs (pp. A136A137). Geological Society of America.

Bobrowsky, P., \& Rickman, H. (Eds.). (2007). Comet/asteroid impacts and human society. Berlin: Springer. Bocquet-Appel, J. P., \& Demars, P. Y. (2000). Populational kinetics in Upper Palaeolithic in Western Europe. Journal of Archaeological Science, 27, 551-570.

Bonadonna, F., Leone, G., \& Zanchetta, G. (1995). Composición isotópica de los fósiles de gasterópodos continentales de la provincia de Buenos Aires. Indicaciones paleoclimáticas. In M. T. Alberdi, G. Leone, \& E. Tonni (Eds.), Evolución biológica y climática de la Región Pampeana durante los últimos cinco millones de años. Un ensayo de correlación con el Mediterráneo occidental (pp. 77-104). Madrid: Museo Nacional de Ciencias Naturales, Consejo Superior de Investigaciones Científicas.

Borrero, L. A. (2001). Regional taphonomy: background noise and the integrity of the archaeological record. In L. A. Kuznar (Ed.), Ethnoarchaeology of Andean South America. Contributions to archaeological method and theory (pp. 214-254). Ann Arbor: International Monographs in Prehistory Ethnoarchaeological Series 4.

Boslough, M. B. (2010). Younger Dryas boundary (YDB) impact; Physical and statistical impossibility. Geological Society of America Annual Meeting, Abstracts with Programs, 42(5), 172.

Boslough, M. B. E., \& Crawford, D. A. (2008). Low-altitude airbursts and the impact threat. International Journal of Impact Engineering, 35, 1441-1448.

Bottke, W. F., Jr. (2007). Understanding the near-Earth object population: the 2004 perspective. In P. Bobrowsky \& H. Rickmann (Eds.), Comet/asteroid impacts and human society (pp. 175-187). Berlin: Springer.

Bottke, W. F., Jr., Cellino, F., Paolicchi, P., \& Binzel, R. P. (Eds.). (2002). Asteroids III. Tucson: University of Arizona Press.

Bottke, W. F., Vokrouhlický, D., \& Nesvorný, D. (2009). An asteroid breakup 160 Myr ago as the probable source of the K/T impactor. Nature, 449, 48-53.

Bourgeois, J., \& Weiss, R. (2009). "Chevrons" are not mega-tsunami deposits - a sedimentologic assessment. Geology, 37, 403-406.

Bradtmöller, M., Pastoors, A., Weninger, B., \& Weniger, G. (2012). The repeated replacement model—rapid climatic change and population dynamics in late Pleistocene Europe. Quaternary International, 247, 38-49.

Broecker, W. S., Denton, G. H., Edwards, R. L., Cheng, H., Alley, R. B., \& Putnam, A. E. (2010). Putting the Younger Dryas cold event into context. Quaternary Science Reviews, 29, 1078-1081.

Bryant, E. (2004). Natural Hazards (2nd ed.). Camridge: Cambridge University Press.

Bryant, E. (2008). Tsunami: the underrated hazard (2nd ed.). New York: Springer.

Buchanan, B., Collard, M., \& Edinborough, K. (2008). Paleoindian demography and the extraterrestrial impact hypothesis. Proceedings of the National Academy of Sciences of the United States of America, 105, 11651-11654.

Buchanan, B., Hamilton, M., Edinborough, K., O’Brien, M. J., \& Collard, M. (2011). A comment on Steele's (2010) "Radiocarbon dates as data: quantitative strategies for estimating colonization front speeds and event densities". Journal of Archaeological Science, 38, 2116-2122. 
Bunch, T. E., Hermes, R. E., Moore, A. M. T., Kennett, D. J., Weaver, J. C., Wittke, J. H., et al. (2012). Very high-temperature impact melt products as evidence for cosmic airbursts and impacts 12,900 years ago. Proceedings of the National Academy of Sciences of the United States of America. Published online before print June 18, 2012, doi:10.1073/pnas.1204453109.

Byers, D. A., \& Broughton, J. M. (2004). Holocene environmental change, artiodactyl abundances, and human hunting strategies in the Great Basin. American Antiquity, 69, 235-256.

Cabrera, A., \& Yepes, J. (1960). Mamíferos sudamericanos. Buenos Aires: Ediar. Cajal, J. L., \& Ojeda, R. A. (1994). Camélidos silvestres y mortalidad por tormentas de nieve en la cordillera frontal de la Provincia de San Juan, Argentina. Mastozoología Neotropical, 1, 81-88.

Cajal, J. L., \& Ojeda, R. A. (1994). Camélidos silvestres y mortalidad por tormentas de nieve en la cordillera frontal de la Provincia de San Juan, Argentina. Mastozoología Neotropical, 1, 81-88.

Cantú, M. P., \& Degiovanni, S. B. (1984). Geomorfología de la región centro sur de la provincial de Córdoba. In Noveno Congreso Geológico Argentino, Actas 4 (pp. 76-92). San Carlos de Bariloche.

Carlini, A. A., \& Tonni, E. P. (2000). Mamíferos fósiles del Paraguay. La Plata: Artes Gráficas San Miguel.

Cashman, K. V., \& Giordano, G. (Eds.) (2008). Volcanoes and human history. Journal of Volcanology and Geothermal Research, 176, 325-438.

Cassidy, W. A. (2003). Meteorites, ice, and Antarctica: a personal account. Cambridge: Cambridge University Press.

Cassidy, W. A., \& Renard, M. L. (1996). Discovering research value in the Campo del Cielo, Argentina, meteorite craters. Meteoritics \& Planetary Science, 31, 433-448.

Cassidy, W. A., Villar, L. M., Bunch, T. E., Kohman, T. P., \& Milton, D. J. (1965). Meteorites and craters of Campo del Cielo, Argentina. Science, 149, 1055-1064.

Chaisson, E., \& McMillan, S. (2011). Astronomy today (7th ed.). San Francisco: Pearson AddisonWesley.

Chamberlain, A. T. (2006). Demography in archaeology. Cambridge: Cambridge University Press.

Chapman, C. R. (2008). Meteoroids, meteors, and the near-Earth object impact hazard. Earth, Moon, and Planets, 102, 417-424.

Chapman, C. R. (2011). What will happen when the next asteroid strikes? Astronomy, 39(5), 30-35.

Chapman, C. R., \& Morrison, D. (1994). Impacts on the Earth by asteroids and comets: assessing the hazard. Nature, 367, 33-40.

Chatterjee, S. (1997). Multiple impacts at the KT boundary and the death of the dinosaurs. 30th International Geological Congress, 26, 31-54.

Chatterjee, S., \& Rudra, D. K. (2008). Shiva impact event and its implications for Deccan Volcanism and Dinosaur. Extinction. Palaeobotanist, 57, 235-250.

Chesley, S. R., \& Ward, S. N. (2006). A quantitative assessment of the human and economic hazard from impact-generated tsunamis. Natural Hazards, 38, 355-374.

Cione, A. L., Tonni, E. P., San Cristóbal, J., Hernández, P. J., Benítez, A., Bordignon, F., \& Perí, J. A. (2002). Putative meteoritic craters in Río Cuarto (Central Argentina) interpreted as eolian structures. Earth Moon Planets, 91, 9-24.

Cleland, C. E. (2002). Methodological and epistemic differences between historical science and experimental science. Philosophy of Science, 69, 474-496.

Clube, V., \& Napier, B. (1982). The cosmic serpent. New York: Universe Books.

Clube, V., \& Napier, B. (1990). The cosmic winter. Cambridge, MA: Basil Blackwell.

Collard, M., Buchanan, M., Hamilton, M. J., \& O’Brien, M. J. (2010). Spatiotemporal dynamics of the Clovis-Folsom transition. Journal of Archaeological Science, 37, 2513-2519.

Collins, G. S., Artemieva, N., Wünnemann, K., Bland, P. A., Reimold, W. U., \& Koeberl, C. (2008). Evidence that Lake Cheko is not an impact crater. Terra Nova, 20, 165-168.

Collins, G. S., Melosh, H. J., \& Marcus, R. A. (2005). Earth Impact Effects Program: a web-based computer program for calculating the regional consequences of a meteoroid impact on Earth. Meteoritics and Planetary Science, 40, 817-840.

Collins, G. S., Melosh, H. J., \& Osinski, G. R. (2012). The impact-cratering process. Elements, 8, 25-30.

Courty, M. A. (1998). The soil record of an exceptional event at 4000 BP in the Middle East. In J. Peiser, T. Palmer, \& M. E. Bailey (Eds.), Natural catastrophes during Bronze Age civilizations: archaeological, geological, astronomical, and cultural perspectives (BAR International Series 728, pp. 93-108). Oxford: Archaeopress.

Courty, M. A. (2001). Evidence at Tell Brak for the Late EDIII/Early Akkadian Air Blast Event (4 kyr BP). In D. Oates, J. Oates, \& H. McDonald (Eds.), Excavation at Tell Brak. Vol. 2: Nagar in the Third Millennium BC (Vol. 2, pp. 367-372). London: McDonald Institute for Archaeology/British School of Archaeology in Iraq. 
Courty, M. A., Crisci, A., Fedoroff, M., Grice, K., Greenwood, P., Mermoux, M., et al. (2008). Regional manifestation of the widespread disruption of soil-landscapes by the $4 \mathrm{kyr}$ BP impact-linked dust event using pedo-sedimentary micro-fabrics. In S. Kapur, A. Mermut, \& G. Stoops (Eds.), New trends in soil micromorphology (pp. 211-236). Berlin: Springer.

Daniels, P. (2009). The new solar system: ice worlds, moons, and planets redefined. Washington, D.C.: National Geographic.

De Pater, I., \& Lissauer, J. J. (2010). Planetary sciences (2nd ed.). Cambridge: Cambridge University Press. de Silva, S. L., \& Francis, P. W. (1991). Volcanoes of the Central Andes. New York: Springer.

del Moral, R., \& Grishin, S. Y. (1999). The consequences of volcanic eruptions. In L. R. Walker (Ed.), Ecosystems of disturbed ground (pp. 137-160). Amsterdam: Elsevier Science.

Deloria, V., Jr. (1995). Red Earth, White Lies: Native Americans and the myth of scientific fact. New York: Scribner.

Dinerstein, E., Olson, D. M., Graham, D. J., Webster, A. L., Primm, S. A., Bookbinder, M. P., \& Ledec, G. (1995). A conservation assessment of the terrestrial ecoregions of Latin America and the Caribbean. Washington, D.C.: The World Bank.

Douglass, D. C., Singer, B. S., Kaplan, M. R., Ackert, R. P., Mickelson, D. M., \& Cafee, M. W. (2005). Evidence of early Holocene glacial advances in southern South America from cosmogenic surfaceexposure dating. Geology, 33, 237-240.

Duncan, M. J., \& Levision, H. F. (1997). A disk of scattered icy objects and the origin of Jupiter-family comets. Science, 276, 1670-1672.

Durda, D. D., \& Kring, D. A. (2004). Ignition threshold for impact-generated fires. Journal of Geophysical Research, 109, 1-14.

Dypvik, H., Burchell, M., \& Claeys, P. (Eds.). (2004). Cratering in marine environments and on ice. Berlin: Springer.

Echaurren, J. C. (2007). Numerical estimations for impact conditions on Campo del Cielo, crater field, South America. Meteoritics \& Planetary Science, 42, 5003.

Echo-Hawk, R. C. (2000). Ancient history in the New World: integrating oral traditions and the archaeological record. American Antiquity, 65, 267-290.

Ernstson, K., Mayer, W., Neumair, A., Rappenglück, B., Rappenglück, M. A., Sudhaus, D., \& Zeller, K. W. (2010). The Chiemgau crater strewn field: evidence of a Holocene large impact event in southeast Bavaria, Germany. Journal of Siberian Federal University, Engineering and Technologies, 1, 72-103.

Fairbanks, R. G., Mortlock, R. A., Chiu, T., Cao, L., Kaplan, A., Guilderson, T. P., et al. (2005). Radiocarbon calibration curve spanning 10,000 to 50,000 years BP based on paired ${ }^{230} \mathrm{Th} /{ }^{234} \mathrm{U} /{ }^{238} \mathrm{U}$ and ${ }^{14} \mathrm{C}$ Dates on pristine Corals. Quaternary Science Reviews, 25, 1781-1796.

Farley, K. A. (2009). Late Eocene and late Miocene cosmic dust events: comet showers, asteroid collisions, or lunar impacts? Geological Society of America Special Papers, 452, 27-35.

Fayek, M., Anovitz, L. M., Allard, L. F., \& Hull, S. (2012). Framboidal iron oxide: chondrite-like material from the black mat, Murray Springs, Arizona. Earth and Planetary Science Letters, 319-320, 251258.

Figueiro, G., \& Sans, M. (2011). El ADN mitocondrial de Laguna Tres Reyes 1 y el contexto genético del Cono Sur. In M. F. Cesani Comp (Ed.), Libro de resúmenes de las X Jornadas Nacionales de Antropología Biológica (p. 26). City Bell: Asociación de Antropología Biológica Argentina.

Firestone, R. B., West, A., Kennett, J. P., Becker, L., Bunch, T. E., Revay, Z. S., et al. (2007). Evidence for an extraterrestrial impact 12,900 years ago that contributed to the megafaunal extinctions and the Younger Dryas cooling. Proceedings of the National Academy of Sciences, 104, 16016-16021.

Fitzhugh, B. (2012). Hazards, impacts, and resilience among hunter-gatherers of the Kuril Islands. In J. Cooper \& P. Sheets (Eds.), Surviving sudden environmental change. Answers from archaeology (pp. 19-42). Boulder: University Press of Colorado.

Folco, L., Perchiazzi, N., D’Orazio, M., Frezzotti, M. L., Glass, B. P., \& Rochette, P. (2010). Shocked quartz and other mineral inclusions in Australasian microtektites. Geology, 38, 211-214.

Folke, C., Carpenter, S. R., Elmqvist, T., Gunderson, L., Holling, C. S., \& Walker, S. B. (2002). Resilience and sustainable development: building adaptive capacity in a world of transformations. Ambio, 31, $437-440$.

Folke, C., Carpenter, S., Walker, S. B., Scheffer, M., Elmqvist, T., Gunderson, L., \& Holling, C. S. (2004). Regime shifts, resilience, and biodiversity in ecosystem management. Annual Review of Ecology, Evolution, and Systematics, 35, 557-581.

Fowler, M. E. (1989). Medicine and surgery of South American camelids: llama, alpaca, vicuña, guanaco. Ames: Iowa State University Press. 
French, B. M. (1998). Traces of catastrophe. A handbook of shock-metamorphic effects in terrestrial meteorite impact structures. Lunar and Planetary Institute, Contribution No. 954. Houston: Texas. http://www.lpi.usra.edu/publications/books/CB-954/CB-954.intro.html.

French, B. M., \& Koeberl, C. (2010). The convincing identification of terrestrial meteorite impact structures: what works, what doesn't, and why. Earth-Science Reviews, 98, 123-170.

Friend, T. (2011). Vermin of the sky. The New Yorker, February 28, 2011, 22.

Fujiwara, A., Kawaguchi, J., Yeomans, D. K., Abe, M., Mukai, T., Okada, T., et al. (2006). The rubble-pile asteroid Itokawa as observed by Hayabusa. Science, 312, 1330-1334.

Gad-el-Hak, M. (2008). The art and science of large-scale disasters. In M. Gad-el-Hak (Ed.), Large-scale disasters: prediction, control, and mitigation (pp. 5-68). Cambridge: Cambridge University Press.

Gallant, R. A. (2002). Meteorite hunter: the search for Siberian meteorite craters. New York: McGraw-Hill.

Gamble, C., Davies, W., Pettitt, P., \& Richards, M. (2004). Climate change and evolving human diversity in Europe during the last glacial. Philosophical Transactions of the Royal Society of London B, 359, 243254.

Garvey, R. (2008). A behavioural ecological approach to a proposed Middle Holocene occupational gap. Before Farming 2008/2, Article 2.

Gasperini, L., Alvisi, F., Biasini, G., Bonatti, E., Longo, G., Pipan, M., et al. (2007). A possible impact crater for the 1908 Tunguska Event. Terra Nova, 19, 245-251.

Gault, D. E., Quaide, W. L., \& Oberbeck, V. R. (1968). Impact cratering mechanics and structures. In B. M. French \& N. M. Short (Eds.), Shock metamorphism of natural materials (pp. 87-100). San Francisco: Mono.

Gehrels, T. (Ed.). (1994). Hazards due to comets \& asteroids. Tucson: University of Arizona Press.

Gil, A. (2005). Arqueología de La Payunia (Mendoza, Argentina) (BAR International Series 1477). Oxford: Archaeopress.

Gil, A., Zárate, M., \& Neme, G. (2005). Mid-Holocene paleoenvironments and the archeological record of southern Mendoza, Argentina. Quaternary International, 132, 81-94.

Giménez Benítez, S. R., López, A. M., \& Mammana, L. A. (2000). Meteorites of Campo del Cielo: impact on the Indian Culture. In C. Esteban \& J. A. Belmonte (Eds.), Oxford VI and SEAC 99: astronomy and cultural diversity (pp. 335-34). Tenerife: Organismo Autónomo de Museos del Cabildo de Tenerife.

Gisler, G., Weaver, R., \& Gittings, M. (2011). Calculations of asteroid impacts into deep and shallow water. Pure and Applied Geophysics, 168, 1187-1198.

Gkiasta, M., Russell, T., Shennan, S., \& Steele, S. (2003). Neolithic transition in Europe: the radiocarbon dates revisited. Antiquity, 77, 45-66.

Gladman, B., Michel, P., \& Froeschlé. (2000). The near-Earth object population. Icarus, 146, 176-189.

Glass, B. P., Hubrt, H., \& Koeberl, C. (2004). Geochemistry of Cenozoic microtektites and clinopyroxenebearing spherules. Geochimica et Cosmochimica Acta, 68, 3971-4006.

Glass, B. P., \& Koeberl, C. (2006). Australasian microtektites and associated impact ejecta in the South China Sea and the Middle Pleistocene supereruption of Toba. Meteoritics and Planetary Science, 41, 305-326.

González, B. A., Palma, R. E., Zapata, B., \& Marín, J. C. (2006). Taxonomic and biogeographical status of guanaco Lama guanicoe (Artiodactyla, Camelidae). Mammal Review, 36, 157-178.

Gould, R. A. (Ed.). (2007). Disaster archaeology. Salt Lake City: University of Utah Press.

Grayson, D. K. (2000). Mammalian responses to Middle Holocene climatic change in the Great Basin of the western United Status. Journal of Biogeography, 27, 181-192.

Grün, E., Gustafson, B. A. S., Dermott, S. F., \& Fechtig, H. (Eds.). (2001). Interplanetary dust. Berlin: Springer.

Gusiakov, V. K. (2007). Tsunami as a destructive aftermath of oceanic impacts. In P. Bobrowsky \& H. Rickmann (Eds.), Comet/asteroid impacts and human society (pp. 247-263). Berlin: Springer.

Gusiakov, V. K. (2012). Expert database on Earth impact structures. http://tsun.sscc.ru/nh/edeis.html. Accessed January 10, 2012.

Gusiakov, V. K., Abbott, D. H., Bryant, E. A., Masse, W. B., \& Breger, D. (2010). Megatsunami of the World oceans: chevron dune formation, micro-ejecta, and rapid climate change as the evidence of recent oceanic bolide impacts. In T. Beer (Ed.), Geophysical hazards: minimizing risk, maximizing awareness (pp. 197-227). Berlin: Springer.

Gutiérrez, M., \& Martínez, G. (2008). Trends in the faunal human exploitation during the late Pleistocene and early Holocene in the Pampean region (Argentina). Quaternary International, 191, 53-68.

Hamacher, D. W., \& Norris, R. P. (2009). Australian Aboriginal geomythology: eyewitness accounts of cosmic impacts? Archaeoastronomy, 22, 60-93.

Hamilton, M. J., \& Buchanan, B. (2007). Spatial gradients in Clovis-age radiocarbon dates across North America suggest rapid colonization from the north. Proceedings of the National Academy of Sciences, 104, 15625-15630. 
Harris, R. S., \& Schultz, P. H. (2007). The record of Late Cenozoic impacts in the Argentine Pampas: consequences of hypervelocity collisions into soft sedimentary target. Geological Society of America Annual Meeting, Abstracts with Programs, 39(6), 371.

Harris, R. S., Schultz, P. H., Tancredi, G., \& Ishitsuka, J. (2008a). Preliminary petrologic analysis of impact deformation in the Carancas (Peru) cratering event. $39^{\text {th }}$ Lunar and Planetary Science Conference, extended abstract no. 2446.

Harris, R. S., Schultz, P. H., Tancredi, G., \& Ishitsuka, J. (2008b). Petrology of ejecta from the Carancas (Peru) crater: insights into the dynamics of an unusual impact event. Asteroids, Comets, and Meteorites 2008. Lunar Planetary Sciences Institute, Abstract 8302.

Harris, R. S., Schultz, P. H., \& Zarate, M. (2007). La Dulce Crater: evidence for a $2.8 \mathrm{~km}$ impact structure in the eastern pampas of Argentina. 38th Annual Lunar and Planetary Science Conference, extended abstract no. 2243 .

Hartmann, W. K., \& Miller, R. (2005). The grand tour: a traveler's guide to the Solar System. New York: Workman.

Haynes, C. V., Jr., Boerner, J., Domanik, K., Lauretta, D., Ballenger, J., \& Goreva, J. (2010). The Murray Springs Clovis site, Pleistocene extinction, and the question of extraterrestrial impact. Proceedings of the National Academy of Sciences of the United States of America, 107, 40104015 .

Higgins, M. D., Lajeunesse, P., St-Onge, P., Locat, J., Duchesne, M., Ortiz, J., et al. (2011). Bathymetric and petrological evidence for a young (Pleistocene?) 4-km diameter impact crater in the Gulf of Saint Lawrence, Canada. $42^{\text {nd }}$ Lunar and Planetary Science Conference, abstract no. 1504.

Hildebrand, A. R., Penfield, G. T., Kring, D. A., Pilkington, M., Zanoguera, A. C., Jacobsen, S. B., \& Boynton, W. B. (1991). Chicxulub Crater: a possible Cretaceous/Tertiary boundary impact crater on the Yucatan Peninsula, Mexico. Geology, 19, 867-871.

Hiscock, P. (1985). The need for a taphonomic perspective in stone artefact analysis. Queensland Archaeological Research, 2, 82-95.

Hodge, P. (1994). Meteorite craters and impact structures of the Earth. Cambridge: Cambridge University Press.

Hoffman, S. M., \& Oliver-Smith, A. (Eds.). (2002). Catastrophe \& culture: the anthropology of disaster. Santa Fe: School of American Research Press.

Holliday, V. T., \& Meltzer, D. J. (2010). The 12.9-ka ET impact hypothesis and North American Paleoindians. Current Anthropology, 51, 575-607.

NASA Home (2012). Asteroid nudged by sunlight: Most precise measurement of the Yarkovsky effect. http://www.nasa.gov/topics/universe/features/yarkosky-asteroid.html. Accessed June 5, 2012.

Housley, R. A., Gamble, C. S., Street, M., \& Pettitt, P. B. (1997). Radiocarbon evidence for the Lateglacial human recolonisation of Northern Europe. Proceedings of the Prehistoric Society, 63, 25-54.

Hsieh, H. H., \& Jewitt, D. (2006). A population of comets in the Main Asteroid Belt. Science, 214, 561563.

Hughen, K. A., Southon, J. R., Lehman, S. J., \& Overpeck, J. T. (2000). Synchronous radiocarbon and climate shift during the last deglaciation. Science, 290, 1951-1954.

Ide, S., Baltay, A., \& Beroza, G. C. (2011). Shallow dynamic overshoot and energetic deep rupture in the $2011 M_{\mathrm{w}} 9.0$ Tohoku-Oki Earthquake. Science, 332, 1426-1529.

Ingram, G. (1992). Preliminary report on heat stress in working llamas-1991. http://home.att.net/ lost creekllamas/tempstudyone.html. Accessed 3 January, 2008.

Iriondo, M. H. (1997). Models of deposition of loess and loessoids in the Upper Quaternary of South America. Journal of South American Earth Sciences, 10, 71-79.

Iriondo, M. H. (1999). Climatic change in the South American plains: records of a continental-scale oscillation. Quaternary International, 57-58, 93-112.

Iriondo, M. H. (2006). A comment on volume 132 of Quaternary International. Quaternary International, 142-143, 247-248.

Israde-Alcántara, I., Bischoff, J. L., Dominguez-Vázquez, G., Li, H.-C., DeCarli, P. S., Bunch, T. E., et al. (2012). Evidence from central Mexico supporting the Younger Dryas extraterrestrial impact hypothesis. Proceedings of the National Academy of Sciences, 109(13)], E738-E747; published ahead of print March 5, 2012, doi:10.1073/pnas.1110614109.

Jenniskens, P. (2006). Meteor showers and their parent comets. Cambridge: Cambridge University Press. Jones, S. C. (2010). Palaeoenvironmental response to the $\sim 74 \mathrm{ka}$ Toba ash-fall in the Jurreru and middle Son valleys in southern and north-central India. Quaternary Research, 73, 336-350.

Jones, T. P. (2002). Reply "Extraterrestrial impacts and wildfires." Palaeogeography, Palaeoclimatology, Palaeoecology, 185, 407-408. 
Jones, T. P., \& Lim, B. (2000). Extraterrestrial impacts and wildfires. Palaeogeography, Palaeoclimatology, Palaeoecology, 164, 57-66.

Jourdan, F., Moynier, F., Koeberl, C., \& Eroglu, S. (2011). ${ }^{40} \mathrm{AR} /{ }^{39} \mathrm{AR}$ age of the Lonar crater and consequence for the geochronology of planetary impacts. Geology, 39, 671-674.

Jourdan, F., \& Reimold, W. U. (2012). Impact!-bolides, craters, and catastrophes. Elements, 8, 19-24.

Jourdan, F., Reimold, W. U., \& Deutsch, A. (2012). Dating terrestrial impact structures. Elements, 8, 49-53.

Karner, D. B., Levine, J., Muller, R. A., Asaro, F., Ram, M., \& Stolz, M. R. (2003). Extraterrestial accretion from the GISP2 ice core. Geochemica et Cosmochimica Acta, 67, 751-763.

Karttunen, H., Kröger, P., Oja, H., Poutanen, M., \& Donner, K. J. (Eds.). (2007). Fundamental astronomy (5th ed.). Berlin: Springer.

Kasperson, J. X., Kasperson, R. E., Turner, B. L., II, Hsieh, W., \& Schiller, A. (2005). Vulnerability to global environmental change. In J. X. Kasperson \& R. E. Kasperson (Eds.), The social contours of risk: risk analysis, corporations \& the globalization of risk (pp. 245-285). Sterling, VA: Earthscan.

Kay, C. E. (1998). Are ecosystems structured from the top-down or bottom-up: a new look at an old debate. Wildlife Society Bulletin, 26, 484-498.

Kenkmann, T., Artemieva, N. A., Wünnemann, K., Poelchau, M. H., Elbeshhausen, D., \& Núñez del Prado, H. (2009). The Carancas meteorite impact crater, Peru: geologic surveying and modeling of crater formation and atmospheric passage. Meteoritics \& Planetary Science, 44, 985-1000.

Kennett, D. J. (2010). Comment on "The 12.9 ka ET impact hypothesis and North American Paleoindians," by V. T. Holliday and D. J. Meltzer. Current Anthropology, 51, 591-592.

Kennett, J. P. (2011). Younger Dryas onset marked by dramatic environmental and biotic change. 2011 Meeting of the International Union for Quaternary Research, Bern, Switzerland Abstract Details http:/www.inqua2011.ch/?a=programme\&subnavi=abstract\&id=1666\&sessionid=60. Accessed December 17, 2011.

Kennett, D. J., Kennett, J. P., West, A., Mercer, C., Que Hee, S. S., Bement, L., et al. (2009). Nanodiamonds in the Younger Dryas boundary sediment layer. Science, 323, 94.

Kennett, J. P., \& Teller, J. T. (Conveners) (2011). Session 60 "The enigmatic Younger Dryas climatic episode," 2011 Meeting of the International Union for Quaternary Research, Bern, Switzerland. http:// www.inqua2011.ch/?a=programme\&subnavi=abstractlist. Accessed November 25, 2011.

Kerr, R. A. (2008). Experts find no evidence for a mammoth-killer impact. Science, 319, 1331-1332.

Kerr, R. A. (2010). Mammoth-killer impact flunks out. Science, 329, 1140-1141.

Koeberl, C. (1994). Tektite origin by hypervelocity asteroidal or cometary impact: target rocks, source craters, and mechanisms. In B. O. Dessler, R. A. F. Grieve, \& V. L. Sharpton (Eds.), Large impact structures and planetary evolution (pp. 133-152). Boulder: Geological Society of America Special Paper 293.

Koeberl, C., Brandstätter, F., Glass, B. P., Hecht, L., Mader, D., \& Reimold, W. U. (2007). Uppermost impact fallback layer in the Bosumtwi crater (Ghana): mineralogy, geochemistry, and comparison with Ivory Coast tektites. Meteoritics \& Planetary Science, 42, 709-729.

Koessler-Ilg, B. (2000). Cuentan los araucanos. Mitos, leyendas y tradiciones (5th ed.). Buenos Aires: Del Nuevo Extremo.

Kolesnikov, E. M., Rasmussen, K. L., Hou, Q., Xie, L., \& Kolesnikova, N. V. (2007). Nature of the Tunguska impactor based on peat material from the explosion area. In P. Bobrowsky \& H. Rickman (Eds.), Comet/asteroid impacts and human society (pp. 291-301). Berlin: Springer.

Kring, D. A. (1997). Air blast produced by the Meteor Crater impact event and a reconstruction of the affected environment. Meteoritics \& Planetary Science, 32, 517-530.

Kring, D. A. (2000). Impact events and their effect on the origin, evolution, and distribution of life. GSA Today, 10(8), 1-7.

Kring, D. A. (2007). Guidebook to the geology of Barringer Meteorite Crater Arizona (a.k.a. Meteor Crater). Houston: Lunar and Planetary Institute. Contribution No. 1355.

Krinov, Y. L. (1966). Giant meteorites. New York: Pergamon.

Krinov, E. L. (1971). New studies of the Sikhote-Alin iron meteorite shower. Meteoritics, 6, 127-138.

Kromer, B., Friedrich, M., Hughen, K. A., Kaiser, F., Remmele, S., Schaub, M., \& Talamo, S. (2004). Late Glacial ${ }^{14} \mathrm{C}$-ages from a floating, 1270-ring pine chronology. Radiocarbon, 46, 12031209.

Krot, A. N. (2011). Planetary science: bringing part ofanasteroidbackhome. Science, 333, 1098-1099.

Kurbatov, A. V., Mayewski, P. A., Steffensen, J. P., West, A., Kennett, D. J., Kennett, J. P., et al. (2010). Discovery of a nonodiamond-rich layer in the Greenland ice sheet. Journal of Glaciology, 56(199), 749-759. 
L'Heureux, G. L. (2008). El estudio arqueológico del proceso coevolutivo entre las poblaciones humanas y las poblaciones de guanaco en Patagonia Meridional y Norte de Tierra del Fuego. BAR International Series 1751. Oxford: Archaeopress.

Langbroek, M., \& Roebroeks, W. (2000). Extraterrestrial evidence on the age of hominids from Java. Journal of Human Evolution, 38, 595-600.

Le Pichon, A., Antier, K., Cansi, Y., Hernandez, B., Minaya, E., Burgoa, B., et al. (2008). Evidence for a meteoritic origin of the September 15, 2007, Carancas crater. Meteoritics \& Planetary Science, 43, 1797-1809.

Leary, N., \& Beresford, S. (2009). Vulnerability of people, places and systems to environmental change. In G. Knight \& J. Jaeger (Eds.), Integrated regional assessment of global climate change (pp. 117-149). Cambridge: Cambridge University Press.

Levi-Strauss, C. (1969). The raw and the cooked. New York: Harper \& Row.

Levi-Strauss, C. (1973). From honey to ashes. New York: Harper \& Row.

Lewis, J. S. (1996). Rain of iron and ice: the very real threat of comet and asteroid bombardment. New York: Addison Wesley.

Li, J.-Y., Kuchner, M. J., Allen, R. J., \& Sheppard, S. S. (2011). Measuring the sizes, shapes, surface features and rotations of Solar System objects with interferometry. Icarus, 211, 1007-1021.

Liberman, R. G., Niello, F., di Tada, M. L., Fifield, L. K., Masarik, J., \& Reedy, R. C. (2002). Campo del Cielo iron meteorite: sample shielding and meteoroid's preatmospheric size. Meteoritics \& Planetary Science, 37, 295-300.

Littleton, J., \& Allen, H. (2007). Hunter-gatherer burials and the creation of persistent places in southeastern Australia. Journal of Anthropological Archaeology, 26, 283-298.

Longo, G. (2007). The Tunguska event. In P. Bobrowsky \& H. Rickman (Eds.), Comet/asteroid impacts and human society (pp. 303-330). Berlin: Springer.

Loponte, D. (1996-1998). Arqueología, etnohistoria y estado sanitario de L. guanicoe (Mammalia, Artiodactyla, Camelidae) en la Pampa Ondulada. Palimpsesto, 5, 41-65.

Loponte, D. (2008). Arqueología del humedal del Paraná inferior (Bajíos Ribereños Meridionales). Series monográficas “Arqueología de la Cuenca del Plata.". Buenos Aires: Instituto Nacional de Antropología y Pensamiento Latinoamericano.

Louderback, L. A., Grayson, D. K., \& Llobera, M. (2011). Middle-Holocene climates and human population densities in the Great Basin, western USA. The Holocene, 21, 366-373.

Lyman, R. L. (1994). Vertebrate taphonomy. Cambridge: Cambridge University Press.

Ma, P., Aggrey, K., Tonzola, C., Schnabel, C., de Nicola, P., Herzog, G. F., et al. (2004). Beryllium10 in Australasian tektites: constraints on the location of the source crater. Geochimica et Cosmochimica Acta, 68, 3883-3896.

MacCraken, M. C. (2007). The climatic effects of asteroid and comet impacts: consequences for an increasingly interconnected society. In P. Bobrowsky \& H. Rickman (Eds.), Comet/asteroid impacts and human society (pp. 277-289). Berlin: Springer.

MacDonagh, E. J. (1949). Los guanacos de Curámalal. Notas del Museo de la Plata, Zoología, 14, 505537.

Mahaney, W. C., Krinsley, D., Langworthy, K., Kalm, V., Havics, T., Hart, K. M., et al. (2011). Fired glaciofluvial sediment in the northwestern Andes: biotic aspects of the Black Mat. Sedimentary Geology, 237, 73-83.

Mainzer, A., Grav, T., Bauer, J., Masiero, J., McMillan, R. S., Cutri, R. M., et al. (2011). NEOWISE observations of near-Earth objects: preliminary results. The Astrophysical Journal, 743, 156172.

Mancini, M. V., Paez, M. M., Prieto, A. R., Stutz, S., Tonillo, M., \& Vilanova, I. (2005). Mid-Holocene climatic variability reconstruction from pollen records $\left(32^{\circ}-52^{\circ} \mathrm{S}\right.$, Argentina). Quaternary International, 132, 47-59.

Marcus, R., Melosh, H. J., \& Collins, G. (2010). Earth impact effects program. http://impact.ese.ic.ac.uk/ ImpactEffects/. Accessed 5 January, 2012.

Mark, K. (1987). Meteorite craters. Tucson: University of Arizona Press.

Marlon, J. R., Bartlein, P. J., Walsh, M. K., Harrison, S. P., Brown, K. J., Edwards, M. E., et al. (2009). Wildfire responses to abrupt climate change in North America. Proceedings of the National Academy of Sciences, 106, 2519-2524.

Martínez, G. A., \& Gutiérrez, M. A. (2004). Tendencias en la explotación humana de la fauna durante el Pleistoceno final-Holoceno en la Región Pampeana (Argentina). In G. L. Mengoni Goñalons (Ed.), Zooarchaeology of South America (BAR, International Series 1298, pp. 81-98). Oxford: Archaeopress. 
Marvin, U. B. (2006). Meteorites in history: an overview from the Renaissance to the $20^{\text {th }}$ century. In G. J. H. McCall, A. J. Bowden, \& R. J. Howarth (Eds.), The history of meteoritics and key meteorite collections; Fireballs, falls and finds (pp. 15-71). London: Geological Society of London Special Publication 256.

Mason, B. G., Pyle, D. M., \& Oppenheimer, C. (2004). The size and frequency of the largest explosive eruptions on Earth. Bulletin of Volcanology, 66, 735-748.

Masse, W. B. (1995). The celestial basis of civilization. Vistas in Astronomy, 39, 463-477.

Masse, W. B. (1998). Earth, air, fire, \& water: the archaeology of Bronze Age cosmic catastrophes. In B. J. Peiser, T. Palmer, \& M. E. Bailey (Eds.), Natural catastrophes during Bronze Age civilisations: archaeological, geological, astronomical, and cultural perspectives (BAR International Series 728, pp. 53-92). Oxford: Archaeopress.

Masse, W. B. (2007). The archaeology and anthropology of Quaternary period cosmic impact. In P. Bobrowsky \& H. Rickman (Eds.), Comet/asteroid impacts and human society (pp. 25-70). Berlin: Springer.

Masse, W. B. (2012). The celestial engine at the heart of traditional Hawaiian culture. In M. A. Rappenglück, B. Rappenglück, \& N. Campion (Eds.), Astronomy and power: how worlds are structured (BAR International Series). Oxford: Archaeopress. In press.

Masse, W. B., Barber, E. W., Piccardi, L., \& Barber, P. T. (2007). Exploring the nature of myth and its role in science. In L. Piccardi \& W. B. Masse (Eds.), Myth and geology (pp. 9-28). London: Geological Society of London Special Publication 273.

Masse, W. B., Carter, L. A., \& Somers, G. F. (1991). Waha'ula heiau: the symbolic and regional context of Hawai'i Island's 'Red Mouth' temple. Asian Perspectives, 30, 19-56.

Masse, W. B., Forte, M., Janecky, D. R., \& Barrientos, G. (2010). Virtual impact: visualizing the potential effects of cosmic impact in human history. In M. Forte (Ed.), Cyber-archaeology (BAR International Series 2177, pp. 31-45). Oxford: Archaeopress.

Masse, W. B., \& Masse, M. J. (2007). Myth and catastrophic reality: using myths to identify cosmic impacts and massive Plinian eruptions in Holocene South America. In L. Piccardi \& W. B. Masse (Eds.), Myth and geology (pp. 177-202). London: Geological Society of London Special Publication 273.

Mayr, E. (1997). This is biology: the science of the living world. Cambridge: Mass. Belknap Press of Harvard University Press.

McCafferty, P., \& Baillie, M. (2005). The Celtic gods: comets in Irish mythology. Stroud, Gloucestershire: Tempus.

McCormac, F. G., Hogg, A. G. G., Blackwell, P. G., Buck, C. E., Higham, T. F. G., \& Reimer, P. J. (2004). SHCa104 Southern Hemisphere Calibration 0-1000 cal BP. Radiocarbon, 46, 1087-1092.

McFarland, J. (2009). The day the Earth trembled. http://star.arm.ac.uk/impact-hazard/Brazil.html. Accessed November 25, 2011

McGhee, R. (1996). Ancient people of the Arctic. Vancouver: UBC Press.

McLean, D. M. (1979). Global warming and late Pleistocene mammalian extinctions. Geological Society of America, Southeastern Section meeting, Abstracts, p. 205

McLean, D. M. (1981). Size factor in the late Pleistocene mammalian extinctions. American Journal of Science, 281, 1144-1152.

McLean, D. M. (1991). A climate change mammalian population collapse mechanism. In E. Kainlauri, A. Johansson, I. Kurki-Suonio, \& M. Geshwiler (Eds.), Energy and environment (pp. 93-100). Atlanta: ASHRAE.

McLean, D. M. (1994). The Deccan Traps volcanism-greenhouse dinosaur extinction theory. http://filebox. vt.edu/artsci/geology/mclean/Dinosaur_Volcano_Extinction/pages/studentv.html. Accessed March 3, 2011.

Medina, M., \& Rivero, D. (2007). Zooarqueología, Lama guanicoe y dinámica evolutiva del Chaco Serrano. Mundo de Antes, 5, 211-234.

Melosh, H. J. (2007). Physical effects of comet and asteroid impacts: beyond the crater rim. In P. Bobrowsky \& H. Rickman (Eds.), Comet/asteroid impacts and human society (pp. 211-224). Berlin: Springer.

Melosh, H. J. (2011). Planetary surface processes. Cambridge: Cambridge University Press.

Melosh, H. J., \& Collins, G. S. (2005). Meteor Crater formed by low-velocity impact. Nature, 434, 157.

Melott, A. L., Thomas, B. C., Dreschhoff, G., \& Johnson, C. K. (2010). Cometary airburst and atmospheric chemistry; Tunguska and a candidate Younger Dryas event. Geology, 38, 355-358.

Members, C. O. H. M. A. P. (1988). Climatic change of the last 18,000 years: observations and model simulations. Science, 241, 1043-1052. 
Mercer, J. H. (1982). Holocene glacial variations in southern Patagonia. Striae, 18, 35-40.

Merino, M. L., Jorge, L., \& Cajal, J. L. (1993). Estructura social de la población de guanacos (Lama guanicoe Muller, 1776) en la costa norte de Península Mitre, Tierra del Fuego, Argentina. Studies on Neotropical Fauna and Environment, 28, 129-138.

Métraux, A. (1946). Myths of the Toba and Pilagá Indians of the Gran Chaco. Philadelphia: American Folklore Society.

Mignan, A., Grossi, P., \& Muir-Wood, R. (2011). Risk assessment of Tunguska-type airbursts. Natural Hazards, 56, 869-880.

Misawa, K., Kohno, M., Tomiyama, T., Noguschi, T., Nakamura, T., Nagao, K., et al. (2010). Two extraterrestrial dust horizons found in the Dome Fuji ice core, East Antarctica. Earth and Planetary Science Letters, 289, 287-297.

Morello, J. (1984). Perfil ecológico de Sudamérica (Vol. 1: Características estructurales de Sudamérica y su relación con espacios semejantes del planeta). Barcelona: Ediciones de Cultura Hispánica.

Morrison, D. (2010). Did a cosmic impact kill the mammoths? The Skeptical Inquirer, 34, 14-18.

Morrison, D., Harris, A. W., Sommer, G., Chapman, C. R., \& Carusi, A. (2002). Dealing with the impact hazard. In W. Bottke, A. Cellino, P. Paolicchi, \& R. P. Binzel (Eds.), Asteroids III (pp. 739-754). Tucson: University of Arizona Press.

Muhs, D. R., \& Zárate, M. (2001). Late Quaternary eolian records of the Americas and their paleoclimatic significance. In V. Markgraf (Ed.), Interhemispheric climate linkages (pp. 183-215). San Diego: Academic.

Mumby, P. J., Vitolo, R., \& Stephenson, D. B. (2011). Temporal clustering of tropical cyclones and its ecosystem impacts. Proceedings of the National Academy of Sciences of the United States of America, 108, 17626-17630.

Murton, J. B., Bateman, M. D., Dallimore, S. R., Teller, J. T., \& Yang, Z. (2010). Identification of Younger Dryas outburst flood path from Lake Agassiz to the Artic Ocean. Nature, 464, 740-743.

Myagkov, N. N. (1998). Model of a strong volcanic blast and a method of estimating the mass ejected. Geophysical Journal International, 133, 209-211.

Napier, W. M. (2010). Palaeolithic extincts and the Taurid Complex. Monthly Notices of the Royal Astronomical Society, 405, 1901-1906.

Napier, B., \& Asher, D. (2009). The Tunguska impact and beyond. Astronomy and Geophysics, 50, 18-26.

NASA Jet Propulsion Laboratory (2012a). Near-Earth asteroid discovery statistics. http://neo.jpl.nasa.gov/ stats/. Accessed July 28, 2012.

NASA Jet Propulsion Laboratory (2012b). JPL Solar System dynamics. http://ssd.jpl.nasa.gov/. Accessed July 22, 2012.

NASA National Space Science Data Center (2012). Near Earth object fact sheet. http://nssdc.gsfc.nasa.gov/ planetary/factsheet/neofact.html. Accessed July 22, 2012.

National Research Council of the National Academies. (2010). Defending planet Earth: near Earth object surveys and hazard mitigation strategies. Washington, D.C.: The National Academies Press.

Neme, G., \& Gil, A. (2009). Human occupation and increasing Mid-Holocene aridity. Southern Andean perspectives. Current Anthropology, 50, 149-163.

Norton, O. R., \& Chitwood, L. (2008). Field guide to meteors and meteorites. New York: Springer.

Oliver-Smith, A., \& Hoffman, S. M. (Eds.). (1999). The angry Earth: disaster in anthropological perspective. New York: Routledge.

Paine, M., \& Peiser, B. (2004). The frequency and predicted consequences of cosmic impacts in the last 65 million years. In R. P. Norris \& F. H. Stootman (Eds.), Bioastronomy 2002: life among the stars. IAU Symposium, Vol. 213 (pp. 289-294). San Francisco: Astronomical Society of the Pacific.

Perez, S. I. (2002a). El poblamiento del sudeste de la Región Pampeana: un análisis de morfometría geométrica. Relaciones de la Sociedad Argentina de Antropología (n.s.), 27, 163-176.

Perez, S. I. (2002b). Variabilidad temporal en la morfología craniofacial en muestras de restos humanos del Sudeste de la Región Pampeana: Implicaciones para la discussion del poblamiento regional durante el Holoceno. In D. L. Mazzanti, M. A. Berón, \& F. W. P. Oliva (Eds.), Del mar a los salitrales: Diez mil años de historia pampeana en el umbral del Tercer Milenio (pp. 155-167). Mar del Plata: Universidad Nacional de Mar del Plata and Sociedad Argentina de Antropología.

Perez, S. I. (2006). El poblamiento holocénico del sudeste de la Región Pampeana: Un estudio de morfometría geométrica. Unpublished Doctoral Dissertation. Facultad de Ciencias Naturales y Museo, UNLP.

Perlmutter, S., \& Muller, R. A. (1988). Evidence for comet showers in meteorite ages. Icarus, 74, 369-373.

Peros, M. C., Muñoz, S. E., Gaweski, K., \& Viau, A. E. (2010). Prehistoric demography of North America inferred from radiocarbon data. Journal of Archaeological Science, 37, 656-664. 
Piccardi, L., \& Masse, W. B. (Eds.). (2007). Myth and geology. Geological Society of London Special Publication 273.

Pierazzo, E., Garcia, R. R., Kinnison, D. E., Marsh, D. R., Lee-Taylor, J., \& Crutzen, P. J. (2010). Ozone perturbation from medium-size asteroid impacts in the ocean. Earth and Planetary Science Letters, $299,263-272$.

Pinter, N., \& Ishman, S. E. (2008). Impacts, mega-tsunami and other extraordinary claims. GSA Today, 18, 37-38.

Pinter, N., Scott, A. C., Daulton, T. L., Podoll, A., Koeberl, C., Anderson, R. S., \& Ishman, S. E. (2011). The Younger Dryas impact hypothesis: a réquiem. Earth-Science Reviews, 106, 247-264.

Planetary and Space Science Centre (2011). Earth impact database. http://www.unb.ca/passc/ImpactDatabase/. Accessed July 22, 2012.

Politis, G. G. (1984). Arqueología del área Interserrana bonaerense. Unpublished Doctoral Dissertation. Facultad de Ciencias Naturales y Museo, UNLP.

Politis, G. G., Barrientos, G., \& Scabuzzo, C. (2010). Los entierros de Arroyo Seco 2. In G. G. Politis, M. A. Gutiérrez, \& C. Scabuzzo (Eds.), Estado actual de la investigaciones en el sitio Arroyo Seco 2 (Región Pampeana, Argentina). Olavarría: Facultad de Ciencias Sociales. In press.

Politis, G. G., Prates, L., Merino, M., \& Tognelli, M. F. (2011). Distribution parameters of guanaco (Lama guanicoe), pampas deer (Ozotoceros bezoarticus) and marsh deer (Blastocerus dichotomus) in Central Argentina: archaeological and paleoenvironmental implications. Journal of Archaeological Science, 38, 1405-1416.

Politis, G. G., \& Salemme, M. (1990). Pre-hispanic mammal exploitation and hunting strategies in the eastern Pampas subregion of Argentina. In L. Davis \& B. Reeves (Eds.), Hunters of the recent past (pp. 353-372). London: Unwin Hyman.

Politis, G. G., \& Tonni, E. (1980). La distribución del guanaco (Mammalia, Camelidae) en la Pcia. de Buenos Aires durante el Pleistoceno Tardío y Holoceno. Los factores climáticos como causas de su retracción. Ameghiniana, 17, 53-66.

Pollack, J. B., Toon, O. B., Ackerman, T. P., McKay, C. P., \& Turco, R. P. (1983). Environmental effects of an impact-generated dust cloud: implications for the Cretaceous-Tertiary Extinctions. Science, 219, 287-289.

Porter, S. C. (2000). Onset of neoglaciation in the Southern Hemisphere. Journal of Quaternary Science, 15, 395-408.

Prasad M. S., Mahale, V. P., \& Kodagali, V. N. (2007). New sites of Australasian microtektite in the central Indian Ocean: implications for the location and size of source crater. Journal of Geophysical Research, 112, E06007. doi:10.1029/2006JE002857.

Prasad, M. S., Roy, S. K., \& Gupta, A. (2010). Changes in abundance and nature of microimpact craters on the surfaces of Australasian microtektites with distance from the proposed source crater location. Meteoritics \& Planetary Science, 45, 990-1006.

Pyne, S. J., Andrews, P. L., \& Laven, R. D. (1996). Introduction to wildland fire (2nd ed.). New York: Wiley.

Quattrocchio, M. E., Borromei, A. M., Deschanps, C. M., Grill, S. C., \& Zavala, C. A. (2008). Landscape evolution and climate changes in the Late Pleistocene-Holocene, southern Pampa (Argentina): evidence from palynology, mammals and sedimentology. Quaternary International, $181,123-138$.

Raedeke, K. J. (1976). El guanaco de Magallanes, distribución y biología. Publicación Técnica no. 4. Santiago: Corporación Nacional Forestal de Chile, Ministerio de Agricultura, Chile.

Rappenglück, B., Rappenglück, M. A., Ernstson, K., Mayer, W., Neumair, A., Sudhaus, D., \& Liritzis, I. (2010). The fall of Phaethon: a Graeco-Roman geomyth preserves the memory of a meteorite impact in southern Bavaria (south-east Germany). Antiquity, 84, 428-439.

Rappenglück, B., Rappenglück, M. A., Ernstson, K., Mayer, W., Neumair, A., Sudhaus, D., \& Liritzis, I. (2011). Reply to Doppler et al. 'Response to "The fall of Phaethon: a Graeco-Roman geomyth preserves the memory of a meteorite impact in southern Bavaria (south-east Germany) (Antiquity 84).”. Antiquity, 85, 278-280.

Reimer, P. J., Baillie, M. G. L., Bard, E., Bayliss, A., Beck, J. W., Blackwell, P. G., et al. (2004). IntCa104: Terrestrial radiocarbon age calibration, 0-26 cal kyr B.P. Radiocarbon, 46, 1029-1058.

Riede, F. (2009). Climate and demography in early prehistory: using calibrated ${ }^{14} \mathrm{C}$ dates as population proxies. Human Biology, 81, 309-337.

Ringuelet, R. A., \& Aramburu, R. H. (1957). Enumeración sistemática de los vertebrados de la provincia de Buenos Aires. La Plata: Ministerio de Asuntos Agrarios. Publicación No 119.

Romero, C. E. (1927). Llamas, alpacas, vicuñas y guanacos. Buenos Aires: Gurfinkel. 
Rubin, A. E., \& Grossman, J. N. (2010). Meteorite and meteoroid: new comprehensive definitions. Meteoritics \& Planetary Science, 45, 114-122.

Rubtsov, V. (2009). The Tunguska mystery. Berlin: Springer.

San Cristóbal, J. O. (1999). El más probable origen de las escorias y tierras cocidas. Resúmenes, XV Jornadas Argentinas de Paleontología de Vertebrados. Ameghiniana, 36(4).

Scheffers, A., Scheffers, S. R., Kelletat, D., Abbott, D. H., \& Bryant, E. A. (2008). Chevrons: enigmatic coastal features. Zeitschrift für Geomorphologie, 52, 375-402.

Schiffer, M. B. (1987). Formation processes in the archaeological record. Albuquerque: University of New Mexico Press.

Schulte, P., Aleret, L., Arenillas, I., Arz, J. A., Barton, P. J., Brown, P. R., et al. (2010). The Chicxulub asteroid impact and mass extinction at the Cretaceous-Paleogene boundary. Science, 327, 1214-1218.

Schulte, P., Deutsch, A., Salge, T., Berndt, J., Kontny, A., MacLeod, K. G., et al. (2009). A dual-layer Chicxulub ejecta sequence with shocked carbonates from the Cretaceous-Paleogene (K-Pg) boundary, Demerara Rise, western Atlantic. Geochimica et Cosmochimica Acta, 73, 1180-1204.

Schultz, P. H. (1991). Atmospheric effects of oblique impacts. In Proceedings of the Lunar and Planetary Science Conference 22 (pp. 1191-1192). Houston: Lunar and Planetary Institute.

Schultz, P. H., Harris, R. S., Tancredi, G., \& Ishitsuka, J. (2008a). Implications of the Carancas meteorite impact. 39th Lunar and Planetary Science Conference, extended abstract no. 2409.

Schultz, P. H., Koeberl, C., Bunch, T., Grant, J., \& Collins, W. (1994). Ground truth for oblique impact processes: new insight from the Rio Cuarto, Argentina, crater field. Geology, 22, 889-892.

Schultz, P. H., \& Lianza, R. E. (1992). Recent grazing impacts on the Earth recorded in the Rio Cuarto crater field, Argentina. Nature, 355, 232-237.

Schultz, P. H., Zarate, M., Hames, W., Camilión, C., \& King, J. (1998). A 3.3 Ma impact in Argentina and possible consequences. Science, 282, 2061-2063.

Schultz, P. H., Zárate, M., Hames, W. E., Harris, R. S., Bunch, T. E., Koeberl, C., et al. (2006). The record of Miocene impacts in the Argentine Pampas. Meteoritics \& Planetary Science, 41, 749-771.

Schultz, P. H., Zárate, M., Hames, B., Koeberl, C., Bunch, T., Storzer, D., et al. (2004). The Quaternary impact record from the Pampas, Argentina. Earth and Planetary Sciences Letters, 219, 221-238.

Scott, A. C., Pinter, N., Collinson, M. E., Hardiman, M., Anderson, R. S., Brain, A. P. R., et al. (2010). Fungus, not comet or catastrophe, accounts for carbonaceous spherules in the Younger Dryas "impact layer. Geophysical Research Letters, 37, L14302. doi:10.1029/2010GL043345, 5 pages.

Sheets, P. (1999). The effects of explosive volcanism on ancient egalitarian, ranked, and stratified societies in Middle America. In A. Oliver-Smith \& S. Hoffman (Eds.), The angry Earth: disaster in anthropological perspective (pp. 36-58). Routledge: New York.

Sheets, P. D., \& Grayson, D. K. (1979). Volcanic activity and human ecology. New York: Academic.

Smit, J. (1999). The global stratigraphy of the Cretaceous-Tertiary boundary impact ejecta. Annual Review of Earth and Planetary Sciences, 27, 75-113.

Smith, C., Russell, S., \& Benedix, G. (2009). Meteorites. London: The Natural History Museum.

Snyder, D., Masse, W. B., \& Carucci, J. (2011). Dynamic settlement, landscape modification, resource utilization, and the value of oral tradition in Palauan archaeology. In J. Liston, G. Clark, \& D. Alexander (Eds.), Pacific island heritage: archaeology, identity, community (Terra Australis 35, pp. 155-180). Canberra: ANU E Press, Australian National University.

Spriggs, M. (1989). The dating of the island Southeast Asian Neolithic: An attempt at chronometric hygiene and linguistic correlation. Antiquity, 63, 587-613.

Steel, D. (1995). Rogue asteroids and doomsday comets. New York: Wiley.

Steel, D. (1996). A "Tunguska" event in British Guyana in 1935? Meteorite! February. http:// meteoritemag.uark.edu/back\%20issues/NZ/feb96_2.html. Accessed August 12, 2011.

Steele, J. (2010). Radiocarbon dates as data: Quantitative strategies to estimating colonization front speed and event densities. Journal of Archaeological Science, 37, 2017-2030.

Stuart, J. S., \& Binzel, R. P. (2004). Bias-corrected population, size-distribution, and impact hazard for the near-Earth objects. Icarus, 170, 295-311.

Surovell, T. A., \& Brantingham, P. J. (2007). A note on the use of temporal frequency distributions in studies of prehistoric demography. Journal of Archaeological Science, 34, 1868-1877.

Surovell, T. A., Finley, J. B., Smith, G. M., Brantingham, P. J., \& Kelly, R. (2009a). Correcting temporal frequency distributions for taphonomic bias. Journal of Archaeological Science, 36, 1715-1724.

Surovell, T. A., Holliday, V. T., Gingerich, J. A. M., Ketron, C., Haynes, C. V., Hilman, I., et al. (2009b). An independent evaluation of the Younger Dryas extraterrestrial impact hypothesis. Proceedings of the National Academy of Sciences of the United States of America, 106, 18155-18158. 
Suslov, I. M. (2006). Questioning witnesses in 1926 about the Tunguska catastrophe. RIAP Bulletin, 10, 16-20.

Svetsov, V. V. (2002). Comment on "Extraterrestrial impacts and wildfires. Paleogeography, Paleoclimatology, Paleoecology, 185, 403-405.

Tancredi, G., Ishitsuka, J., Schultz, P. H., Harris, R. S., Brown, P., ReVelle, D. O., et al. (2009). A meteorite crater on Earth formed on September 15, 2007: The Carancas hypervelocity impact. Meteoritics \& Planetary Science, 44, 1967-1984.

Thenhaus, P. C., Campbell, K. W., \& Khater, M. M. (2011). Spatial and temporal earthquake clustering: part 1-global earthquake clustering. Oakland, CA: EQECAT.

Tian, H., Schryvers, D., \& Clayes, P. (2011). Nanodiamonds do not provide unique evidence for a Younger Dryas impact. Proceedings of the National Academy of Sciences of the United States of America, 108, 40-44.

Tonello, M. S., \& Prieto, A. R. (2010). Tendencias climáticas para los pastizales pampeanos durante el Pleistoceno tardío-Holoceno: Estimaciones cuantitativas basadas en secuencias polínicas fósiles. Ameghiniana, 47, 501-514.

Tonni, E., Cione, A., \& Figini, A. (1999). Predominance of arid climates indicated by mammals in the pampas of Argentina during the Late Pleistocene and Holocene. Paleogeography, Paleoclimatology, Paleoecology, 147, 257-281.

Toon, O. B., Zahnle, K., Morrison, D., Turco, R. P., \& Covey, C. (1997). Environmental perturbations caused by the impacts of asteroids and comets. Reviews of Geophysics, 35, 41-78.

Torrence, R., \& Grattan, J. (Eds.). (2002). Natural disasters and cultural change. New York: Routledge.

U.S. Congress, Office of Technology. (1989). The containment of underground nuclear explosions. OTAISC-414. Washington, D.C: U.S. Government Printing Office.

U.S. Geological Survey. (2000). Mount St. Helens - from the 1980 eruption to 2000. USGS Fact Sheet 03600. Washington, D.C: Department of the Interior.

U.S. Geological Survey. (2011). Magnitude 9.0 Sumatra-Andaman Islands earthquake FAQ. http:// earthquake.usgs.gov/earthquakes/eqinthenews/2004/us2004slav/faq.php. Accessed March 26, 2011.

van der Slujis, M. A. (2009). Review of myth and geology. Myth \& Symbol, 5(2), 58-74.

van Ginneken, M., Folco, L., Perchiazzi, N., Rochette, P., \& Bland, P. A. (2010). Meteoritic ablation debris from the Transarctic Mountains: evidence for a Tunguska-like impact over Antarctica ca. 480 ka ago. Earth and Planetary Science Letters, 293, 104-113.

van Hoesel, A., Hoek, W. Z., Braadbaart, F., van der Plicht, J., Pennock, G. M., \& Drury, M. R. (2012). Nanodiamonds and wildfire evidence in the Usselo horizon postdate the Allerød-Younger Dryas boundary. Proceedings of the National Academy of Sciences of the United States of America, 109, $7648-7653$.

Vansina, J. (1985). Oral tradition as history. Madison: University of Wisconsin Press.

Vesconi, M. A., Wright, S. P., Spagnuolo, M., Jacob, R., Cerrutti, C., Garcia, L., et al. (2011). Comparison of four meteoritic penetration funnels in the Campo del Cielo crater field, Argentina. Meteoritics \& Planetary Science, 46, 935-949.

Veski, S., Heinslau, A., Poska, A., Saarse, L., \& Vassiljev, J. (2007). The physical and social effects of the Kaali meteorite impact — a review. In P. Bobrowsky \& H. Rickman (Eds.), Comet/asteroid impacts and human society (pp. 265-275). Berlin: Springer.

Villalba, L., \& Bonacic, C. (2006). Rediscovering the guanaco in the Paraguay Chaco. The Camelid Quarterly, March, 2006, 1-2.

Vitaliano, D. B. (1973). Legends of the Earth: their geologic origins. Bloomington: University of Indiana Press.

Vitaliano, D. B. (2007). Geomythology: geological origins of myths and legends. In L. Piccardi \& W. B. Masse (Eds.), Myth and geology (pp. 1-7). London: Geological Society of London Special Publication 273.

Vizcaìno, S. F., Fariña, R. A., Zárate, M., Bargo, M. S., \& Schultz, P. (2004). Paleoecological implications of the Mid-Pliocene faunal turnover in the Pampean region (Argentina). Palaeogeography, Palaeoclimatology, Palaeoecology, 213, 101-113.

Wasson, J. T. (2003). Large aerial bursts: an important class of terrestrial accretionary events. Astrobiology, $3,163-179$.

Watt, N., Bouchet, R. A., \& Lee, C. A. (2011). Exploration of tektite formation processes through water and metal content measurements. Meteoritics \& Planetary Science, 46(S1), 1-8.

Weninger, B. (1997). Studien zur dendrochronologischen Kalibration von archäologischen ${ }^{14}$ C-Daten. Frankfurt: Habelt Verlag.

Weninger, B., \& Jöris, O. (2007). Towards an absolute chronology at the middle to Upper Palaeolithic transition in Western Eurasia: A new Greenland ${ }_{\text {Hulu }}$ time-scale based on U/Th ages. www.calpal.de. Accessed 9 March, 2008. 
Wheeler, K. (1983). The fall of Japan. Morristown: Time-Life.

Whiteley, P. M. (2002). Archaeology and oral tradition: the scientific importance of dialogue. American Antiquity, 67, 405-415.

Wilbert, J. (Ed.). (1978). Folk literature of the Gê Indians. Los Angeles: UCLA Latin American Center Publications.

Wilbert, J., \& Simoneau, K. (1978). Folk literature of the Gê Indians. UCLA Latin American studies 44. Los Angeles. Los Angeles: UCLA Latin American Center Publications.

Wilbert, J., \& Simoneau, K. (Eds.) (1982a). Folk literature of the Toba Indians (Vol. 1). UCLA Latin American Center Publications.

Wilbert, J., \& Simoneau, K. (Eds.) (1982b). Folk literature of the Mataco Indians. UCLA Latin American Center Publications.

Wilbert, J., \& Simoneau, K. (Eds.) (1984a). Folk literature of the Gê Indians (Vol. 2). UCLA Latin American Center Publications.

Wilbert, J., \& Simoneau, K. (Eds.) (1984b). Folk literature of the Tehuelche Indians. UCLA Latin American Center Publications.

Wilbert, J., \& Simoneau, K. (Eds.) (1985). Folk literature of the Chorote Indians. UCLA Latin American Center Publications.

Wilbert, J., \& Simoneau, K. (Eds.) (1987). Folk literature of the Nivaklé Indians. UCLA Latin American Center Publications.

Wilbert, J., \& Simoneau, K. (Eds.) (1988). Folk literature of the Mocovi Indians. UCLA Latin American Center Publications.

Wilbert, J., \& Simoneau, K. (Eds.) (1989). Folk literature of the Toba Indians (Vol. 2). UCLA Latin American Center Publications.

Wilbert, J., \& Simoneau, K. (Eds.) (1992). Folk literature of South American Indians: General index. UCLA Latin American Center Publications.

Williams, A. (2012). The use of summed radiocarbon probability distributions in archaeology: a review of methods. Journal of Archaeological Science, 39, 578-589.

Wilmshurst, J. M., Hunt, T., Lipo, C., \& Anderson, A. (2011). High precision radiocarbon dating shows recent and rapid initial human colonization of East Polynesia. Proceedings of the National Academy of Sciences of the United States of America, 108, 1815-1820.

Winchester, S. (2003). Krakatoa: the day the world exploded: August 27, 1883. New York: Harper-Collins.

Wright, S. P., Vesconi, M. A., Spagnuolo, M. G., Cerutti, C., Jacab, R. W., \& Cassidy, W. A. (2007). Explosion craters and penetration funnels in the Campo del Cielo, Argentina crater field. Lunar and Planetary Science, 38, No. 2017.

Zárate, M. A. (2002). Los ambientes del Tardiglacial y Holoceno en Mendoza. In A. F. Gil \& G. A. Neme (Eds.), Entre montañas y desiertos: Arqueología del sur de Mendoza (pp. 9-42). Buenos Aires: Sociedad Argentina de Antropología.

Zárate, M. A. (2005). El Cenozoico tardío continental de la provincia de Buenos Aires. In R. E. de Barrio, R. O. Etcheverry, M. F. Caballé y E. Llambías (Eds.), Geología y recursos minerales de la provincia de Buenos Aires. Relatorio del $16^{\circ}$ Congreso Geológico Argentino (pp. 139-158). La Plata.

Zárate, M., Espinosa, M., \& Ferrero, L. (1998). Paleoenvironmental implications of a Holocene diatomite, Pampa Interserrana, Argentina. Quaternary of South America and Antarctic Peninsula, 13, 135-152. 